\title{
The Capacitive Coupling Modalities for Oncological Hyperthermia
}

\author{
Andras Szasz \\ Department of Biotechnics, St. Istvan University, Budaörs, Hungary \\ Email: Szasz.Andras@gek.szie.hu
}

How to cite this paper: Szasz, A. (2021) The Capacitive Coupling Modalities for Oncological Hyperthermia. Open Journal of Biophysics, 11, 252-313.

https://doi.org/10.4236/ojbiphy.2021.113010

Received: April 9, 2021

Accepted: July 16, 2021

Published: July 19, 2021

Copyright $\odot 2021$ by author(s) and Scientific Research Publishing Inc. This work is licensed under the Creative Commons Attribution International License (CC BY 4.0).

http://creativecommons.org/licenses/by/4.0/

\begin{abstract}
The local-regional oncological hyperthermia has various electromagnetic methods for energy-transfer. The differences involve conceptual considerations and technical solutions. The most frequently applied energy transfer is capacitive coupling, concentrating the electric field to be the active heating component. The realization of the capacitive coupling set-up is divided into two different categories based on their goals for heating: 1) the homogeneous (conventional) heating, using isothermal conditions for dosing, and 2) the selective heterogeneous heating, using cellularly absorbed energy for dosing. The homogeneous heating utilizes plane-wave matching, absorbing the wave for energy transfer. The heterogenic heating uses impedance matching, selecting the malignant cells by their electromagnetic specialties, like their heterogenic impedance, higher membrane-raft density, and different spatio-temporal (pathologic pattern) arrangements. This article's objective is to compare and discuss the details of the two kinds of capacitive coupling techniques.
\end{abstract}

\section{Keywords}

Plane-Wave Matching, Impedance Matching, Apoptosis, DAMP, ICD, Selective Heating, Electromagnetic Heterogeneity, Membrane Raft

\section{Introduction}

\subsection{Strategy in the Fight against Cancer}

Life is based on energetically open systems, where environmental conditions determine their equilibrium. The general system's theory [1] was one of the early efforts to show the complexity of open living systems focusing on the deep embedment of its processes in the environmental interactions. Due to the environmental actions, the physical laws work well to explain the evolutionary processes 
[2]. The energetically open living system intensively interacts with its environment, exchanging molecules and various thermodynamic and electromagnetic parameters. Simply speaking: our focus differs from living motility to the energy-transfer. A. Szent-Gyorgyi described the life-energy relationship using the analogy that it is not important that the monkey goes through the jungle, what is important is how the jungle goes through the monkey, in the form of nutrition, water, and oxygen, keeping the monkey alive using the environmental energy-sources [3]. The living system is complexly controlled, to maintain homeostasis. Diseases, especially cancers, break the relative equilibrium and risk the system's relative instability. The human body tries to re-establish homeostasis in many ways by enhancing the negative feedback controls. Multiple actions of human physiology try to compensate and correct the damage caused by cancer.

Healthy homeostasis struggles to control the malignancy. The first few attempts block the proliferation and start intracellularly controlling the DNA replication. It fails for various reasons, including genetic aberration [4], mitochondrial dysfunction [5], or other intracellular [6], and additionally extracellular [7] hallmarks of malignancy.

The malignancy in this general meaning is a distortion of the healthy cellular network, the rules of a multicellular organization being broken. The breaking of cellular networks is a general behavior of all tumors independent of their locations within the body. In this sense, cancer is an organizing (networking) disease, where the cells unleashed from their networks abandon the living advantages of collectivism, and individualism prevails [8]. Cancerous and bacterial proliferations have a lot in common [9]. The tumor itself has atavism qualities [10], in the sense that the malignant cells act like self-ruled unicellular organisms. The atavism-like process is general, not only with the loss of cellular connections but also with the altered intracellular genetic structures. The unicellular individualism develops the great potential for adaptability to environmental changes, making these cells more vigorous than those in the multicellular network. The modified genetic activity at the active boundary between unicellular and multicellular areas, causes disorganization of the multicellular structure, promoting primitive transcriptional programs [11]. However, the similarity with atavism is only formal. The atavistic development is supported by the environment which is rich in energy-resources needed for the proliferation. Still, the active use decreases the valuable matter around the bacteria, and only some physical processes (like diffusion, flows in aqueous solution, etc.) may passively replace the missing materials. In cancer conditions, the proliferating cell actively changes its environment, forcing the healthy host to supply the needed materials [12]. The cancer is afforded a friendly environment by the host, which tries to "heal" the abnormality by strengthening angiogenesis, injury current, and numerous other supportive mechanisms. There are telling arguments for the likening of the cancerous process to wound repair [13]. The bio-system falsely recognizes the tumor-as a wound and stimulates its environment to heal the irregularity (meaning to produce cells to heal) [14]. 
We are in a war against this disease [15]. The end of this war seems to be far away [16]. This war's strategic decision may be borrowed from the military: attack the enemy's weakest point, and avert to direct fight with its strongest forces. The most vital force of the malignancy is its uncontrolled proliferation, while the weakest side is the autonomy of the proliferated cells, and their isolation from the regular cellular network. The cooperation of the healthy cells regulates, controls, and supplies the members of the network. The malignant cells are "individual fighters" competing against all healthy and malignant cells for the energy sources to proliferate. This "loneliness" behavior makes the malignant cells vulnerable. They miss the complex support from the network. The missing network otherwise helps the proliferative development due to the easy motility and forming micro and macro metastases. Following this strategy, the final aim of cancer treatments is to eliminate the cancer cells throughout the body.

\subsection{Some Tactical "Weapons"}

To follow the strategic goal to attack the malignant cells' individualism, we have multiple "tactical" possibilities to choose from. The lack of coherence and support it in the network modifies the cells and their microenvironment. This modification could be used to select and kill the cells. The most characteristic changes are a result of the cells' autonomy:

- The individual cells are more vulnerable than the cells connected via the network. Healthy cells may share their extra absorbed energy with the neighbors, while the autonomous cells are at risk of being overloaded by the absorbed energy can be overloaded.

- The autonomy means that the cell's microenvironment is like an ocean around it, only with a few, if any, connections. The molecular "bridges" that made the bonds in the network are broken, and numerous transmembrane proteins remain unconnected and free to move along the membrane and form clusters.

- A large part of the homeostatic control is missing due to the autonomy, and the cells live unregulated. This allows the use of metabolic mechanisms which are rare in networked systems. The mitochondrial symbiosis with the cell has less importance and becomes mostly dysfunctional.

- The autonomy promotes cellular motility that uses the transport systems (lymph and blood), and once separated from the group, these cells more vulnerable.

- Consequently, the energy-demand massively increases in malignant cells as the cells require the extra energy to produce the daughter cells and to support the entire division process.

- The basic chemical reactions are out of systemic harmony. The long-range, and broadly scaled fluctuation and constant multiscale entropy is broken by autonomy, producing easily distinguishable fluctuations (noises) in measurable electromagnetic signals. 
The above points are interconnected, and the "tactical actions" could affect many of them simultaneously. Some of the popularly applied treatments are as follows:

Change the conditions by special, strict diets (like Gerson's diet), constraining the body back to the previously working equilibrium. However, in many cases, it works against the natural homeostasis; the constrained action induces new negative feedbacks from the living object. The living organism starts to fight against our constraints together with the fight against the disease itself, which unnecessarily overloads the controlling system and could lead to its collapse, causing serious side effects.

An interesting tactic is to put out the fire with fire. This method increases the already significant metabolic rate of the malignant cells without allowing an increased delivery of the supplies. This was the original idea of hyperthermia: to locally heat the malignant tissue, and force the cells' metabolism, without allowing the replacement of the energy. This method is against the general physiological control, which is governed the blood-flow. The higher local temperature increases the blood-flow to cool-down the targeted volume. The extra blood delivers nutrients, and oxygen, so the method could easily turn in the opposite direction.

> Some proposed treatments favor fasting or supplying the body with only one kind of nutrient, like blocking carbohydrates' consumption and expecting that the limited supply will starve the malignant cells.

The above treatments do not work, mainly because the living complexity does not isolate one of the other's dynamic characters, so the action easily turns to the opposite. The general problem with these is proposed methods is that the complexity is not accounted for in the applied principles, the principles involve oversimplified mechanisms, due to the lack of complex knowledge. This problem is well formulated by a playwriter Berthold Brecht: "The aim is not to open the door to the infinite wisdom, but to circumscribe the infinite fallacy... The main reason for the poverty in science is the conceited property." [17]. The physicist Stephan Hawking formulated the same: "The greatest enemy of knowledge is not ignorance, it is an illusion of knowledge".

The dark-side of the tactical elements is the multiple quackeries distributed by social media. This approach uses the "formal knowledge" of the complexity, declaring their method as a special secret, which drives the complex processes. This could be characterized by the statement of Frederici Di Trocchio "Swindle was used to art. Nowadays, it became a science too..." [18].

\subsection{Oncological Hyperthermia}

Hyperthermia in oncology appeared in ancient medicine. Today heating processes for medical purposes have become a vital "home remedy", from the sun-bathing to the hot-bathes, including the Japanese high-temperature bath and Finish sauna. Hippocrates first described the application of heat in oncology 
in European medicine. The use of heat therapy to cure cancer has since emerged in various settings in the medical field. The appearance of electromagnetism in medicine renewed the heating efforts, and extended the applications for various cancers. Two main categories divide the electromagnetic-based heating applications: the local deep heating which results in local-regional hyperthermia (LRHT), and the whole-body hyperthermia (WBH). Just as the categories of chemotherapy and radiotherapy include many different modes of treatments, "hyperthermia" is also a large category with different technical aspects. Figure 1 maps the main differences between the technical solutions.

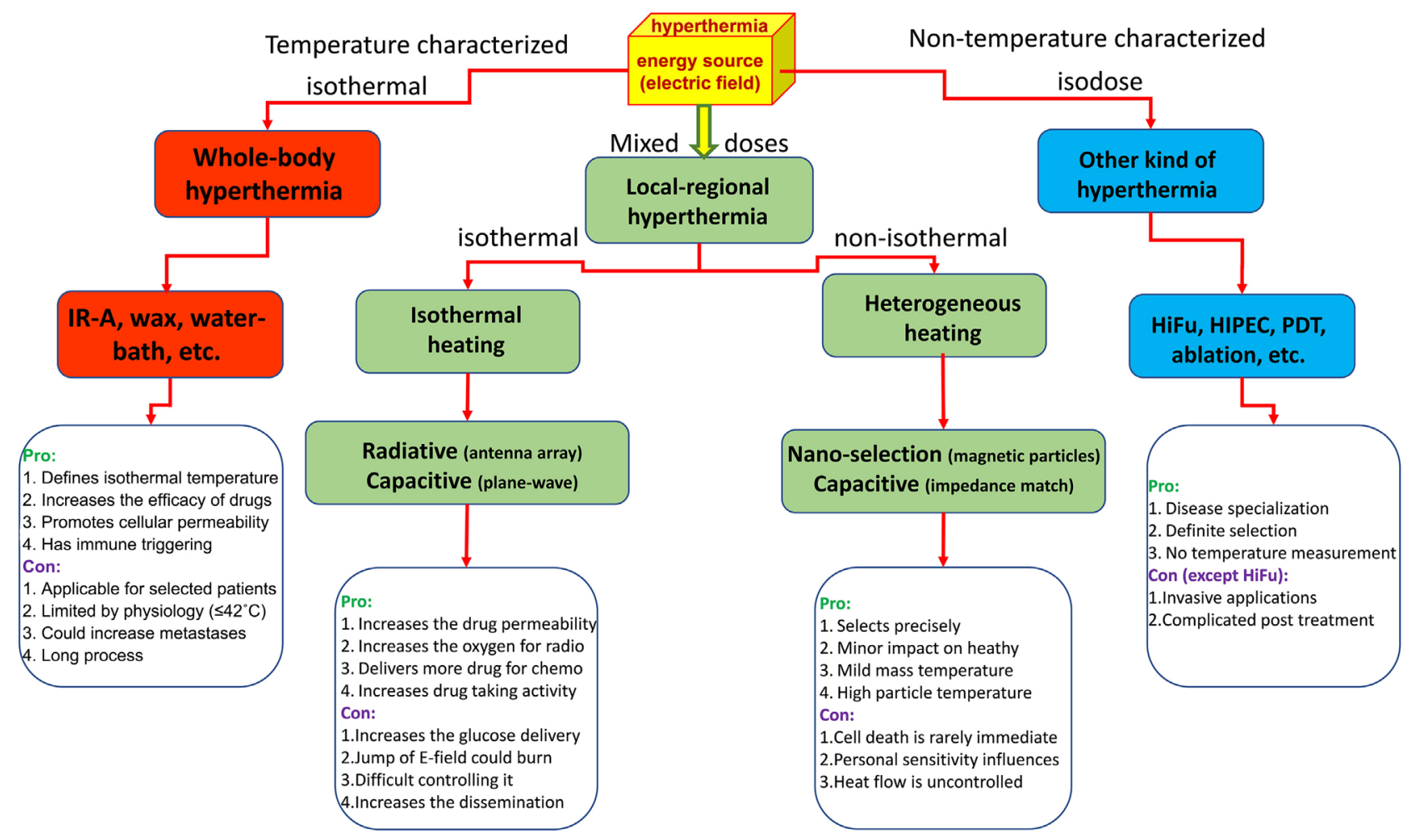

Figure 1. The major categories of hyperthermia methods.

The relatively simple physical-physiological heating concepts do not mean a simple application in humans. The complexity of human physiology, and the non-linear feedbacks of the homeostatic regulation, limits the heating possibilities. Despite the proven in vitro benefits of heating in cancer treatment, the clinical results have strongly demonstrated how the control of treatment is often influenced more by the human body than by the treatment intention. This complication made the development of oncologic hyperthermia non-monotonic, having both great successes and failures [19]. It was clear from the beginning of oncological applications that the real, local cell-distortion must have a high temperature, higher than the physiological limit of $42^{\circ} \mathrm{C}$. However, this limit restricts the high temperature application of $\mathrm{WBH}$ which has moved towards mild temperature range, promoting the reactivation of the immune system. Contrary to WBH, LRHT does not limit by the temperature in the tumor. When the high 
temperature targets the healthy host tissues around the tumor, it could produce unintended necrotic burns with serious damage to the treated organ's function.

Consequently, the energy absorption during the heating process significantly depends on the technique applied. No unified protocol for the various technologically determined targets of the heat has currently been described.

The category "hyperthermia" includes various energy-absorption methods, and each individual solution requires its own protocol. It is very similar in this regard to the chemo-variants of oncological therapies. Chemotherapy, depending on the targets of the drug, has different protocols. Mixing these could cause serious adverse effects and even fatal events such as poisoning. Homogeneous targeting in most of these therapies requires very different protocols to the local or cell-sensitive selection. For example, chemotherapy is administered intravenously (i.v.), at different doses to the doses administered with chemoembolization or other types of local administration. Isodose homogeneity, as in radiotherapy, is also not used in most brachytherapies, radiation seed, or nanoparticle administration. We are sure that the hyperthermia variants also have specific differences in their dose and protocol, sharply depending on their technical solution and targeting method. Defining a general dose and protocol for all hyperthermia methods is a misleading request. The methods are not equal. Their effects are different, so the dose and protocol have to fit the specific situation.

The heating techniques determine the result of the clinical treatment. Just as the categories of chemotherapy or radiotherapy, which include many different treatments, "hyperthermia" is also a large category with different technical aspects. We have seen that exposing the tumor to $42^{\circ} \mathrm{C}$ in whole-body hyperthermia has entirely different results than the same temperature in any local treatment. Characterization of the temperature alone is not enough to categorize the technical solutions.

A water bath is used in many experimental models to achieve hyperthermia, and this models homogeneous heating solutions. The various electromagnetic heating technologies also have their specialties. The bioelectromagnetic action of the technology determines the actions. Evaluating the applied technique, we consider the kind of energy delivery, the method of heat absorption, and handling the target tumor's physiological reactions, together with their inhomogeneities. The target's absorbed energy, and its temperature distribution are not the same [20], and these characteristics are largely determined by the blood-flow. The technical solutions must handle how the provided energy I transformed into the desired temperature.

\subsection{The Electromagnetic Coupling Modalities}

Variants of energy-transfer realize the absorption in the target. Various "antennas" (sources) couple the energy to the target (Figure 2). The homogeneity of the absorption defines the main character of the actual coupling. The inductive arrangements have two heating forms. One is the Eddy-current (induced current loop in the body) and the other uses magnetic materials for heating. In living 
objects, both the Eddy-current and magnetic approaches are applied. Life does not have natural inherent magnetic properties. Artificial magnetic materials (like nanoparticles, seeds, rods, etc.) orient the energy for heating. Internal Eddy-current induction needs an extra high magnetic field, and the induced current has no specified orientation but is sensitive for inhomogeneities inside the body. Consequently, both induction methods heat in a heterogenic way. The conventional relative antenna solution radiates the electromagnetic energy, which is absorbed by the target. It is less sensitive to heterogenic structures, so is usually applied for homogeneous heating to use the dosing of isothermal volumes. The capacitive coupling has two major kinds of energy transfers: 1) the plane-wave antenna process, which aims to achieve similar isothermal absorption of the electromagnetic waves as the radiative applications; 2) the impedance coupling process, which uses the precise impedance-matching of the target. The isothermal kind of capacitive coupling requires high energy transferred via the plane-wave, while the impedance matching (mimics the galvanic match), uses less energy provided the heterogenic absorption processes are exploited and dominate. The galvanic coupling firmly touches the actual target. In non-living applications, this is the simple discrete resistor situation. The galvanic coupling in the case of living items applies tightly connected electrodes invasively with direct solid contact with the body's surface.

(a)

(e)

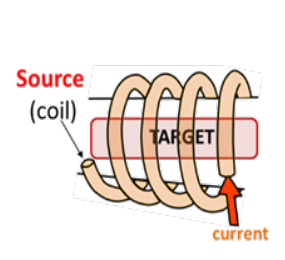

(b)

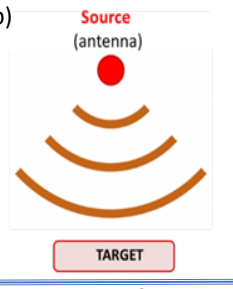

(c) Source (condenser) (d)

Source (resistor)
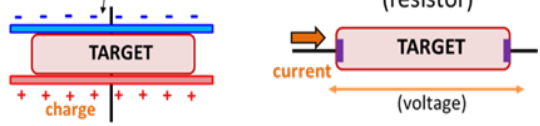

(g)

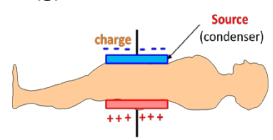

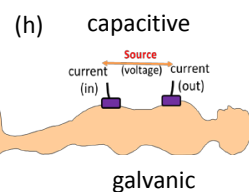

Figure 2. The major coupling methods for local-regional heating. (a)-(d) Homogeneous (non-living) targets; (e)-(h) Heterogeneous (living) target. The energy-absorption induces different effect in various couplings.

Applications using capacitive and radiative (microwave) solutions are the most popular methods used in the technical realization of the treatments; however, due to the sharp decrease of penetration depth with the increase of frequency, microwave solutions are mainly applied for surface lesions (see later). Capacitive coupling of energy delivery has become the most frequently applied technique, and the frequency of choice for the technique is the so-called "free-frequency" of $13.56 \mathrm{MHz}$, approved for industrial, scientific, and medical use (ISM frequency) [21]. Different effects in the human applications are observed, based on the coupling effects of the applied technique, Figure 3. 


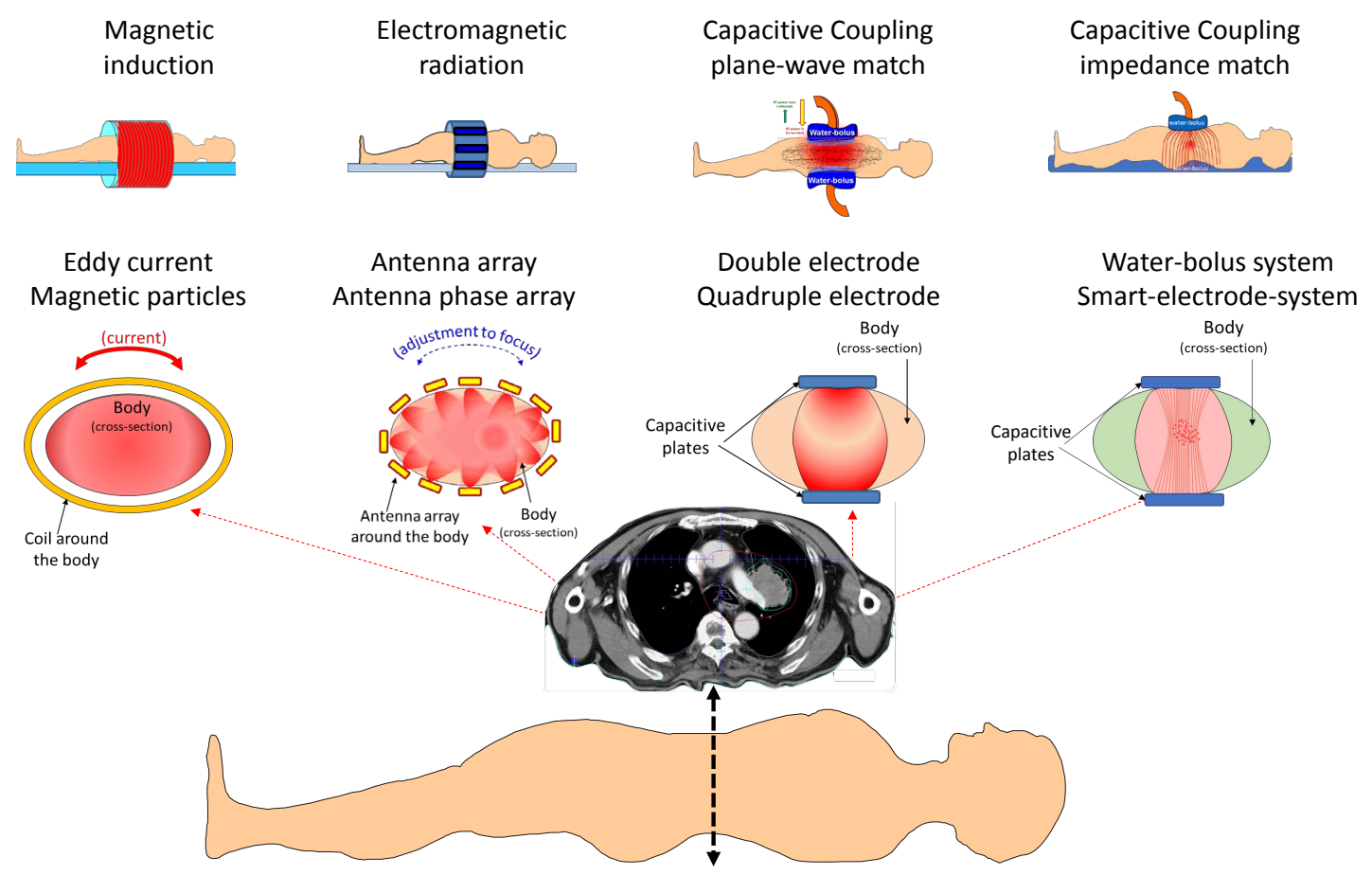

Figure 3. The local-regional treatment intends to select the cross-section of the body for energy absorption.

\section{The Capacitive Coupling}

Two kinds of capacitive couplings exist, depending on how the matching tunes the antenna, how the antenna structure's method and the electronical environment incorporates the tumor in the body as part of the regulated electric circuit. The concept of the complete electric circuit defines the matching method. The complete system, not only the capacitive arrangement of the electrodes, defines the coupling.

\subsection{Plane-Wave Matching}

The conventional solution involves plane-wave matching, in which the antenna's plane-parallel plates are tuned as per the standard antenna-tuning method. This solution does not consider the energy losses by various electric circuit elements and their interactions with the environment. In this case, the increased power $(P)$ compensates for the lost energy. Due to the relatively high complex impedance, the voltage $(V)$ is high, while the current $(I)$ is low. The product of voltage and current defines the useful power, $P_{\text {real }}=V \cdot I \cdot \cos (\varphi)$, while the reactance (the power refused by the load) is $P_{\text {react }}=V \cdot I \cdot \sin (\varphi)$. The possible timing delay of the complex fit of the voltage with current is characterized by the cosine of the phase angle $(\cos (\varphi))$ of the complex values. In case of dielectric losses and/or radiations $0<\varphi<90^{\circ}$. Due to the losses, the impedance of the system $\left(Z_{s y s}\right)$ from the radiofrequency $(R F)$ source to the target is large. The capacitance $(C)$ describes the dielectric (isolating) resistivity, and the conductive part (defined by the real resistivity $(R)$ defines the reaction time of the system (time-constant, 
$\tau=R \cdot C)$. The circuit for the hyperthermia plane-wave system has many various capacitances and resistivities additional to the target in the human body, and then we have to calculate the time-constant in a more complicated way (open-circuit time constant method [22]).

The time constant, in the case of plane wave solution, is relatively high, limiting the tuning's reaction time. This delay could cause a challenge when the physiological changes (breathing, heart-rate, etc.) are quicker than the reaction time. The plane wave method applies conventional antenna tuning where the antenna is fixed, so the reaction time has no relevance.

The plane-wave matching radiates RF-waves for energy-absorption, and direct heating, and necrotic cell-death (CEM $43^{\circ} \mathrm{C} T_{X}$ dose) is expected. This matching technology aims to reach at least $43^{\circ} \mathrm{C}$ temperature in the $T_{x}$ effective percentages of the temperature measurement in the tumor.

The wave matching induces extensive radiation, due to the wave-transmission adding a significant factor to the energy-loss, and this could produce safety issues for operating staff. An important phenomenon of this coupling is that it could tune on the air without a patient in the active radiation zone.

\subsection{Impedance Matching}

The impedance matching of capacitive coupling does not use the wave concept. The system construction approaches the galvanic touch of the electrodes. The normal resistor has the maximal power in the galvanic coupling: $P_{\max }=U \cdot I$, where $U$ is the galvanic potential (voltage), and $I$ is the current (Amps). In the case of a patient's complex impedance $\left(Z_{p a t}\right)$ the imaginary part limits the effective power. When $Z_{\text {pat }}$ coupled galvanically, it modifies the maximal efficient power to: $P_{\text {Pat }}=U \cdot I \cdot \cos (\varphi)$. A resonance solution of the components approaches the minimal imaginary part of the $Z_{p a t}$ impedance [23], and maximizes the power on the patient. The resonance uses a near-zero phase angle $\varphi \cong 0$ consequently $\cos (\varphi) \cong 1$ [24]. The low imaginary part decreases the voltage and increases on the same ratio the RF-current, [25] [26]; because $I_{\text {Pat }}^{2}=\frac{P_{P a t}}{Z_{p a t}}$, and $U_{\text {Pat }}^{2}=P_{\text {Pat }} \cdot Z_{\text {pat }}$.

Approaching the proper impedance matching, the solution has negligible reflected power (order of $1 \mathrm{~W}$ ), mimicking the skin's galvanic contact as much as possible. When the electrodes directly touch the targeted volume's surface, the galvanic situation, without any isolating materials, offers the most amount of available current. The impedance matching aims to mimic the galvanic situation as much as possible. This solution minimizes the reactive part and maximizes the real power on the load.

The main principle of impedance matching is to approach the "galvanic-like-touching" that would be the best available non-invasive electromagnetic energy-delivery. The invasive method (when electrodes are inserted into the body) is also "galvanic", but its invasivity has multiple medical complications, 
such as bleeding, a high risk of infections, ulcer formation, and inflammation. One of the invasive "galvanic" methods is ablation technology, which has remarkable successes in local, small tumors [27]. With minimal energy loss, impedance matching allows the concentration of the energy on the malignant volume [28]. Due to the selection, this solution has better efficacy and offers a safer treatment because the voltage could be less than in higher resistivity isolation cases, at the same power application, while the current is increased.

The full arrangement of impedance matching minimizes the losses in the circuit $\left(Z_{\text {loss }}=Z_{\text {sys }}-Z_{p a t} \Rightarrow \min\right.$. ). The minimal loss allows optimization of the reaction time with a low time-constant. The small delay of the reaction to the physiological changes allows prompt adaptation to alterations during the treatment; even small animals in preclinical experiments have a significantly higher heartbeat and breathing frequency than humans [29].

The impedance matching needs a conductive media between the electrodes, and the RF-current flows through it. Consequently, the system cannot tune on the situation when a patient does not present in the active radiation zone. The technique therefore induces minimal radiation to the environment, and it is safe.

Due to the forced RF-current, the patient becomes an electric component of the real-time adaptive tuned electric circuit, representing active electrical impedance. In this matching, the patient is not simply an "energy absorbent" but an active electric element of the serial circuit.

\subsection{Comparison of Capacitive Couplings}

In general, all capacitive couplings are equal based on the formal capacitive arrangement level, however their technical details differentiate them. The variation could be so significant that it produces-either homogeneous or heterogeneous heating in the target.

Comparing the variants of capacitive couplings requires a detailed study of the electronic, structural, and material design differences of the circuits. All capacitive couplings involve a capacitor used for energy transmission to the target, emphasizing the electromagnetic interactions' electric field component, using electrodes with the target volume placed between them.

The plane wave capacitive coupling transmits the radiofrequency by the plane antenna, and some of the radiofrequency is even transmitted through the air, Figure 4. A popular hyperthermia technique applies a typical radiative plane-wave solution [30], but the high voltage for radiation necessitates enormous power (600 W for a mouse with tumors weighing $2 \mathrm{~g}$ ) [31] [32]. However, the plane-wave solution could work with a lower power when the distance (space in the air) between the electrode and the body surface is small, or negligible, or the matching parameters allow high voltage and low current for the applied power.

Importantly, impedance matching of capacitive coupling does not work when isolated (i.e. when there is a space or air between the electrode and body surface), Figure 5. 

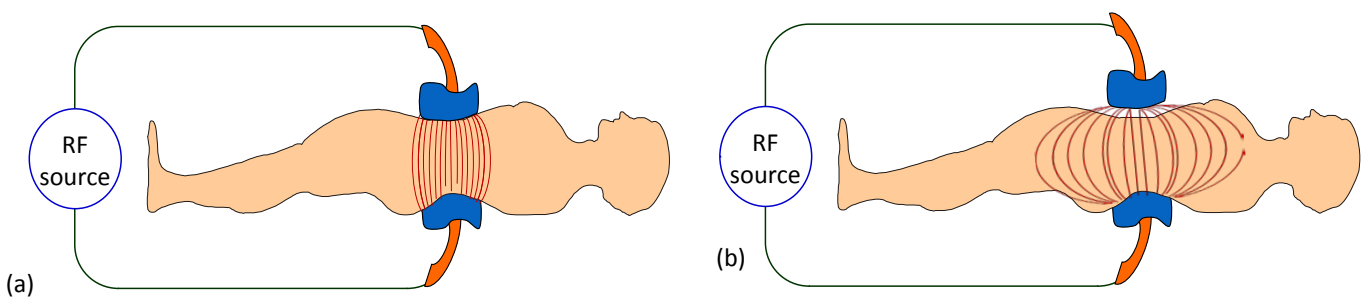

(c)
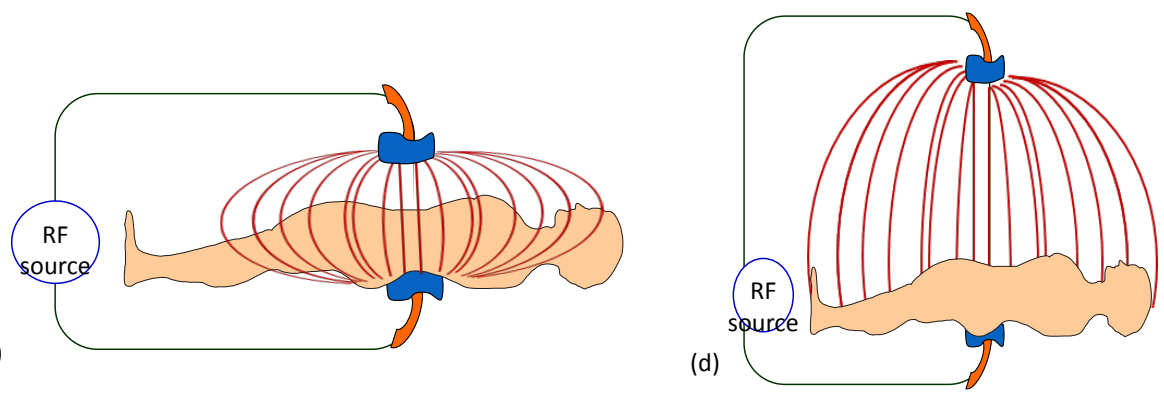

Figure 4. The plane-wave radiation works through the air, and so it is not sensitive for electrode fixing.

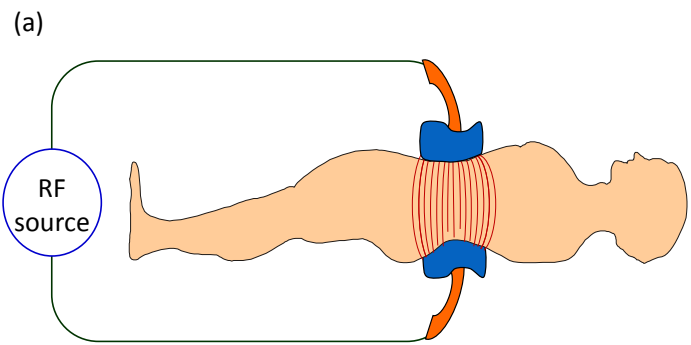

(b)

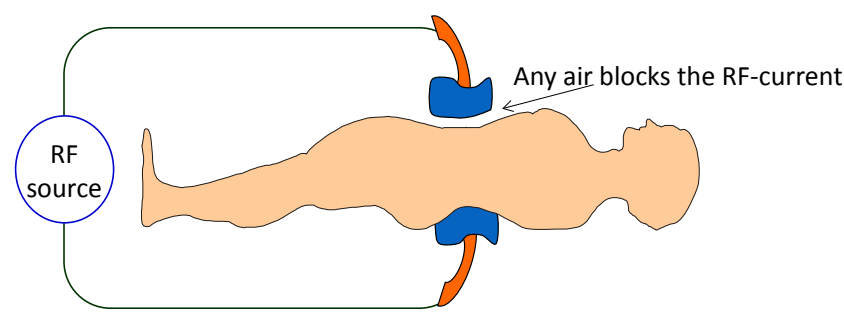

Figure 5. The impedance matching uses the RF-current-flow through the body and does not work when an air slit exists between the electrode and the body.

All capacitive couplings have an engineering control point to optimize and maximize the provided power from the RF source and, using the power-supply safely, to avoid its overheating. The measuring points fit the circuit's impedance to the source's internal resistivity, using the conventional standard $50 \Omega$. However, this engineering control does not take into account the medical control. The medical control or reference point refers to the point at which there is minimal loss of energy to the environment and maximal absorption in the patient while ensuring the safety of the patient and minimizing unwanted hot spots.

The optimal engineering settings do not necessarily align with the optimal requirements for the patient safety and treatment, Figure 6. 


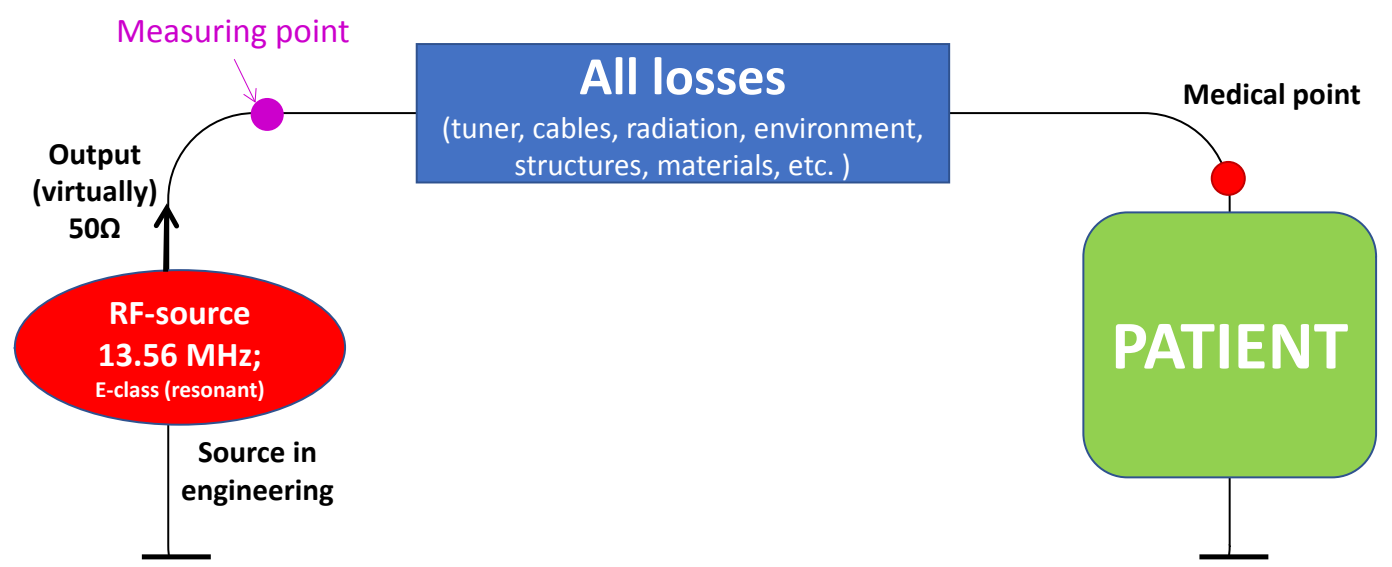

Figure 6. All losses are minimized by proper geometry, material-selection, careful design of specialized electronics, super-low imaginary (reflected) power, $(\varphi \cong 0)$ etc.

There are decisional differences between the realization of capacitive coupling methods at the level of simple measuring observations. The two major categories are the plane-wave and impedance matching techniques Figure 7, and other solutions combine these two categories.

(a)

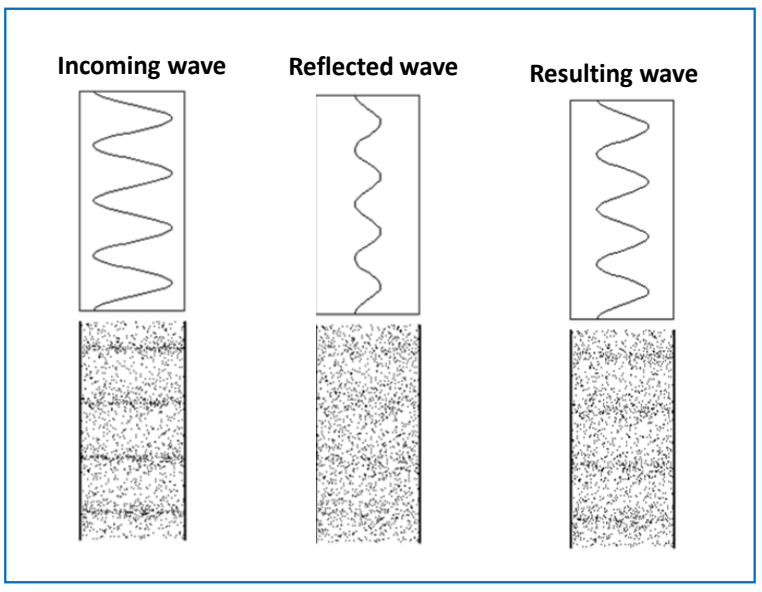

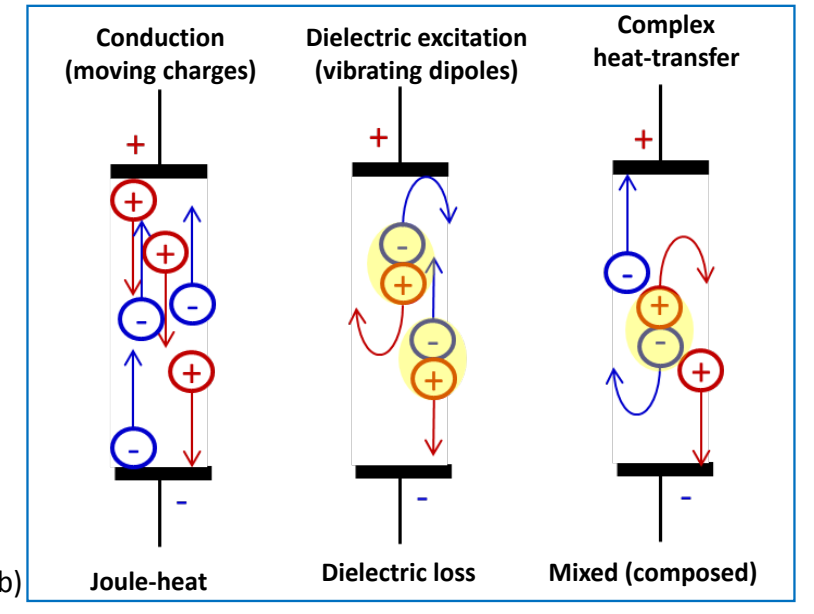

Figure 7. The matching arrangements. (a) The plane-wave matching uses a forwarded power and measures the reflected one to deduct and calculate the resulting radiative power; (b) The impedance (quasi-galvanic) matching uses the current-flow of the free charges (ionic species in aqueous electrolytes in the body) and the rotational or gradient-induced linear movements of dipoles in the tissues.

The observed differences could be technically detected by measuring the engineering reference point (optimal engineering set-up), and the medical reference-request point. The inequality between the reference points is due to the losses in the circuit, including the matching tuner, cables, radiation processes, used materials, and structures, as well as the capacitive coupling with the environmental objects (like walls, other types of equipment nearby, or the operating personnel). At this point, the engineering control and the medical control could significantly differ from each other, Figure 8. 


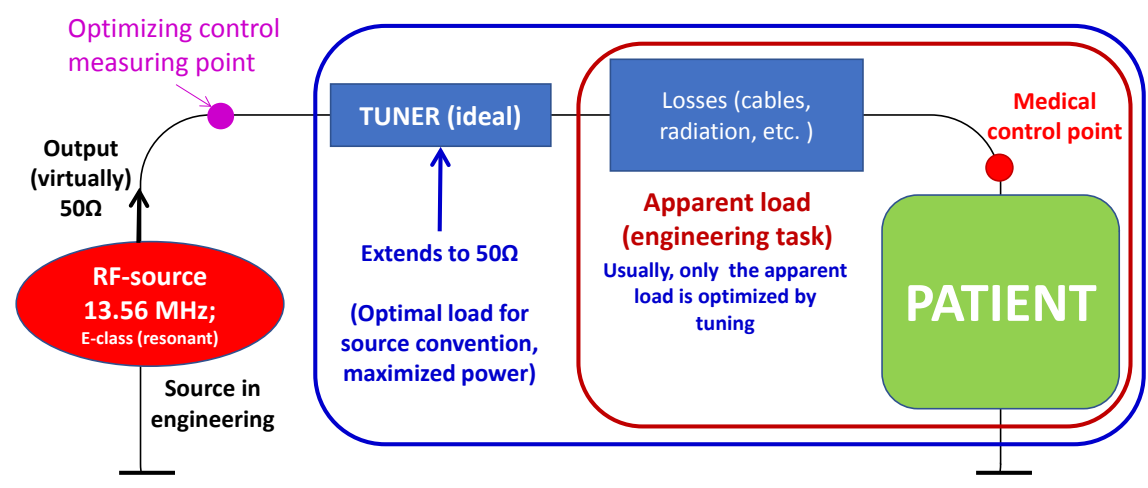

Figure 8. All losses are minimized by proper geometry, material-selection, careful design of specialized electronics, super-low imaginary (reflected) power, $(\varphi \cong 0)$ etc. The matching has to accurately control the medical point shown in the figure.

The tuner electronically compensates for the overall losses, and the powersupply increases the power to replace the missing, lost energy. This type of matching procedure favors plane-waves on the patient, which uses wave-absorption, with a particular exponential decrease from the surface incident energy in the body, and is intended to create homogeneous heating in an actual depth.

The compensation of the general losses by the circuit components and environmental interactions do not optimize the patient-power from a medical point of view. After the medical point (which begins at the electrode), the initial RF-current enters the "coupling complex," including the patient's targeted volume. After this point, new unwanted losses challenge the optimization of the treatment. These include the electrode structure, electrode material, the bolus system, the patient's surface adipose tissue, the healthy impedance, etc. This extra impedance is the vital target: the impedance of the tumor. Hence the optimization of the treatment point is crucial in order to successfully heat the tumor. How this is optimised defines the type of capacitive coupling (Figure 9).
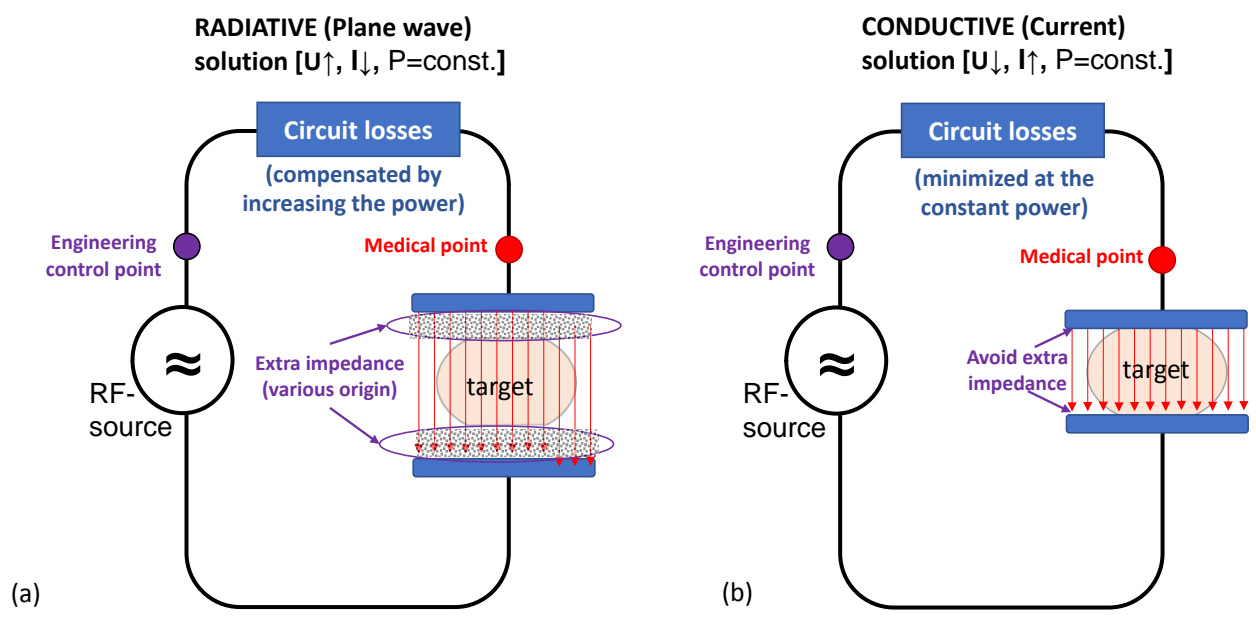

Figure 9. (a) The plane-wave matching allows a lazy connection of the electrode for various reasons; (b) The impedance (quasi-galvanic) matching does not work with improper impedance between the "medical point" and the body surface. 
The impedance matching focuses on the medical control-point, minimizing the impedance of components that derail the primary target's energy, the tumor. Without taking into account the medical point, the RF-current flows through two different impedance categories: the objects' impedance, which fits the current transfer to the body, and the body impedance.

The various components of object impedance challenge the conductive approach (Figure 10).

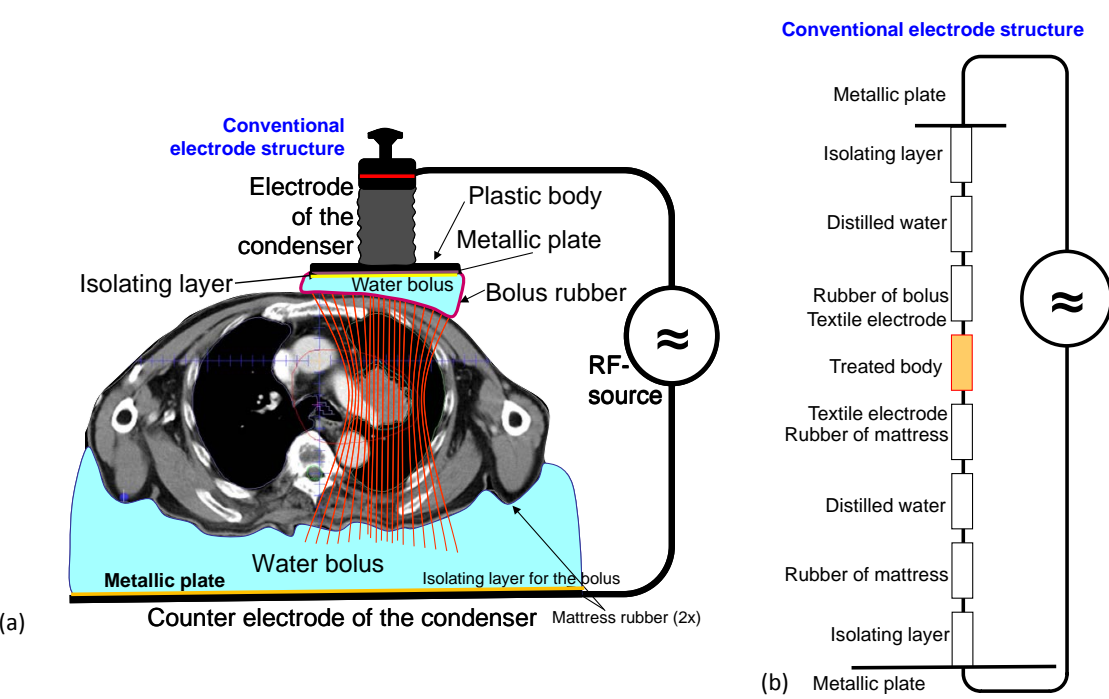

Figure 10. Numerous serial impedances modify the energy-distribution in capacitive coupling. (a) The main structure of the conventional capacitive coupling with water-bolus; (b) The draft of the impedance of the conventional electrode structure.

The best solution would be the galvanic contact of electrodes (Figure 11), which may be approached by the electrode design accompanied with the resonant compensation.
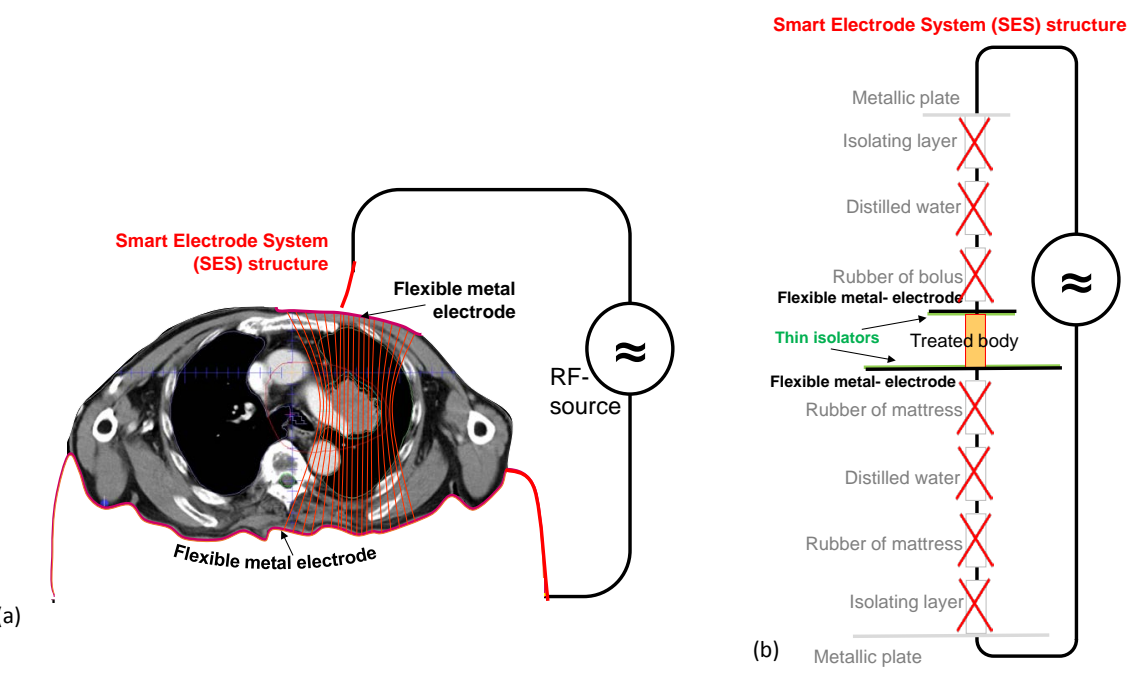

Figure 11. The draft of the design of impedance matching, which is (a) quasi-galvanic, or (b) the solution mimics the galvanic touching with a precise resonant compensation. 
The body impedance contains a very heterogenic structure. Each of which represents a resistor and a serial capacitor (the inductive parts are missing) (Figure 12).

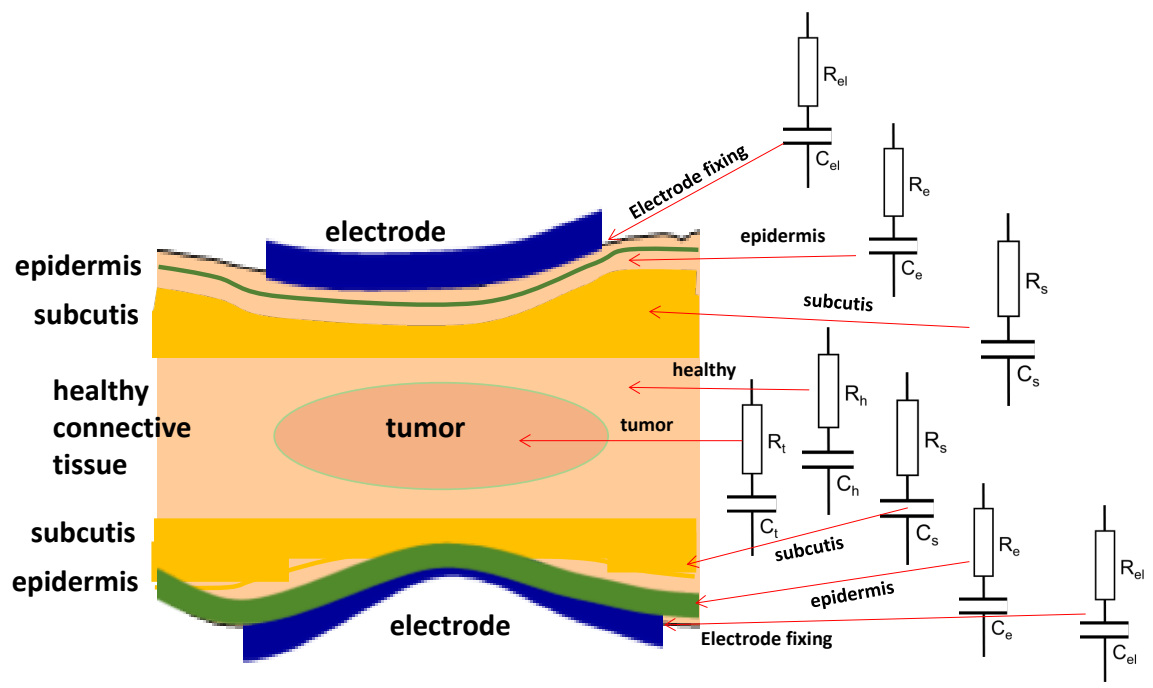

Figure 12. The major layers of the human body's targeted volume show the serial RC parts in every layer.

The compensation procedure in impedance matching minimizes the capacitive (imaginary reactance) factor, and the resistive part remains in focus. A particular category of impedance matching is the modulated electro-hyperthermia (mEHT) which selects the malignant cells in this heterogeneity, and the tumor-cells concentrate the primary energy absorption (see later text below). Consequently, the dominant resistivity part is the set of the tumor-cells in the targeted volume. On this basis, we approximate the effect of the different resistivities and the resistivity of the healthy tissues is negligible in the first attempt (Figure 13).
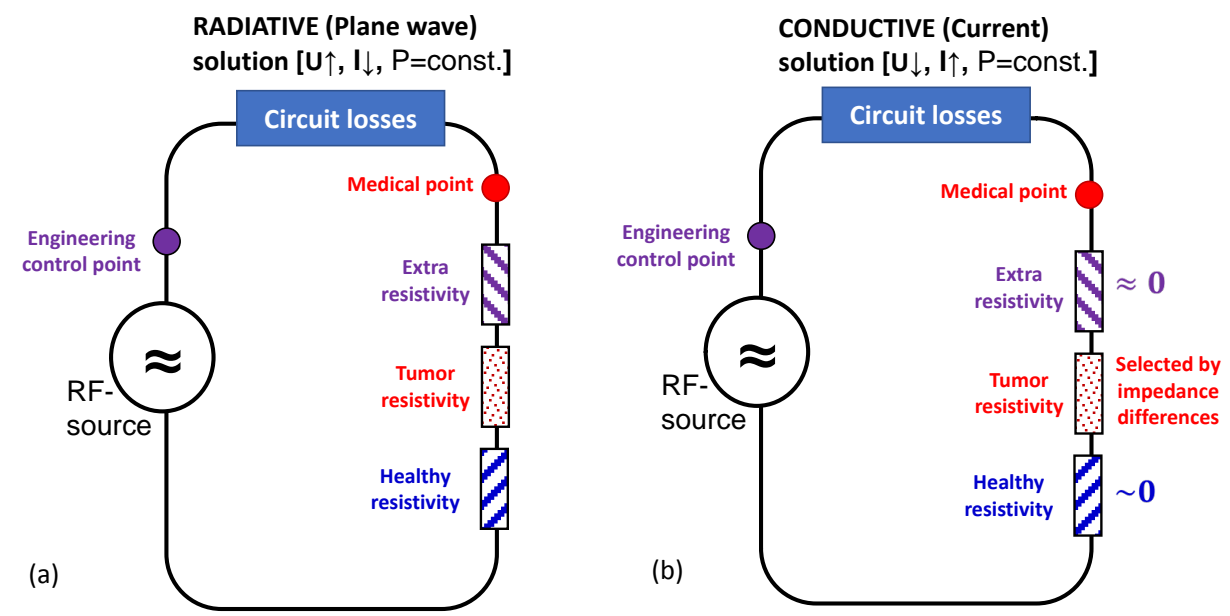

Figure 13. The voltage and current generation with the same value of power in plane-wave matching (a), and in impedance (quasi-galvanic) matching solutions (b). 
All of these considerations involve a resonant matching method. AC/RF circuits imply a certain frequency determined by the values of the resistance, capacitance, and inductance of the serial circuit (Figure 14).

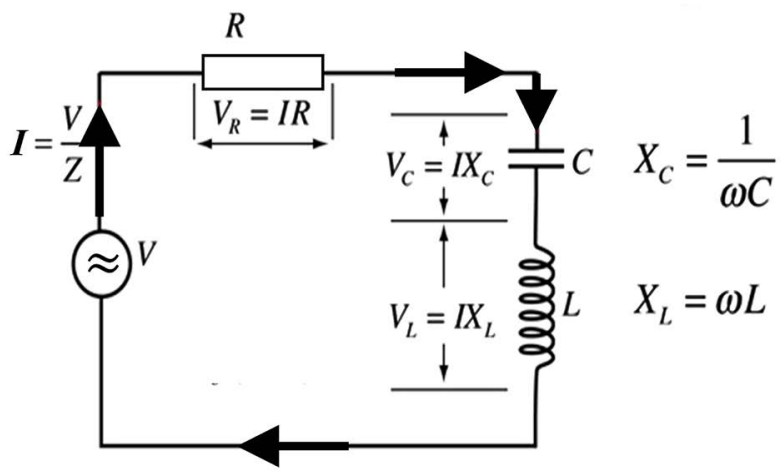

Figure 14. The discrete representation of the circuit describing the impedance matching. $V_{R}, V_{C}$ and $V_{L}$ are the voltage drop on the discrete elements. The resonant compensation produces the $V_{L}$.

The dielectric permittivity and the conductivity affect the RF-current differently, and the result is called impedance. Mathematics using complex numbers describe the two independent effects showing the conduction on the real conductor while the dielectric permittivity defines the isolators, where the conduction of the RF-current is imaginary. The patient's impedance represents the real part $\left(R_{p a t}\right)$, and the reactive part $\left(Y_{p a t}\right)$, and $Z_{p a t}=R_{p a t}+i Y_{p a t}$, where $i=\sqrt{-1}$ denotes the imaginary part. In geometrical representation, it shows a vector (Figure 15).

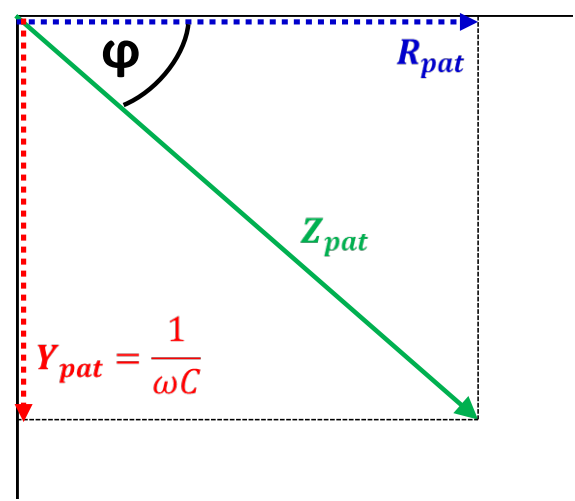

Figure 15. The vector picture of the impedance in living objects. The $R_{p a t}$ real resistance and $Y_{p a t}$ imaginary reactance produces the $Z_{p a t}$ impedance with the $\varphi$ phase angle. Due to the only capacitive part (no inductive element exists in the living organisms), reactance is negative. The current appears earlier on the capacitor than the voltage. The impedance matching approaches the $\varphi \cong 0$ compensation.

The impedance minimum characterizes the serial resonance. The impedance from the imaginary parts of capacity $(C)$, and inductivity $(L)$ are $Y_{C}=\frac{1}{\omega C}$, and 
$Y_{L}=\omega L$, respectively, and the impedance is $Z=\sqrt{R^{2}+\left(Y_{L}-Y_{C}\right)^{2}}$. Hence, when $\omega_{0}=\frac{1}{\sqrt{L \cdot C}}$ then $Y_{L}=Y_{C}$, and the resulting minimal impedance is $Z=R$ with zero phases. The selectivity of a circuit depends on the circuit's serial resistance.

The $Y_{p a t}$ depends on the applied frequency $(\tilde{f})$, while the real conductor does not depend on $f$. The living matter has a negligible inductive (coil-like) component in $Y_{\text {pat }}$. Mostly the membranes, and the other isolation layers form $Y_{\text {pats }}$ which act as a $C$ capacitor, $Y_{p a t}=\frac{1}{2 \pi f C}=\frac{1}{\omega C}$ Where $\omega=2 \pi f$. Applying the vector representation of the impedances (Figure 15), the variation of the major layers in the target volume of a human body gives a resultant impedance $R_{\text {pat }}=\sum_{i=1}^{N} R_{i}$, and $Y_{p a t}=\frac{1}{\omega} \sum_{i=1}^{N} \frac{1}{C_{i}}$. Using the resonance frequency $\omega_{0}=\frac{1}{\sqrt{L \cdot C}}$, an additional inductive factor would compensate the $Y_{p a t}$ to minimize the impedance of the target. The necessary inductivity for resonance is $L=\frac{\omega_{0}^{2}}{C}=\omega_{0}^{2} \sum_{i=1}^{N} \frac{1}{C_{i}} \quad$ (Figure 16).

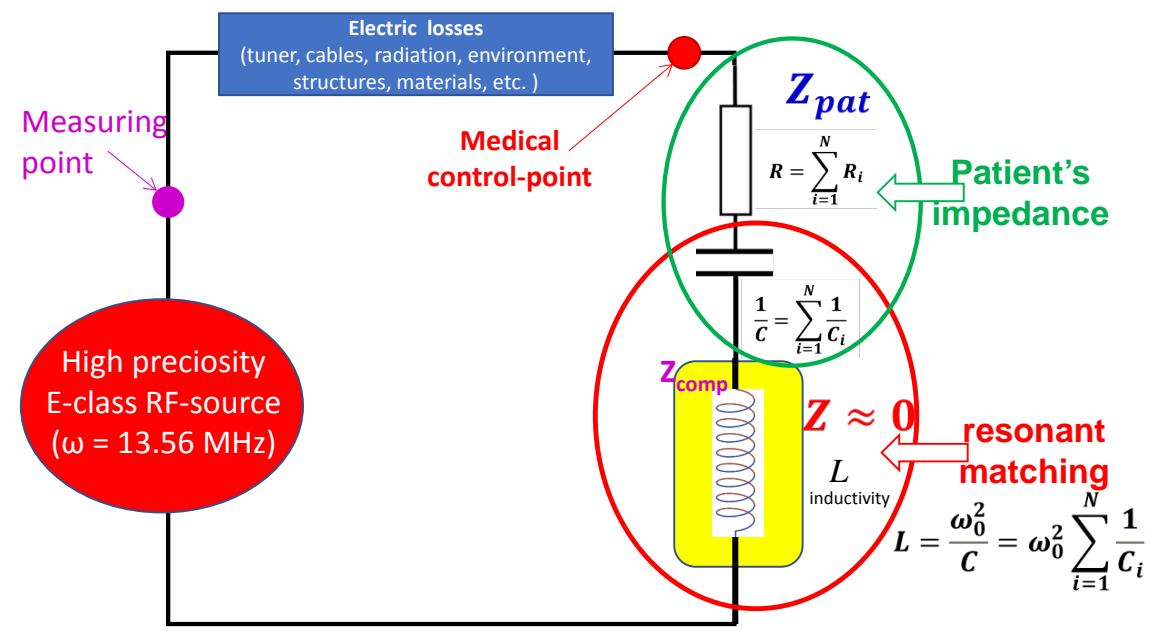

Figure 16. The patient is an electric component of a precisely tuned resonant circuit. The compensation clears the target impedance minimizing its reactance.

The compensation transforms the impedance near a real resistance value as shown in vectorial representation (Figure 17). The vectors show the complex impedances of some critical layers in the body during the RF-current flow. The horizontal axis is the real part (the real conduction), while the perpendicular one is the imaginary part, representing the isolation. All tissues have isolation also due to the various membranes. The electrode isolations are neglected, so the resulting impedance vector shows a decline, which a single inductive resonance could easily compensate for. 


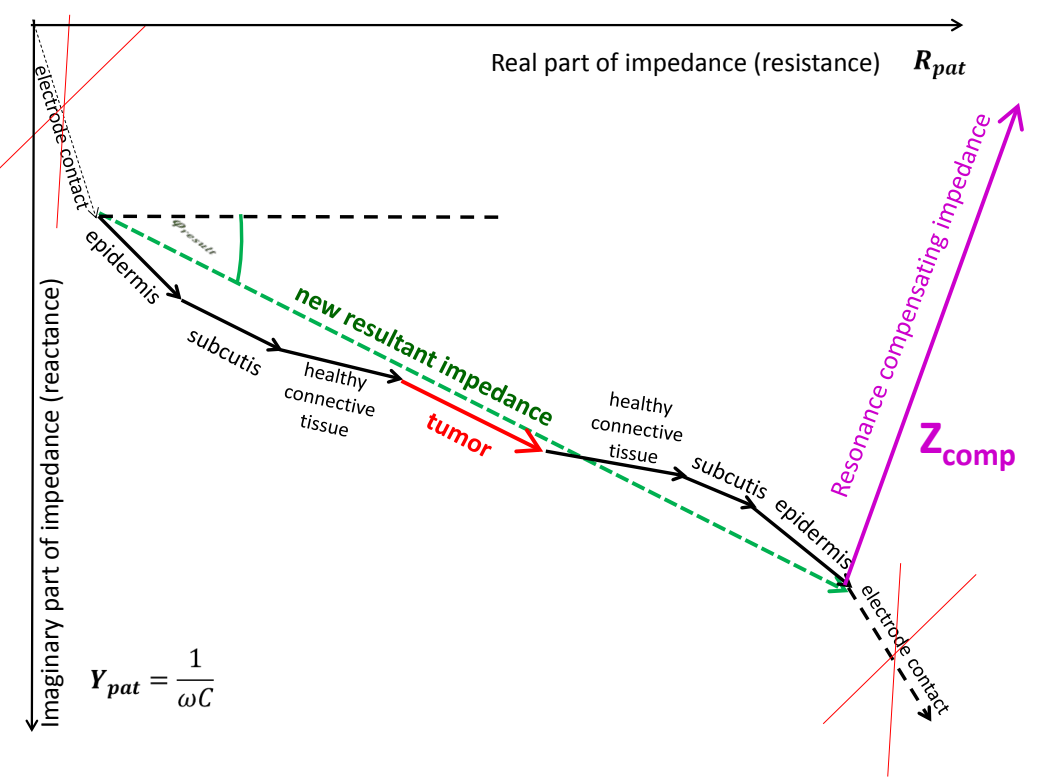

Figure 17. The vector diagram of the cross-sectional impedances in the average human body. Only the major components are shown, and for clarity, they are regarded as a discrete element.

The original current was $I_{\text {orig }}=\frac{V}{Z}=\frac{V}{\sqrt{R^{2}+\left(\omega L-\frac{1}{\omega C}\right)^{2}}}$, the new current in resonance is higher $I_{\text {orig }}<I_{\text {res }}=\frac{V}{R}$, and in resonance depends only on the real resistivity. The current changes by resonance. The RF-current flowing through the target depends on the values of the components of the circuit. The well-selected situation filters a relatively small part of the targeted volume, the malignant cells, so their resistivity is small compared to the complete targeted volume. The small resistivity increases the peak of the current in resonance, Figure 18.

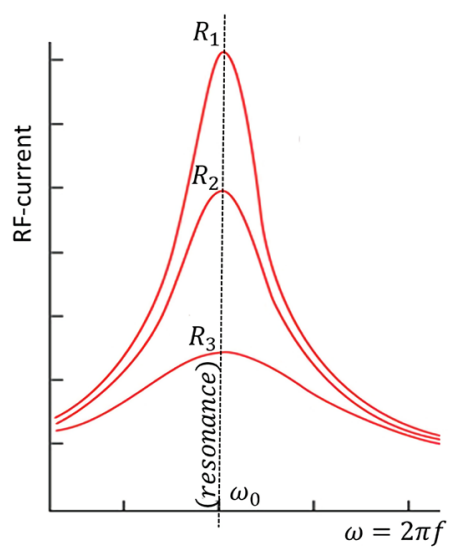

Figure 18. The RF-current distribution in the resonant conditions. The resistivity is decisional; when it is low, the peak is sharper $\left(R_{1}<R_{2}<R_{3}\right)$. The $f_{0}=\frac{\omega_{0}}{2 \pi}$ is the resonant frequency. 
Since this power depends on the square of the current the resonant curves appear steeper and narrower in the presence of lower resistivity. The quality factor $Q$ is defined by $Q=\frac{\omega_{0}}{\Delta \omega}$ where $\Delta \omega$ is the width of the resonant power curve at half maximum (Figure 19).

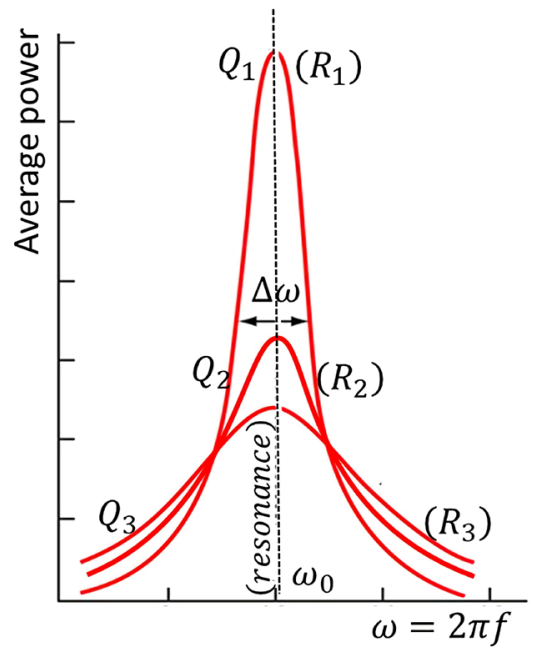

Figure 19. The resonance quality factor $(Q)$ defines the average power in resonance. $R_{1}<R_{2}<R_{3}$, and so $Q_{1}>Q_{2}>Q_{3}$. The $f_{0}=\frac{\omega_{0}}{2 \pi}$ is the resonant frequency.

Since that width turns out to be $\Delta \omega=\frac{R}{L}$, the value of $Q$ can also be expressed as $Q=\frac{\omega_{0} L}{R}$. The $Q$ is a commonly used parameter in electronics, with values are usually in the range of $Q=10$ to $Q=100$ for circuit applications. The smaller the resistance, the higher the " $Q$ " for given values of $L$ and $C$. The power, of course, depends on the product of actual current and voltage. When the current increases due to the resonance, the voltage decreases, while maintaining the same power.

The resonant approach uses the minimizing of the reactance (imaginary part) of impedance. Physiological regulation also has a vital role in the process. One of the reasons for using the plane-wave capacitive coupling is the surface adipose tissue challenge, forming an isolator-like layer at the skin. In a plane-wave situation, the voltage is increased to surmount the gap by the isolator of the adipose layer. However, this way, the energy-absorption in this layer is extremely large, so the risk of burn increases. In order to avoid this risk, the plane-wave method uses intensive cooling of the skin by using the bolus system, Figure 20.

However, this cooling has unexpected positive feedback reactions from the physiological control of the body homeostasis: the cooled skin lowers the bloodflow in the subcutis, which increases the layer's isolation towards RF-current. This induces a higher voltage request, which increases the risk of burn, so a further increase of the cooling is necessary. It further increases the isolation, and so 


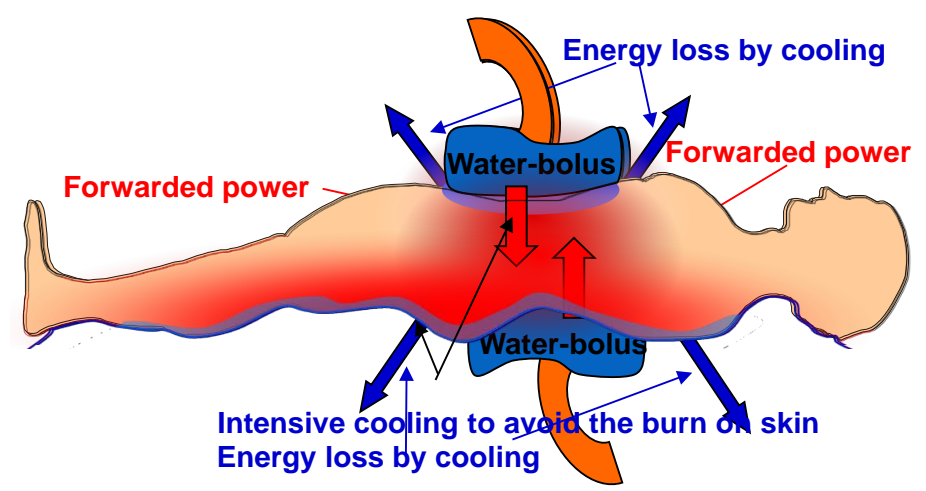

Figure 20. The cooling of the bolus produces uncontrolled energy-loss and induces a positive-feedback physiological regulation. (see the text)

on, the situation would be hard to control. Furthermore, the intensive cooling absorbs a large part of unmeasured energy, which makes the therapy dosing with incident energy impossible, as is similar in the case of ionizing radiation. Consequently, the impedance matching takes attention to the cooling process and keeps the homeostatic control stable in the subcutis layer under the electrodes.

In summary, the strategy of impedance matching concentrates on increasing the current as much as possible. The major factors to maximize the current are:

- the resonance approach,

- the design, structure, materials of the electrode system,

- the grounding optimization to lower the radiation, and coupling to environmental objects,

- the regulation of the homeostatic status of the skin blood-flow (which regulates the imaginary part of the skin-structure of the patient),

- eliminating the losses in an electric circuit as much as possible,

- the high current value (in the unchanged power conditions) makes a more effective selection,

- the high current accompanied with low voltage at the constant power, increasing the safety of the treatment.

\section{The Modulated Electrohyperthermia (mEHT)}

\subsection{The Challenge of Homogeneous Heating}

The classical heating concept applies a mass-heating of the entire tumor. The mass heating tries to be homogeneous in temperature (isotherm), and uses the temperature as the only control parameter.

The control of homogeneous (conventional) heating is problematic because

1) the local blood-flow is enhanced, which increases the risk of dissemination and metastases,

2) colossal power is necessary to ensure quasi homogeneity, which again involves many safety issues,

3) due to the heterogeneity of the target, the control of homogeneity is very complicated, in most cases it could not be achieved, 
4) the homogeneous hyperthermia thermally kills the cells and occasionally triggers immunogenic effects in the area,

5) the challenge of measuring temperatures at has not been solved; MRI thermometry is promising but still has challenges,

6) the only homogenous (and large CEM43T100) solution is the whole body treatment (WBH), which does not show the expected success.

The invasive measurement of the tumor's temperature has multiple problems, as a result the temperature is typically measured in the nearby lumina or cavities of the body. So the mass heating must be regional, having comparable temperature in the nearby lumen (like oesophagus, bronchus, colon, vagina). The same isotherm heating appears in the plane-wave concept of capacitive coupling. The modulated electro-hyperthermia (mEHT) method uses impedance matching of capacitive coupling with some unique features, which have been developed over the past 32 years, and documented and patented. The mEHT method harnesses the impedance matching shown above with additional elements, improving its efficacy.

The present technical challenges are:

1) The energy selection ensures the local place of energy absorption. It has major complications due to the normal physiological movements caused by breathing; and the technical solution has limitations when attempting to heat deep-seated tumors without considerable heating of other tissues.

2) The dose determination, which controls the medical application, is a mandatory parameter, but the heating techniques determine the clinical results. We have seen that exposing the tumor isothermally to $42^{\circ} \mathrm{C}$ in whole-body hyperthermia, has entirely different results than the same temperature in any local treatment. The technical solutions based on the temperature alone do not characterize the applied method.

3) The role and measurement of temperature in the treatment efficacy are challenging. The value of the temperature in the target supposes an isothermal mass-heating, which never happens in LRHT. The temperature measurement approximates the tumor's value, checking the temperature in the nearby lumen (like esophagus, bronchus, colon, vagina). This method assumes that the heating does not focus on the tumor-mass, but equally heats its healthy environment.

Due to the above challenges, temperature measurement is mandatory to approximate the absorbed energy, which differs from the technically provided value. The high energy losses (like various electric losses, losses from cooling water, etc.), and the need to control safety (avoid burns) are fundamental reasons to measure the temperature.

\subsection{Heterogeneous Heating}

The mEHT chooses a new paradigm, it heats the cancer-cells selectively in the tumor, using the malignant cells' unique thermal and electromagnetic characteristics. The structural change of the local heat-capacities, heat-conduction differences, heat transfer by blood, and lymph electrolytes cause the thermal hete- 
rogeneity. Significant differences in the electric behavior of micro-states of living matter determine the electromagnetic heterogeneity. The variation of electric conductivity and dielectric permittivity by the living processes and the differences of lipid-protein structures in the cell-membranes and the cells' cooperative differences appear to be the most influential factors for electric heterogeneity. Further differences between the malignant cells and their healthy counterparts develop as a result of the heat-resistance, motility of the cells, and cellular and extracellular mechanical properties.

Some other significant differences are present at a molecular level, but these are less effective in distinguishing the malignant cells from their healthy counterparts. Using heterogeneity offers a valuable tool to select the malignant cells in the heterogenic tissue. The RF-current presents a possible tool for clear recognizing of the heterogeneities. The current-flow changes based on the electric heterogeneities and its heating effects connect the current to the thermal properties. An essential component of tissue heterogeneity involves molecular reactions, which differ depending on the tissue and cells. For example, the apoptotic control, a well-known regulation in healthy tissues, is almost entirely missing in malignant tissue, as described in the hallmarks of apoptosis could happen through multiple molecular mechanisms, which do not work in cancer.

\subsection{Considering the Homeostatic Regulation}

From the beginning of human medicine, physicians recognized the equilibrium of the living organisms, which defines the healthy state, and has multiple dynamic components which are finely balanced. This was the first recognition of homeostasis, which has definite lower and upper limits of the interactions and conditions. The body homeostasis is stable within a certain interval of the parameters; the level of any interactions is determined and measured by the harm caused at the extreme limits. However, the harm is a relative notion: the safety and the harmless categories are not identical. The "no action" treatment can be safe but harmful because the uncontrolled disease harms, which we can stop by action. The acceptable changes in medical actions attempt to reestablish the normal, healthy homeostasis; or if it is not possible anymore, then it attempts to approach it as close as possible. The Hippocrates-phrase, "Nil nocere" also has to be understood in this way. Otherwise, the meaning is "Do nothing".

The internal transports, like the blood-stream, have a central role in keeping homeostasis. The blood circulation regulates multiple vital processes, including the heat exchange, to ensure the body's proper functional conditions. The blood-stream tries to compensate for the overheating by intensive perfusion and regulation of the vessels' flow-capacity. However, the regulation process of the blood-stream is non-linear. The quantitative analysis [33] shows the non-linear changes of the blood-flow in characteristic tissues varying by the temperature. The deviation (selection) of the tumor blood-flow starts just above $38^{\circ} \mathrm{C}$, Figure 21. 


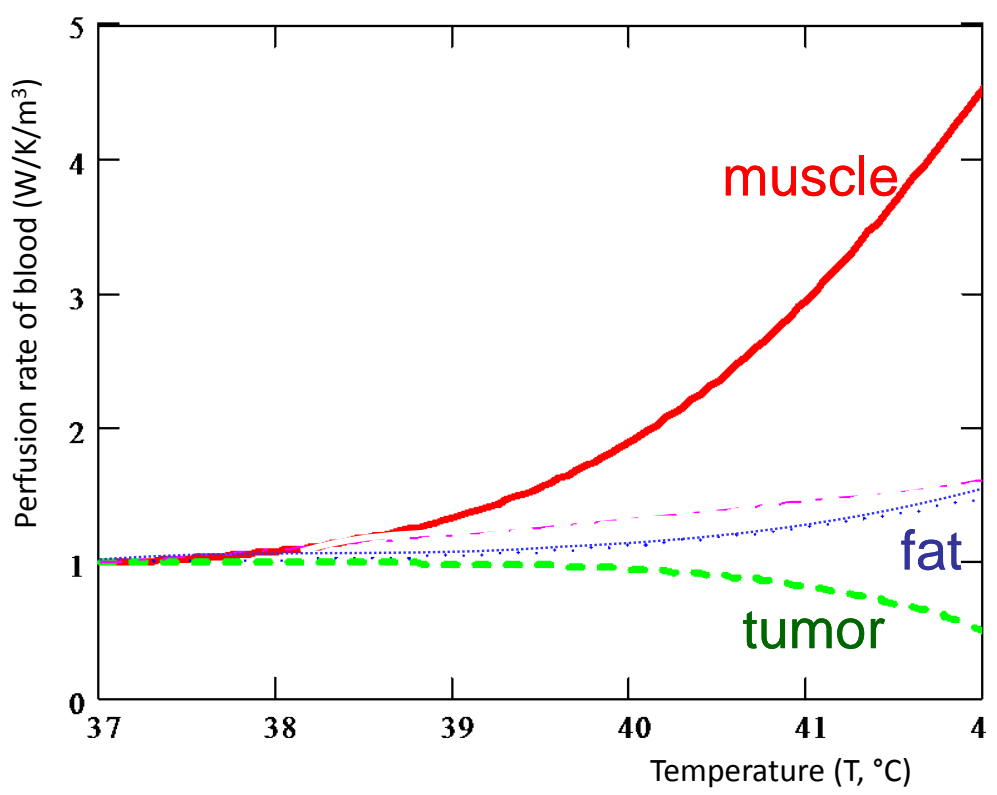

Figure 21. Relative quantitative changes of the blood-flow by a temperature increase in muscle, adipose tissue, and tumor lesion.

Due to the variation of the blood-flow, the necessary energy in a mass unit (specific absorption rate; SAR $[\mathrm{W} / \mathrm{kg}]$ ) non-linearly changes in the range between $39^{\circ} \mathrm{C}-42.5^{\circ} \mathrm{C}$ [34] by the actual temperature, Figure 22 .

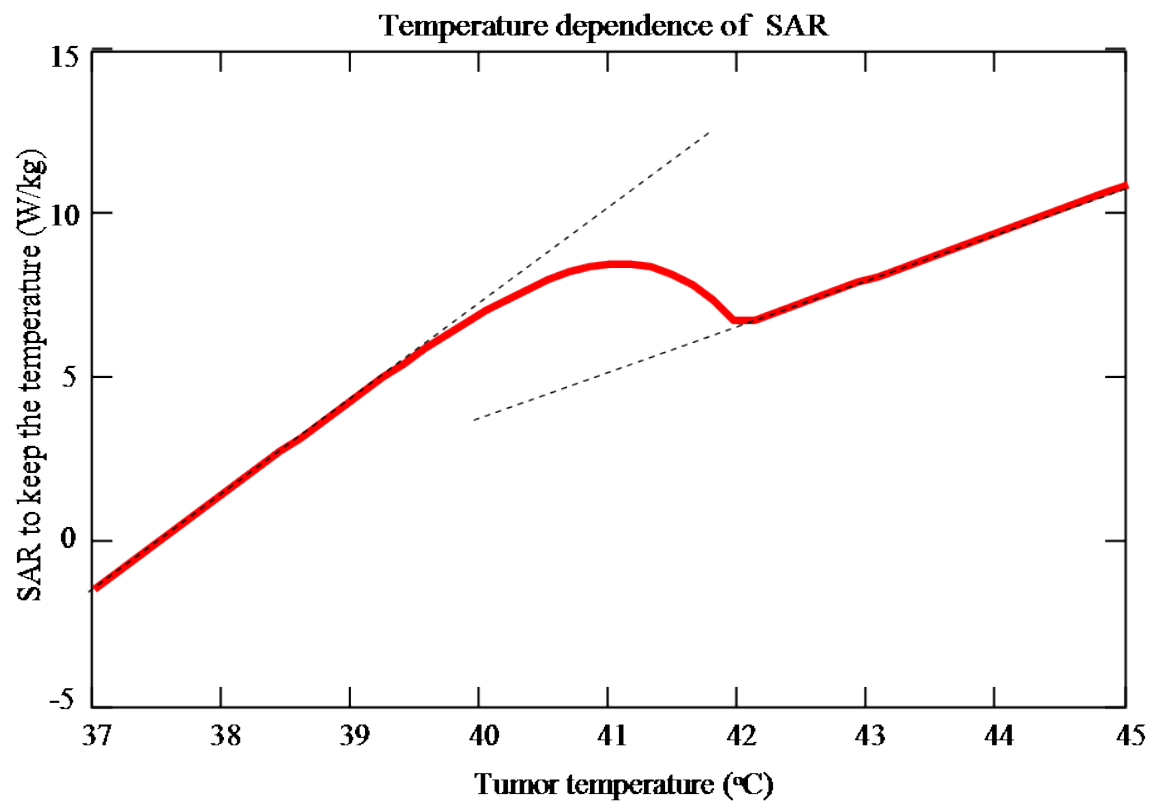

Figure 22. Variation of the requested specific absorption rate (SAR) to keep the given temperature in the tissue.

The non-linear regulation is general, using physiologic control by negative feedbacks. The promoter-suppressor action realizes the contraction of the feedbacks, which has a broad response-time for intervention. 


\subsubsection{The Selection Mode}

The classical heating concept applies mass-heating of the entire tumor. The mass heating tries to be homogeneous in temperature (isotherm) and uses the temperature as the only control parameter. As previously discussed the temperature is usually measured in the nearby lumina or cavity and the same temperature must therefore be achieved in the lumina/cavity. The mEHT method uses a different paradigm, its heats the cancer-cells selectively in the tumor (Figure 23), using the malignant cells' unique thermal and electromagnetic characteristics.

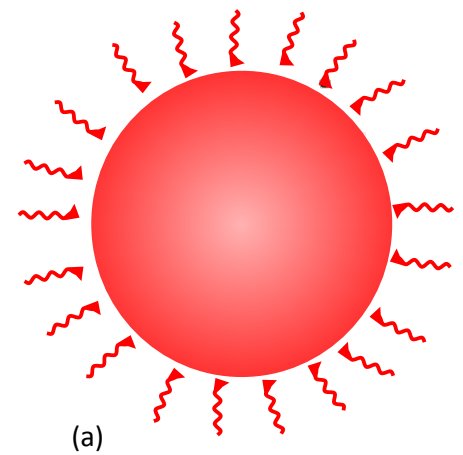

(a)

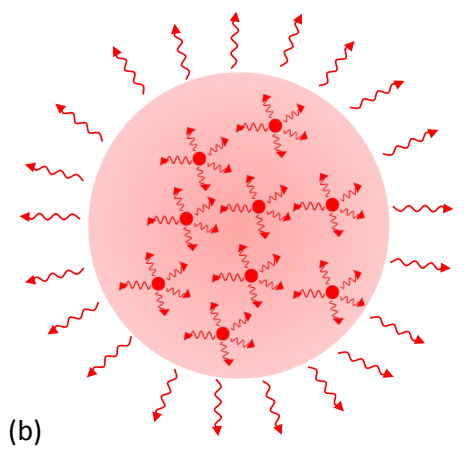

(b)

Figure 23. The differences between the heating paradigms: (a) Plane wave matching homogeneous heating causes energy-absorption in the complete target, while (b) impedance matching could be selective, heats only selected parts in a heterogenic manner, heating up the surrounded tissue by heat conduction (mEHT principle).

The selection uses the natural heterogeneity. The RF-current recognizes the electrical heterogeneity, and its heat effect results in thermal heterogeneity, resulting in the complex synergy of electric, and thermal processes [35], induces molecular changes driven by mEHT. The malignant differences make it possible to distinguish malignant cells from healthy cell structures [36]. The amount and composition of the extracellular aqueous electrolyte in the micro-environment of tumor cells massively differs from healthy tissues.

The malignant cells need a significantly higher energy amount than the healthy cells due to the intensive metabolism required to supply their proliferation [37]. The metabolic rate in most of the tumors is higher than their healthy counterpart (at least 15\%, [38]), which selectively increases their temperature. The process has positive feedback because the higher temperature decreases the tissue's impedance [39]. Their metabolism requests a robust amount of nutrients which in the simplest way demands glucose. Due to the high level of necessary ATP production, the tumor cells predominantly perform simple anaerobic glycolysis instead of mitochondrial phosphorylation. The positron emission tomography (PET [40] [41]) identifies the extreme glucose intake in cancer cells. The rapid, intense fermentative process produces lactate, increasing the electrolyte's ionic conductivity in the cellular microenvironment, jointly with the higher inand outflux transport of other ionic species. The increased ionic concentration means higher conductivity [42] of the microenvironment of tumor-cells, so it lowers the whole tumor's resistivity. This can be used to distinguish between 
healthy and malignant situations [43]. The RF-current selectively flows through the low resistance (highly conductive) tumor rather than the more resistive healthy environment.

Malignant cells are autonomic, independently fighting for the energy against all other cells irrespective of healthy or fellow cancer-cells. For autonomy, they break their networking bonds and stop direct intercellular communications. The bonds formed by adherent proteins and junctions mostly vanish. Due to the missing cellular network, the extracellular matrix of malignant cells has high dielectric permittivity, which can be used for selection [43]. The structure of the microenvironment rearranges due to the missing bonds [44]. The altered structure allows the recognition of the malignant cells by their dielectric properties, which modifies the applied RF current [45] [46]. A well-developed diagnostic method uses this phenomenon [47], and it is applied in mammography [48].

The permittivity and the conduction modify the complete impedance in the microenvironment of the malignant cells [5], allowing their selection in an automatic way, while the RF-current flows in the direction of low electric impedance. The RF-current-density (specially chosen frequency and modulation) self-selectively flows toward the malignant cells, which is measurable by MRI current density imaging, [49] [50] [51]. This effect is completely automatic, it follows all movements of the cells in real-time, actually solving the challenge of focusing. The direct MRI electrical impedance tomography confirms the feasibility of using the impedance differences for selection [52].

The broken bonds between the cells leave the transmembrane proteins unconnected. These transmembrane proteins group by lipid-protein interaction in the membrane. The concentration of lipid rafts on malignant cells' membranes is significantly higher than on the membrane of non-malignant cells. The impedance-selected malignant cells' dense lipid rafts become an easy target of energy absorption. The rafts' clusters absorb the energy from the RF-current selectively [53] because the rafts have significantly lower electric impedance than the surrounding isolating lipid membrane. The selective energy-absorption promoted by a characteristic frequency dispersion in the applied $13.56 \mathrm{MHz}$ frequency range ( $\beta / \delta$ dispersion [54]), and the Schwan effect [55]), targets the lipid-protein interactions and selects water-bound states [56] at the membrane, effectively focusing the energy on the target [57]. This way, the natural electric heterogeneities drive the selection for energy absorption automatically, constructing an "autofocusing" process.

Further selection could be realized by the structural differences of the malignant tissue from their healthy counterpart. Usually, the pathological investigation of biopsies utilizes these differences by image pattern recognition in the samples. The pathological pattern naturally affects the RF-current in-situ, allowing additional selection of cancer tissue in the body. The alterations of the pattern modify the cells' spatiotemporal interactions, which dynamically act via intercellular interactions. The well-chosen noise could transduce free energy for the cellular reactions [58]. The dynamic relations produce a noise of homeostatic 
equilibrium, which is measured as a peculiar signal [59] [60]. This noise differs in malignancy versus healthy tissue and is measurable by the RF current [61]. The noise difference is the basis for the applied modulation on the RF carrier in the mEHT method [62]. The modulation is an information delivery to the malignant lesion. The applied time-fractal has such autocorrelation time-lags that well fit the apoptotic excitation processes and may also act in enzymatic catalysis [58]. The spectrum of the reaction-times and rates appears in the modulation frequencies. The mEHT method applies such modulation, which is in harmony with the homeostatic collective network.

The collective excitations comprise the non-local waves and activate the energy-flow in the homeostatic networks. These excitations are mostly in a low-frequency range, and the expected frequency spectrum follows the natural $1 / \mathrm{f}$ fluctuations. Simply speaking, the modulation acts in harmony with the natural collective processes, promoting them, like keeping the swing in motion using harmonic push. Both the multicellular networked and the unicellular autonomic states of cells maintain a balance which is probably realized by an electromagnetic route [63]. The FDA-approved TTF also uses this kind of interaction to arrest malignant cell-division [64]. The method of mEHT uses an electrical field to modify the polymerization processes in the mitotic phase of the cellular division [65] with fractal noise modulation for a complex effect.

Furthermore, the applied noise is an active harmonizing factor [66], which has an emerging physiological application [67]. The fluctuations of electrical properties have unique information related to cell-membrane processes [68]. The monitoring of the noise as fluctuations in the complex system could be a factor in its surveillance [69]. Forcing harmony reconstructs the broken E-cadherin-betacatenin cellular connections [70], which as was effectively and repeatedly demonstrated in an independent study [71]. The malignant cells' membrane is more rigid [72], while the cells themselves are softer than their neighboring healthy cells. The adherent connections and junctions could be formed only when the reactive ligands are close to each other.

As a result, the cellular connections have a geometric requirement to be re-established. The fermentative way of metabolism of malignant cells develops a strongly negative glycocalyx shell, which works against the proper geometric order, blocking bonding between the appropriate ligands. However, the extremely high fluctuating cataphoretic forces from the pink-noise modulation compensate the repulsion, and make the adherent connections possible.

The modulated carrier signal targets the selected malignant cells, and the cells rectify (demodulate) the received signal. The demodulation process uses two factors:

normal rectification by the highly polarized cell-membrane, [73] [74] [75].

stochastic resonance that makes the rectification, [76]

The non-temperature dependent rectification (non-linearity) was a question-mark for a long time because only linear attenuation was measured through the living object. The double membrane effect causes this apparent linearity. The 
challenge is to measure the rectification in a tissue in which every cell with its opposite positions of the entry and exit points on the cell membrane acts like two diodes connected oppositely. So no rectification could be detected by measuring the tissue alone, Figure 24.

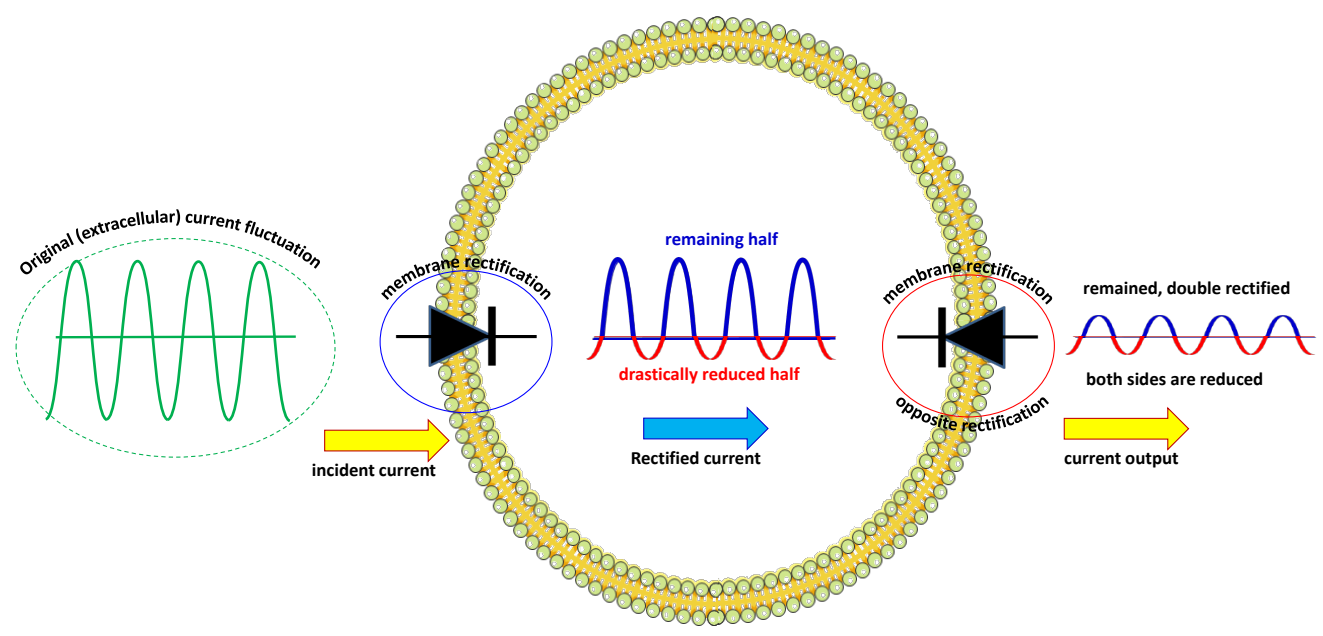

Figure 24. The symmetric but opposite rectification of the cell-membrane when the current goes through the cell makes the measured material linear, the rectification is not visible.

The mEHT impedance-matched capacitive coupling has four interconnected mechanisms for selection: the heterogeneities in conductivity and dielectric permittivity select the tumor, and its independent, while the membrane rafts absorb the energy in selected cells (the hyperthermia step), and the spatiotemporally distinguishable tumor-pattern provides an additional factor for selectivity, and isolation of the malignant cells, Figure 25.
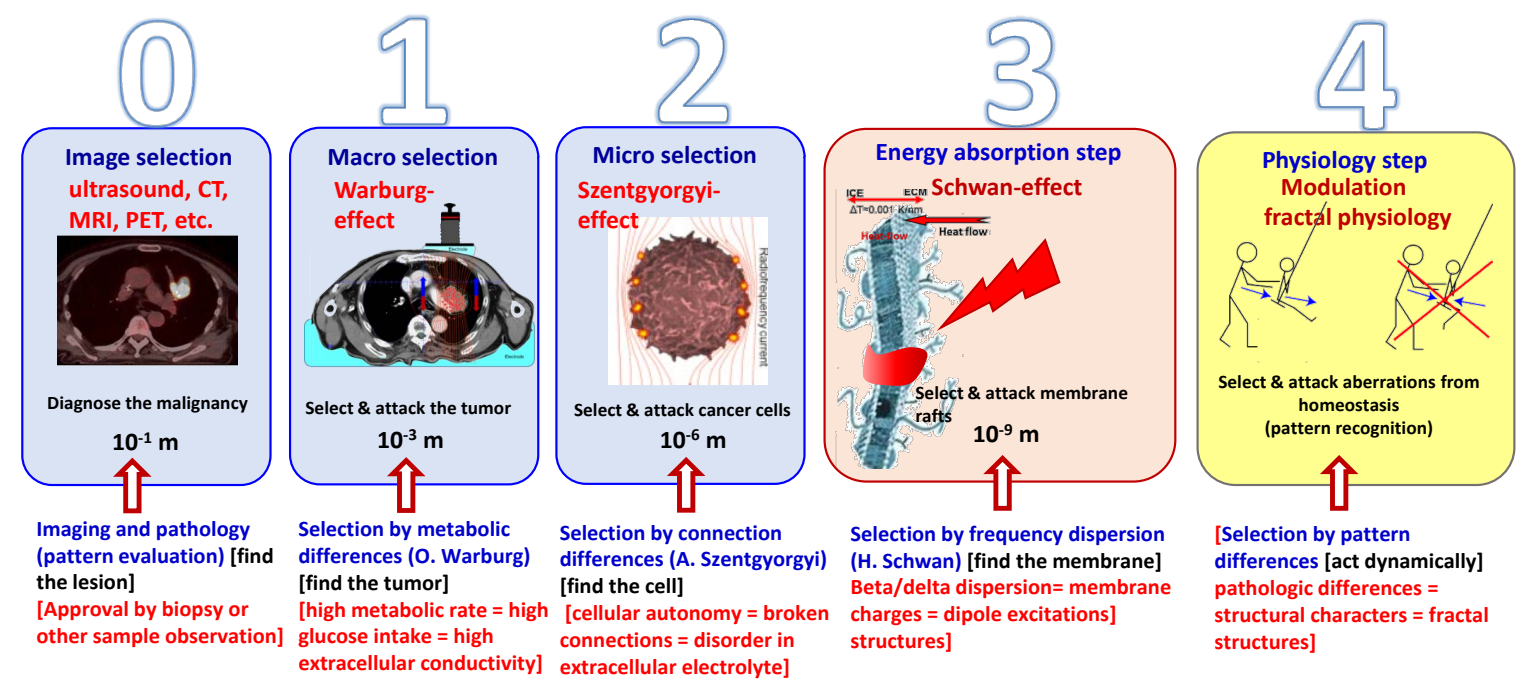

Figure 25. The steps of the mEHT action. (0) The conventional imaging supports the diagnosis; (1) The macro selection by conductive heterogeneities; (2) The micro-selection by the permittivity heterogeneities; (3) The energy absorption (the hyperthermia step) on the nano-range membrane raft; (4) A broad time-fractal spectrum recognizes and corrects the spatiotemporal pattern irregularities in the body. 
Contrary to the above complex focusing (selection) mechanisms of mEHT, the plane-wave capacitive coupling methods regulate their approximate focussing of the energy by the size of the electrodes. The appropriately chosen electrode size is their focusing mechanism and their homogeneous mass-heating does not select on the cellular level.

The homogeneous heating has to balance the higher temperature and the increased blood-flow, induced by the intensive heating. The bloodstreams are a promising sensitizer of chemo- and radiotherapies, but are also a potential promoter of metastases resulting from the massive transport possibility of the cancer-cells. This process risks increase the metastases by forming circulating tumor cells (CTC). The CTCs could produce micrometastases throughout the entire body, which are not observable by the present imaging techniques. Heterogenic heating with microscopic (cellular) selection does not have such a challenge: the targeted particles can be supposed to have equal absorbed energy-doses, so the absorbed energy is the measured parameter. While the homogeneous heating method heats all parts of the target from outside, the heterogenic heating heats only the selected particles, and those heat the tumor where they are located. The selected particles are heated up intensively to have a higher temperature than their environment. The RF current at the $<15 \mathrm{MHz}$ frequency predominantly flows in the extracellular electrolyte. Its energy-absorption creates an active temperature gradient through the membrane [77], converting the electric heterogeneity to a thermal one. The mEHT heating does not make a massive general temperature increase of the targeted volume, macroscopically it presents a moderate temperature increase, but microscopically $\mathrm{mEHT}$ could produce extreme hyperthermia [78] [79]. The gradient causes the complete target's heating to the level of mild hyperthermia [80], which complements the applied chemo- and radiotherapies [81], but reduces the risk of metastases by CTCs. Notably, the pharmacokinetics of drugs are promoted by mEHT selective heating [82] [83].

The mEHT limits the increase of the SAR, which forces the development of the temperature. At a high temperature, the microscopic selection disappears, and an average temperature characterizes the target, like in plane-wave energy absorption Figure 26. For mEHT, the limited energy-absorption is mandatory.
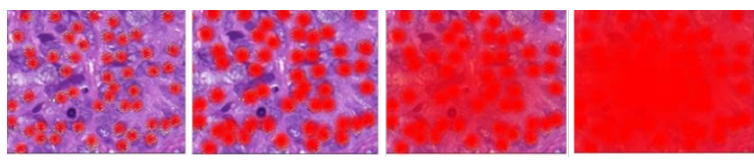

\section{SAR increases}

Figure 26. When the energy is too high, then everything is heated up, no selection could be seen. The selection factors became negligible. The selectivity has been lost, like the difference between the medicament and poison.

The electromagnetic selection mechanisms are general, and valid to all electromagnetic absorption methods treating cancer. However, the careful design 
with focus on the precise selection emphasizes the anyway small effect. The emphasis of the selection over the thermal averaging needs the above factors, which consistently exceed the selection effects over the massive trend to homogeneous temperature averaging. On average, the relatively small SAR is high in the rafts, similar to the nanoparticle selective heating. However, the nanoparticles in mEHT are molecular clusters, which are sensitive to overheating. When the absorbed energy destroys the rafts by overheating them then the mEHT loses its largest advantage: the excitation of signal-transports for apoptosis and immunogenic cell-death.

A natural question arises: without the modulation is the effect of mEHT the same as other capacitive plane wave techniques applied at a lower power? The answer is yes, if their technical solutions fit the low energy, then they could form such complex situations as the modulation and the low-energy selection does.

However, it is not enough to have low energy alone; it must be that the energy is there where we need it, inside. For this, absolute fine-tuning (resonance to kill all imaginary part of the impedance), in order to promote the high current instead of the high voltage at the coupling, and the well-controlled radiation losses. An example for this fine tuning is how: the same Otto engine works in the high and low category cars. However, the same petrol makes different values for dynamism, the fuel consumption of the cars or the same electromotor principle gives different "output" efficiency in the electric car.

In summary, the specialization operates with precise electromagnetic impedance selection [84], using the heat on membrane rafts [53], and makes harmony by applying thermal [85], and non-thermal effects [86] [87]. The applied modulation well supports the precise selection of the malignant cells [85]. The mEHT breaks the paradigm that the physical conditions do not allow the proper biological effects, as researchers show from Charite University [88]. The electric concept in sequential magnification summarizes the main principle, Figure 27.

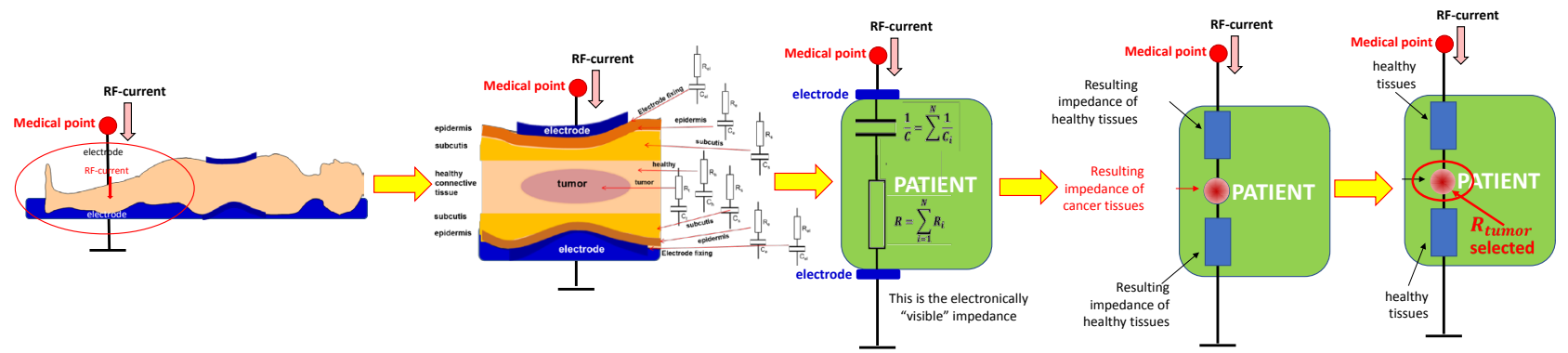

Figure 27. The series of the action of mEHT shows how it matches the focus on the tumor.

\subsubsection{Penetration Depth}

The penetration depth in the case of wave-absorption is the radiative penetration depth defined by the planar-wave absorption [89] [90], which is a loss of the absorbed specific energy or field in the body. The definition of the penetration depth of energy-absorption is the distance in the body when the initial $100 \%$ of 
energy from the surface decreases by $1 /$ e (remains only $37 \%$ of the energy). This does not mean blocking the beam deeper. It is an exponential function. We have practical knowledge about the X-ray diagnosis, which sees the deep lesions in the body. However, these X-rays have less penetration depth than $10 \mathrm{~cm}$, Figure 28 [91].

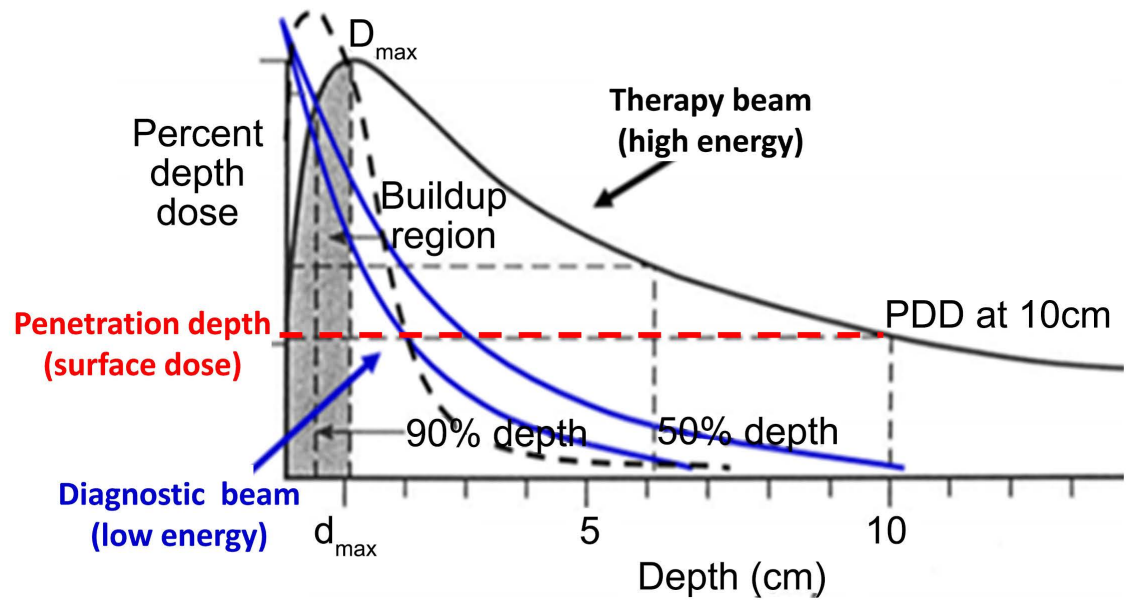

Figure 28. Diagnostic and therapeutical photon beams in X-ray radio diagnosis and therapy. Typical dose curves by photon (X-ray, $\gamma$-ray) radiation with typical penetration into dense tissues.

The beam continues its way in the body with $37 \%$ intensity, reaching the doubling of the penetration depth with $13.7 \%$ intensity, and so on, Figure 29.

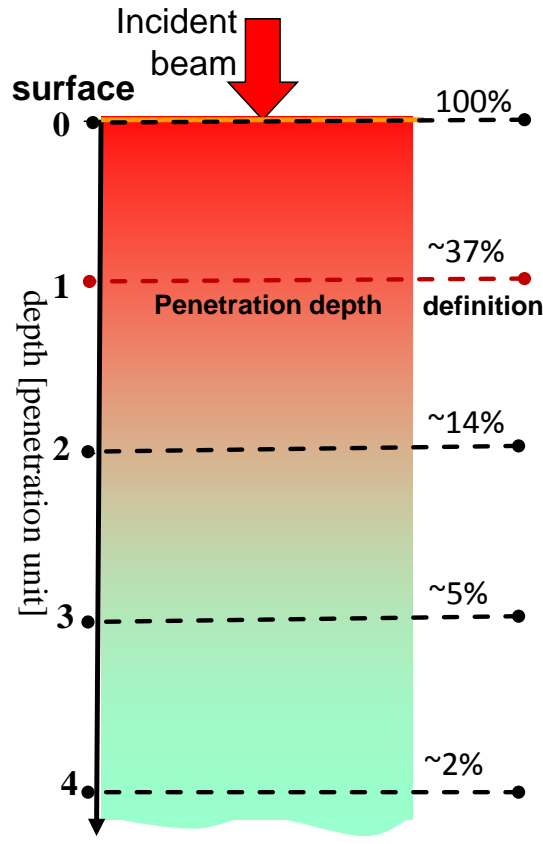

Figure 29. The principle of the definition of penetration depth: when the energy loss is $63 \%$ (remains $37 \%$ ). Four times of penetration-depth, about $2 \%$ of the energy of the incident beam remains. This is the basis of $\mathrm{X}$-ray diagnostic detection. 
Assuming a patient with $20 \mathrm{~cm}$ thickness, the X-ray detection has less than $2 \%$ of the initial $100 \%$ beam intensity, but this is enough to construct an image, Figure 30 [92].

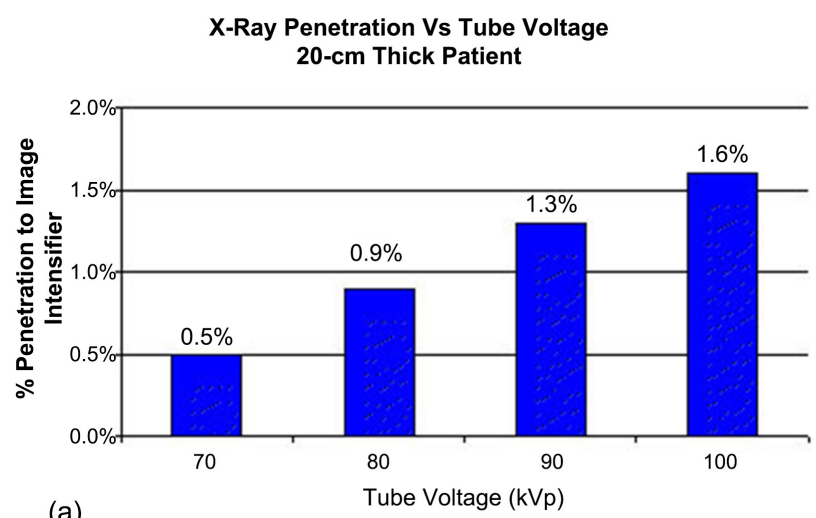

(a)

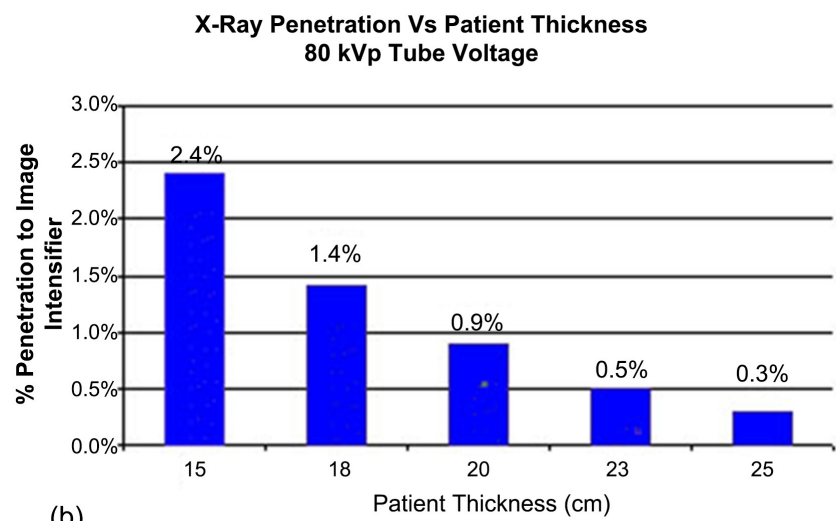

(b)

Figure 30. Typical intensities (percentage of the incident $100 \%$ beam) can be detected for X-ray images through the patient. In this case, and this tube voltage, the $20 \mathrm{~cm}$ patient thickness is approx. four times larger than the penetration depth. (a) Dependence of the voltage of the tube; (b) Dependence of the thickness of the patient at $80 \mathrm{kVp}$ tube voltage.

In the case of electron-beam, the exponential loss is sharper, decreasing quickly, Figure 31 [93].

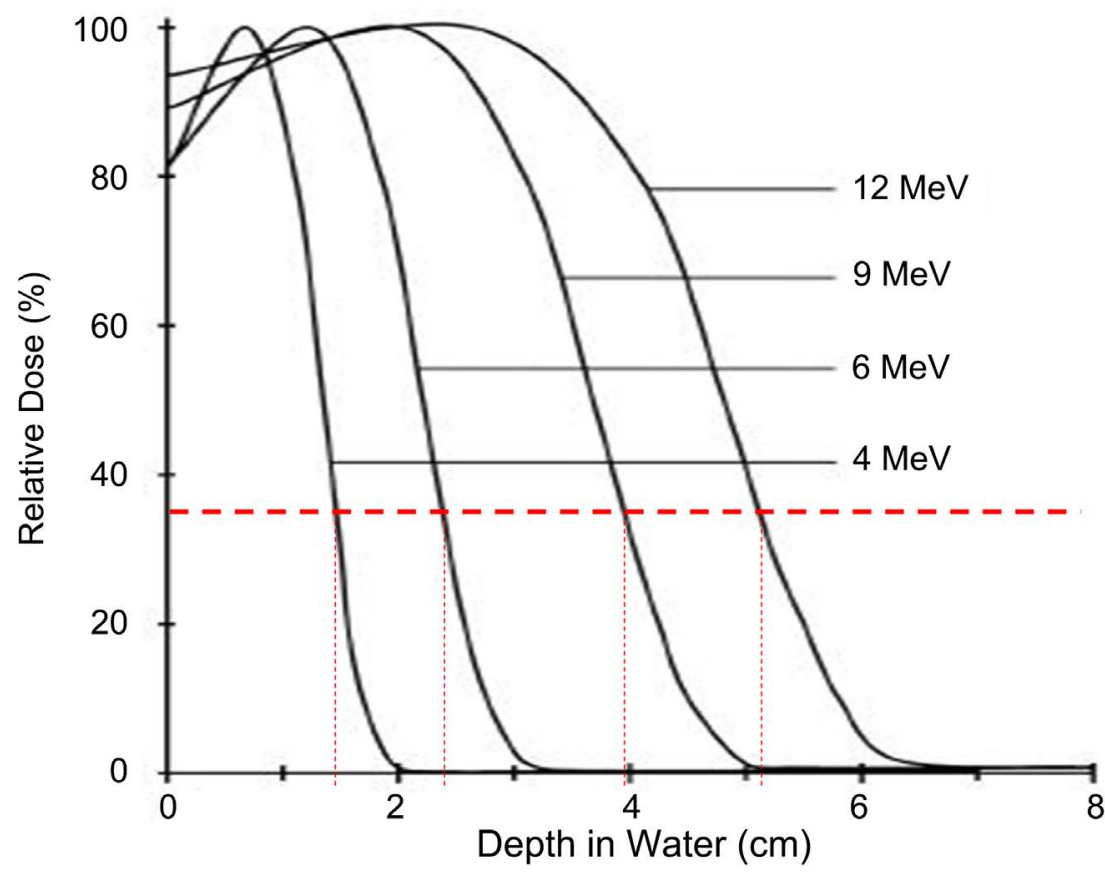

Figure 31. Penetration of electron-beam has a sharper decrease by depth. The definitive penetration depth is a few $\mathrm{cm}$, shown with a dashed line.

In the case of non-ionizing radiation, the penetration is longer depending on the applied frequency (Figure 32) [94] and conductivity of the tissue (Figure 33) [94]. 


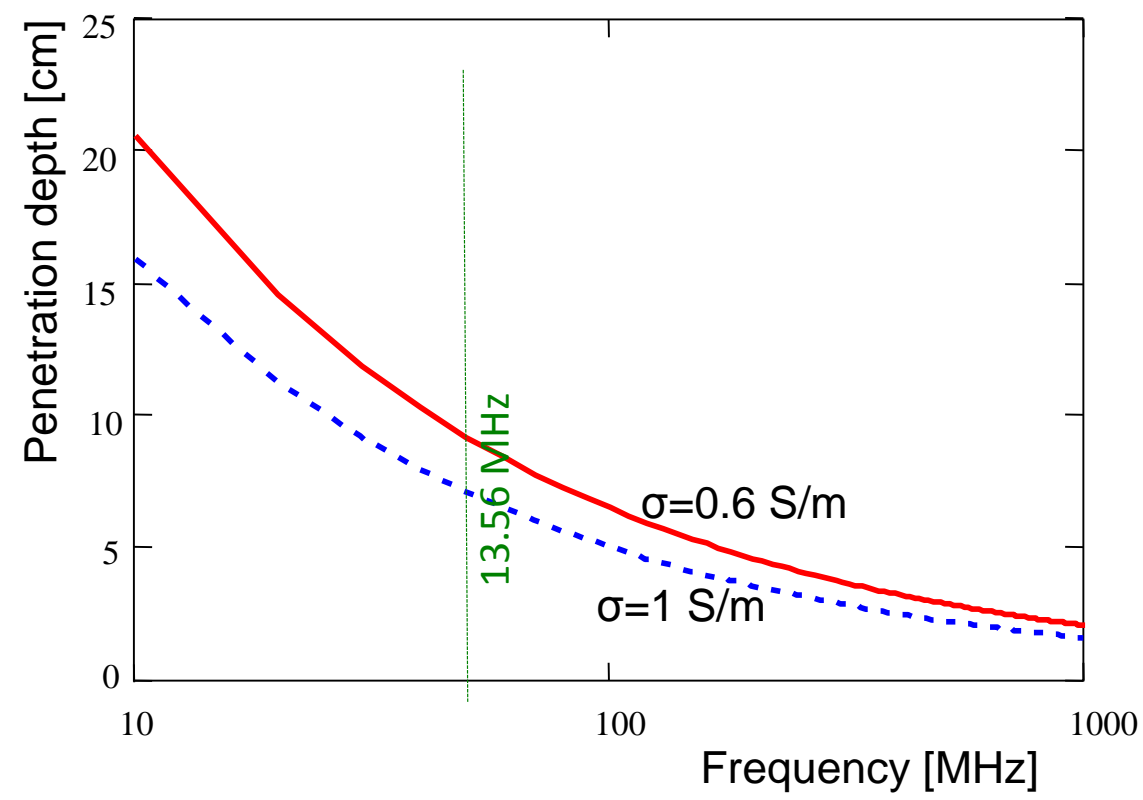

Figure 32. The penetration depth (37\%) depends on the conductivity of the tissue. The average conductivity of muscle is approximately $0.5 \mathrm{~S} / \mathrm{m}$, so the penetration depth at 13.56 MHz frequency is about $17 \mathrm{~cm}$. (at $8 \mathrm{MHz}$, it is approx. $20 \mathrm{~cm}$.)

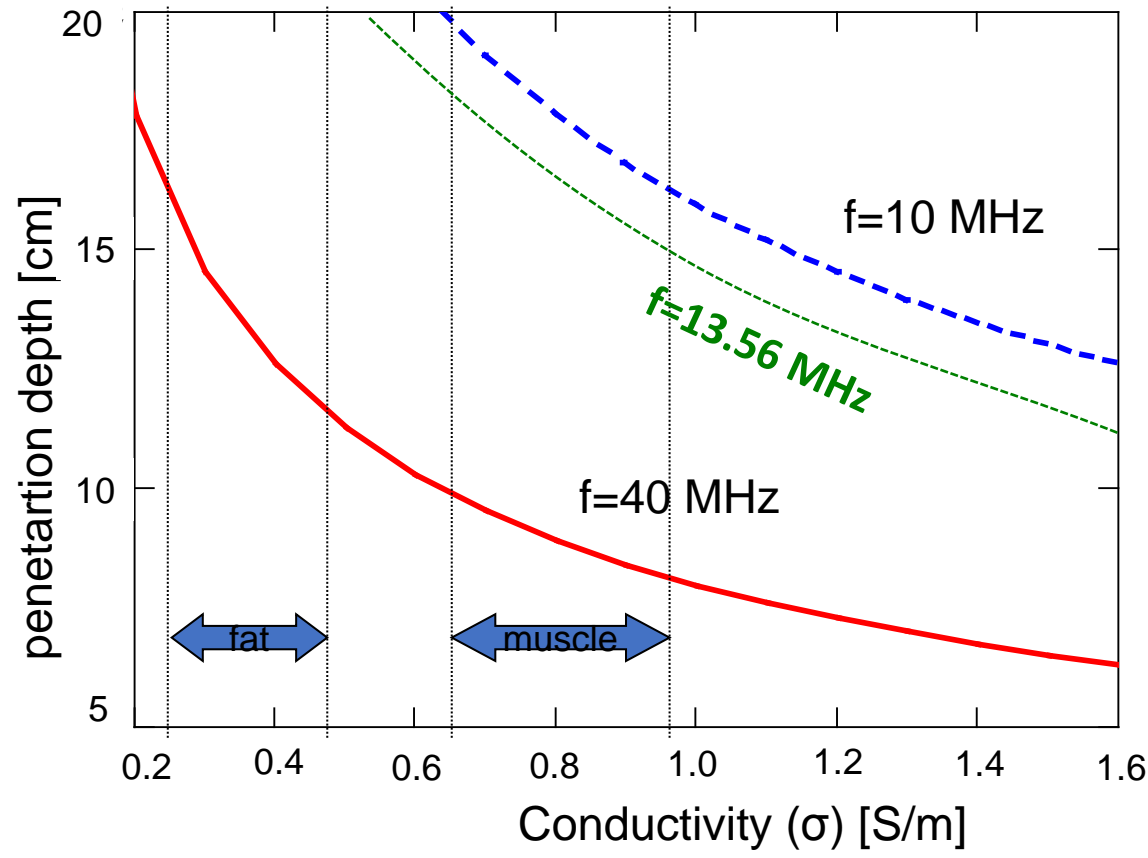

Figure 33. While the penetration depth is high in the fat, that absorbs a high energy value, leading to adipose burn. The apparent contradiction is the constrained increased voltage of the electrode required to push through the fatty tissue.

The jump of the electric field vector on the surface layer causes energy-absorption.

Measurements of the frequency dependence of the penetration depth in ex-vivo tissues show the correctness of the above considerations, Figure 34 [95]. 


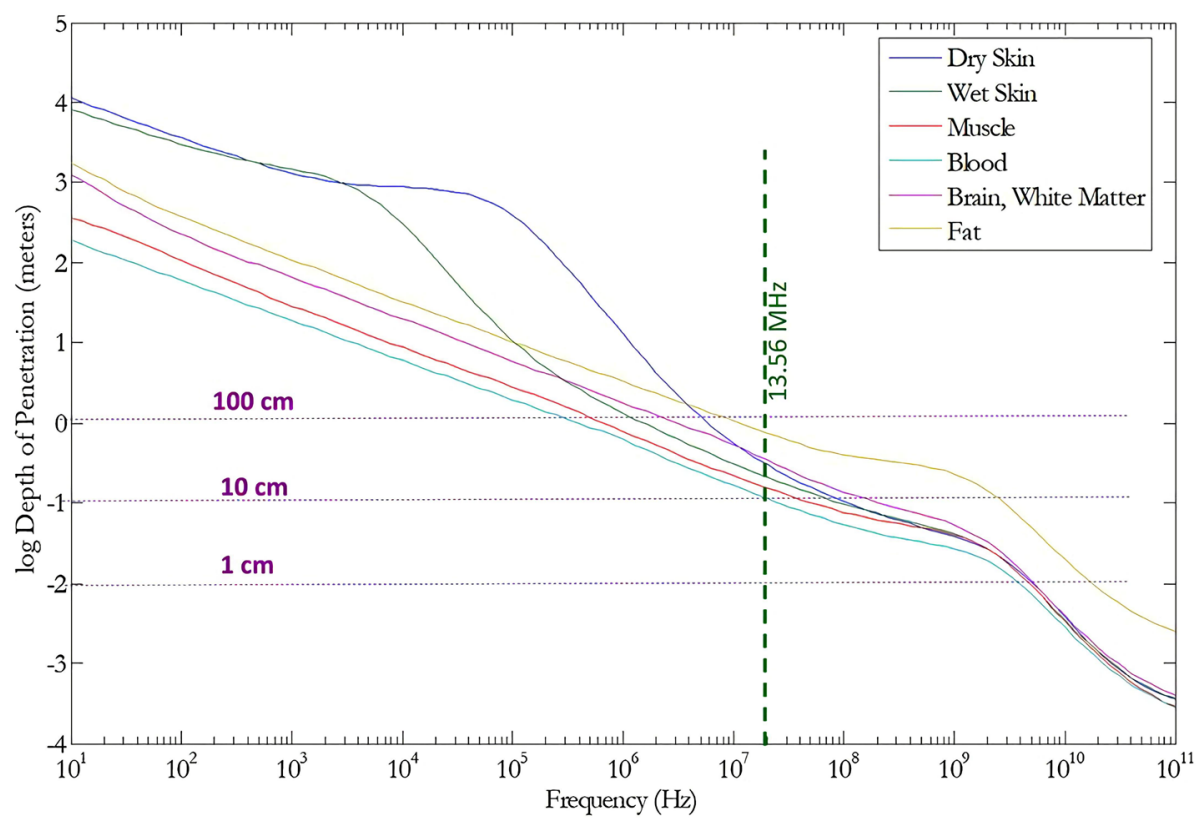

Figure 34. The penetration depth in various tissues vs. applied frequency. The $13.56 \mathrm{MHz}$ is over $10 \mathrm{~cm}$ in all of the cases (the lowest is for blood, which is very good for selection). The penetration is rapidly decreasing by increasing frequency.

It is clear that the same forwarded energy exposition with identical energy-flow $\left[\mathrm{W} / \mathrm{m}^{2}\right]$ can cause different energy-absorptions depending on the given conditions [96] [97], the actual organ [98], and the actual frequency [99]. The penetration depends on the electromagnetic parameters but does not depend on the patients' thickness. The impedance matching increases the penetration depth in homogeneous media by an additional $38 \%$. (Note that the measurements and calculations assume homogeneous media.) The impedance matching selection focuses on the tumor-cells. The mEHT maximizes the RF-current, and only the focusing and the original energy deposit has importance [28]. The selection means that the real penetration is much more, and crosses the entire body.

\subsubsection{Action Depth}

Plane-wave capacitive coupling and all the homogeneous heating methods use only the heat to destroy the cancer-cells. The mEHT in its selective (heterogenic) heating combines the heat effect with the excitation of cellular signals. This fact modifies the induced processes' action depth as mEHT does not need such a massive energy-absorption as homogeneous heating needs in order to heat for the entire tumor-mass. We know very well that the real depth where the action is effective is an interval. For example, the effects of X-ray for apoptosis do not follow the decreasing energy-curve at the penetration. Even oppositely, it increases when the energy drops below a specific level, Figure 35 [100]. This is because the smaller energy can generate bystander effects and so it can trigger apoptotic signals. This makes a complete interval for the apoptosis, which does not correlate with the penetration depth. 
The real depth is an interval where the action is effective. Similar to the X-ray effects

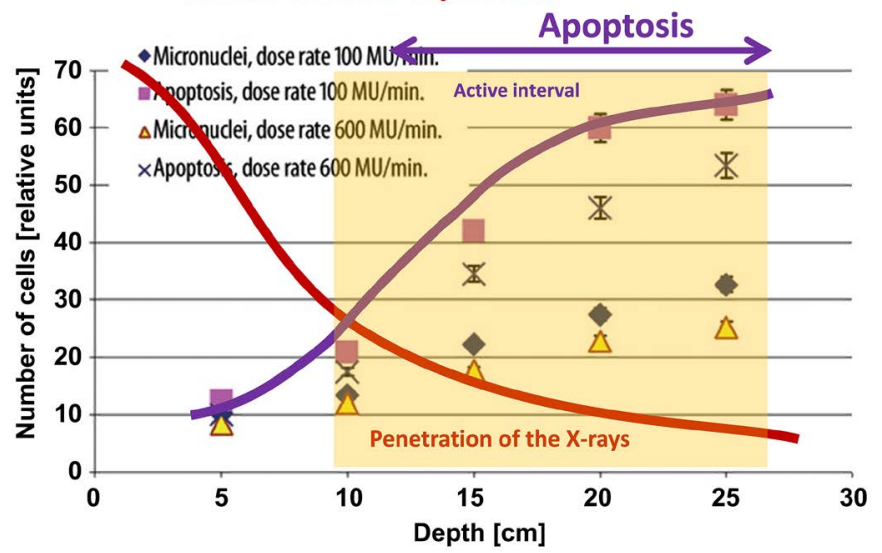

Figure 35. The number of cells with micronuclei, apoptosis as a medium depth function for $100 \mathrm{MU} / \mathrm{min}$, and $600 \mathrm{MU} / \mathrm{min}$ dose rates, $p<0.05$. Each point represents the mean value of three experiments; MU-Monitor Units (arbitrary).

The mEHT method also kills the malignant cells with apoptosis [101]. The apoptotic signal needs much less energy (and field) than the necrotic process [102], shown in the strict synergy of the heat and field effects [35]. The selection and initialization of the process are essential for this, which could happen by a few watts in-depth only. This is even more trivial when we see the immune effects, which are generated, act at distant sites [103], and have no real boundary with the observed abscopal effect [104]. In this meaning, instead of the penetration depth, we have to use the "depth of action," which defines the depth when the $\mathrm{mEHT}$ is active, even when the energy is less than the $37 \%$ of the incident beam, Figure 36 .

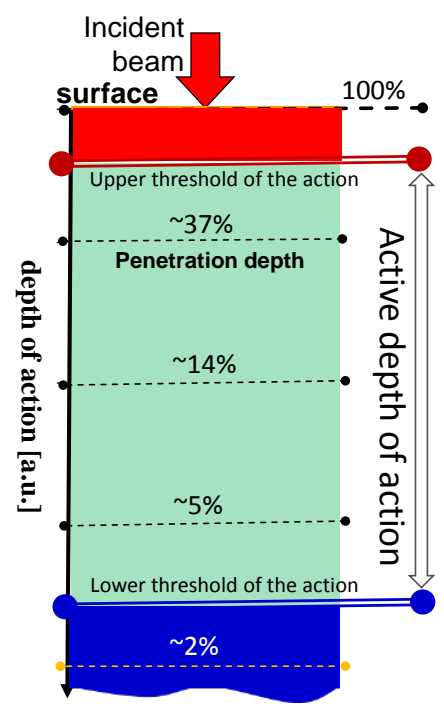

Figure 36. The active depth of mEHT is deeper than the average penetration depth because even $5 \mathrm{~W}$ could cause lethal apoptotic signals in selected cells. When the incident beam has $100 \mathrm{~W}$ energy, the depth when the mEHT is active could be three times the definitive $(37 \mathrm{~W})$ penetration depth. 
The increased drug penetration and intensified pharmacokinetics by mEHT [82] [83] promote further elongation of the action depth.

In summary, the action depth for mEHT is deeper than the thickness of the patient's treated cross-sectional distance up to $60 \mathrm{~cm}(\sim 200 \mathrm{~cm}$ circumflex of the cross-section).

\subsubsection{The Dosing}

Oncological hyperthermia presently faces multiple problems [19], where the most challenging is the lack of a clearly defined and measurable dose for clinical and research applications. The correct dose-definition of hyperthermia therapy is a critical issue in research and is crucial to the future of hyperthermia in oncology [105].

In a homogeneous heating approach, the dose considerations concentrate on the volume percentage, which could be considered having isothermal status. Complete homogeneity of heating of living objects could be achieved only in the WBH process, as LRHT has huge anatomical, physiological, bio-electromagnetic, and thermal heterogeneities, limiting the isodose-type approach. In the WBH process, the temperature was easily measurable and could be used for dosing the therapy. The proposed dose at present is the cumulative equivalent minutes referring to $43^{\circ} \mathrm{C}$ : $C E M 43 T_{x}$ (measured in minutes) [106] [107] [108]; referring to necrotic cell killing at $43^{\circ} \mathrm{C}$. Due to the natural inhomogeneities, this dose contains the percentage of the target which has an approximately isothermal condition, denoted by $T_{x}$ at the end of the practical applications [107]. For example, when the measured temperature is actually $T_{90}$ in $90 \%$ of the monitored sites (referred to as the thermal isoeffect dose in $90 \%$ of the area).

In LRHT, the absorbed energy creates heat, but due to the non-linear feedback by transport properties (intensified blood and lymph flow), the situation is far from a state of equilibrium [109]. The blood-flow increases more in the healthy host tissues, causing a certain gradient of the flow intensity to heat the tumor's boundary. The most vivid, mostly proliferative layer of the tumor is near its border, so the cells which need the most heat-treatment remain at a lower temperature than the internal part of the tumor lesion, so the basic homogenous requirement is less realizable in the vivid tumor part than inside of its volume, which is often necrotic, without transport activity. The temperature dosing is problematic not only by the missing the isotherm condition but also because of its very complicated measurement.

Moreover, CEM43 $T_{X}$ is controversial, it failed to show the local control characterization of clinical results in soft tissue sarcomas, [110], but was correlated with clinical results for superficial tumors [111]. When administering a dose of $C E M 43 T_{90}$ for local hyperthermia, it did not show a correlation between dose and clinical outcomes (like local remissions, local disease-free survival, and overall survival) [112]. It is calibrated by in vitro experiments [110], which are far from the reality of human medicine. Its necrotic reference at $43^{\circ} \mathrm{C}$ makes this 
dose unrealistic because in most human hyperthermia treatments, such a temperature is not reachable in the whole tumor. While the high temperature is realized in the ablation-like locality, the dosing by $C E M 43 T_{x}$ was false [113]. The inapplicability of this in-vitro calibrated dose is echoed in the whole-body hyperthermia (WBH) application, in which $C E M 43 T_{100}$ is very high ( $T_{100}$ means the complete isothermal heating of the tumor by the whole-body heating), but the results are very different from the same dose provided by local hyperthermia of the tumor lesion [114].

However, the challenge is that due to the considerable energy-loss in homogeneous heating processes, the temperature measurement is mandatory because otherwise there is no idea about the actual absorbed power in the target. In the method of mEHT, the measurement is not necessary in order to determine the absorbed power. The technique is able to accurately measure the absorbed energy by the incident beam [84]. Due to the high efficiency of current matching [115], the dosing of the treatment is simply calculable by the absorbed energy [64] [116] instead of by the complicated, inaccurate, and mostly invasive measurement of local temperature.

\subsubsection{Heating Process}

The homeostatic concept allows adaptation time for the physiological regulations to stabilize the actual homeostatic status. This complex approach requests a non-constant power during the treatment [117]. The simplest realization of the complex process involves step-up heating. The step-up heating is crucial. It has multiple additions to the success of mEHT:

- At electromagnetic heating, the stress is considerably focused on the cells which develop stress-proteins (HSPs) (chaperons to defend their status). The healthy cells rapidly develop 10-times more protective intracellular HSPs than the base level, while the stressful malignant cells only develop a maximum of $30 \%-50 \%$ more of these intracellular proteins. This makes the healthy cells more protected compared to their malignant counterparts.

- The gradually increased HSP chaperones in malignant cells have time to go to the membrane and be liberated from the cell when the rafts are excited and the signals force their release (such selection does not occur in healthy cells). This liberation process is one of the factors of immunogenic cell death.

- The step-up heating supports the heating periods and upregulates the power when it starts to be saturated, which is optimal for the mEHT selection system.

- The step-up fits the homeostatic equilibrium, and so mEHT remains within the well-controllable quasi-linear physiological reactions.

- The sudden heating causes non-linear, non-controllable conditions, and the power shoots over the burning limit, and in most of the cases causes blisters (as is frequently reported by radiate heating methods). So the step-up method allows the control of homeostasis and helps the patient adapt to the ac- 
tual energy-increase (I quote a famous experiment when a frog is in the water, which is slowly but gradually heated-up, the animal remains in hot water, even to its death, however, when you try to put a frog in hot water directly, it immediately tries to escape).

When the mEHT is applied strictly as a monotherapy, then step-down heating is necessary to block the neoangiogenic vessels. Due to the missing radio- or chemotherapy effect, the serious cases' metastatic spread has a higher probability, so blocking the vessels' immediately is crucial. But of course, the operating control in these cases has to be more strict.

Even in the step-up approach, the longer heating time tends to the homogenic temperature distribution due to the thermal equalization processes. To keep the non-homogeneous selection, periodic heating is also applicable, but it was only shown in preclinical applications [118].

\subsection{Molecular Differences between the Effects of Impedance, and Plane-Wave Matching}

The high energy absorption excites the rafts to trigger a signal transmission [78] [79]. The extrinsic signal transfer ignites apoptosis [101] [119] [120], Figure 37.

(a)

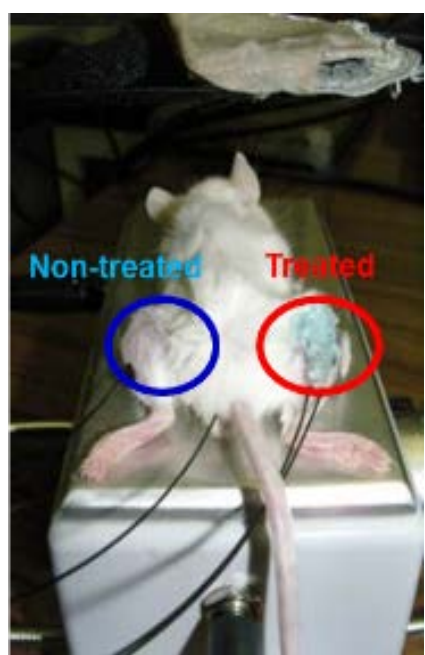

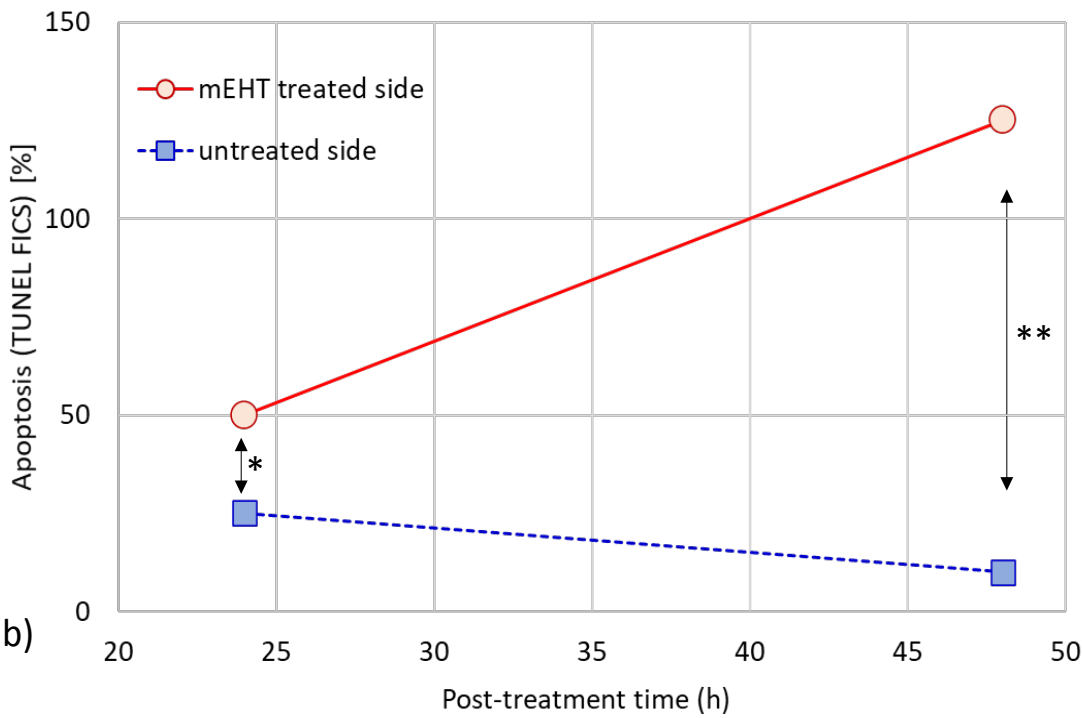

Figure 37. Late apoptosis measurement with TUNEL FICT method (Annexin V positive cells \%) in HT29 cells (in vivo) $42^{\circ} \mathrm{C} 30$ min treatment parameters, two tumor animal models (a), results show a significant increase of apoptosis in the treated side.

The difference between the molecular effect of the two matching methods of capacitive coupling techniques has been effectively demonstrated in vitro [71]. The plane-wave capacitive hyperthermia ( $\mathrm{PWCHT}$ ) gives the same results as the naturally homogeneous water-bath hyperthermia (WBHT), as seen by the apoptotic processes including the reactive oxygen species (ROS) and calreticulin (Figure 38) [121]. 


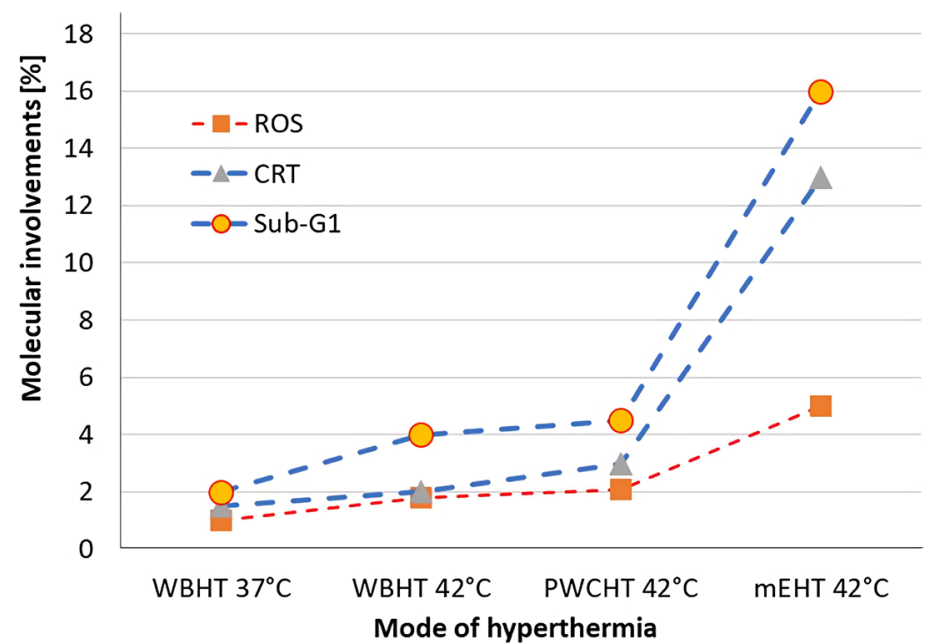

Figure 38. Molecular changes in Hepatoma (HepG2) cell-line in vitro. Apoptosis final state TUNEL (Annexin V positive cells \%). WBHT - water bath hyperthermia (homogeneous heating reference at $37^{\circ} \mathrm{C}$ and $42^{\circ} \mathrm{C}$ ); PWCHT-plane-wave capacitive hyperthermia at $42^{\circ} \mathrm{C}$, $\mathrm{mEHT}$ at $42^{\circ} \mathrm{C}$.

It is important to note that the purely homogeneous heating resulting from the water-bath hyperthermia (WBHT) produces comparable results to the plane-wave matching, indicating that plane-wave matching techniques also favour homogeneous heating, while mEHT differs significantly in the effects and outcomes. The apoptotic process involves a change in the potential of the mitochondria's membrane and the $\mathrm{Ca}^{2+}$ influx into the cell, Figure 39 [122].
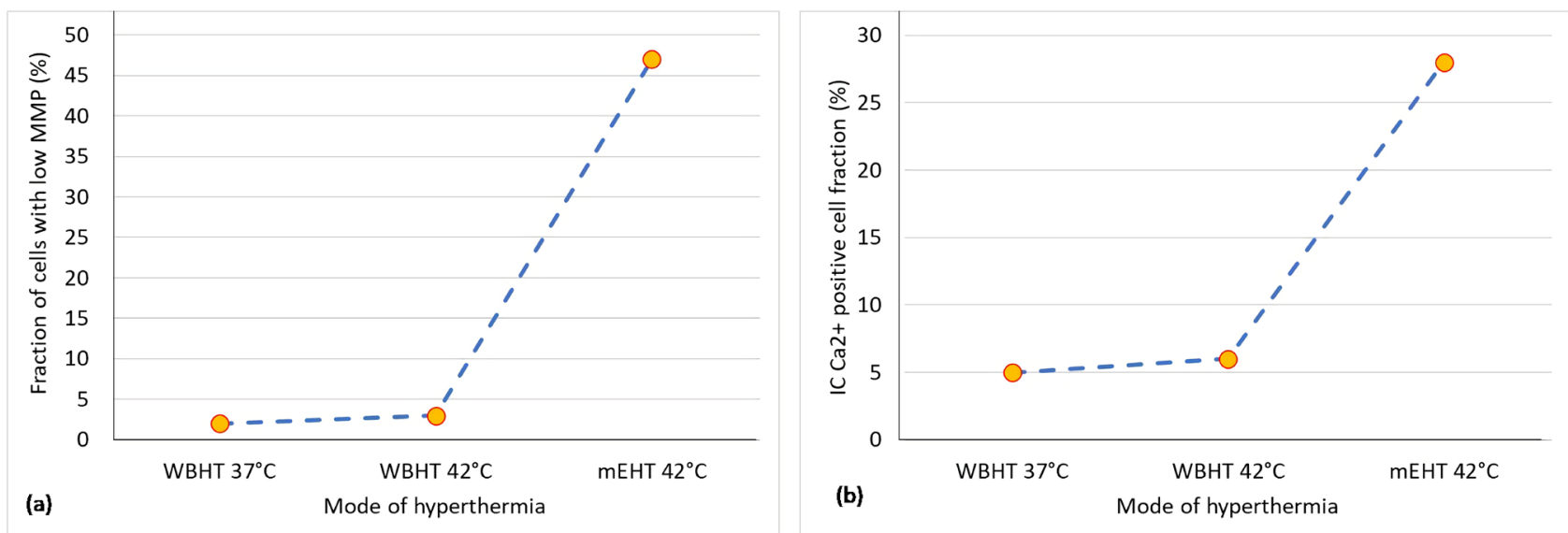

Figure 39. Comparison of heterogeneous heating caused by mEHT with homogeneous heating. (a) Fraction of cells with lowered mitochondrial membrane potential; (b) The calcium influx and intracellular ionic concentration (homogeneous (WBHT) heating reference at $37^{\circ} \mathrm{C}$ and $42^{\circ} \mathrm{C}$, mEHT at $42^{\circ} \mathrm{C}$ ). Abb: WBHT-water bath hyperthermia, mEHT: modulated electro-hyperthermia.

The caspase developments' variants during the apoptosis require the extrinsic and intrinsic pathways (involving Caspases 8 and 9 Figure 40), and the caspase-independent signal routs [101]. Additionally, Septin4 blocks the XIAP, which makes free the extrinsic pathway from this suppressor [123]. All of these factors combined ensure apoptosis is the final result. 


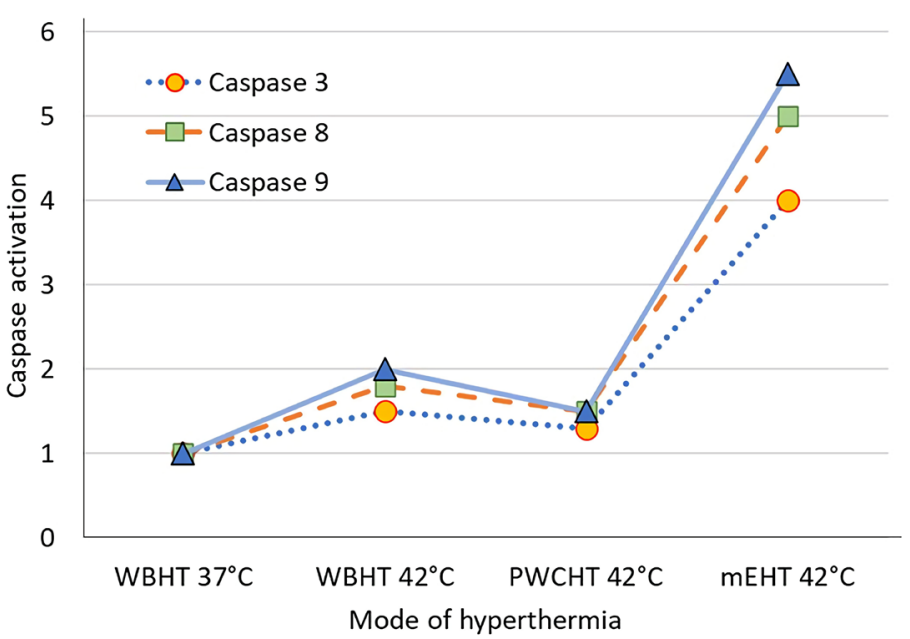

Figure 40. Caspase activation shows Caspase 8 and Caspase 9 for extrinsic and intrinsic pathways, respectively. WBHT-water bath hyperthermia (homogeneous heating reference at $37^{\circ} \mathrm{C}$ and $42^{\circ} \mathrm{C}$ ); PWCHT-plane-wave capacitive hyperthermia at $42^{\circ} \mathrm{C}$, mEHT-modulated electro-hyperthermia at $42^{\circ} \mathrm{C}$.

The homogeneous heating results in energy-absorption in the tumor-mass, in an attempt to realize an isothermal situation. However, mEHT focuses the energy absorption on membrane rafts (nanoscopic size). The excess energy makes the extrinsic excitation of the apoptotic pathways (TRAIL-FAS-FADD complex), and makes the gradients through the cell-membrane, producing various thermal effects [79]. It increases the extracellular and the raft temperature to a level much higher than their environment. In consequence the calibration curves by measuring the apoptotic intensity significantly differ, Figure 41 [35] [79]. It is clear that $\mathrm{mEHT}$ produces the same $25 \%$ relative cell-death as homogeneous heating in $\approx 3^{\circ} \mathrm{C}$ lower temperature, which is an approximate difference between the local nano-temperature (at the membrane rafts) and the tumor-average temperature.
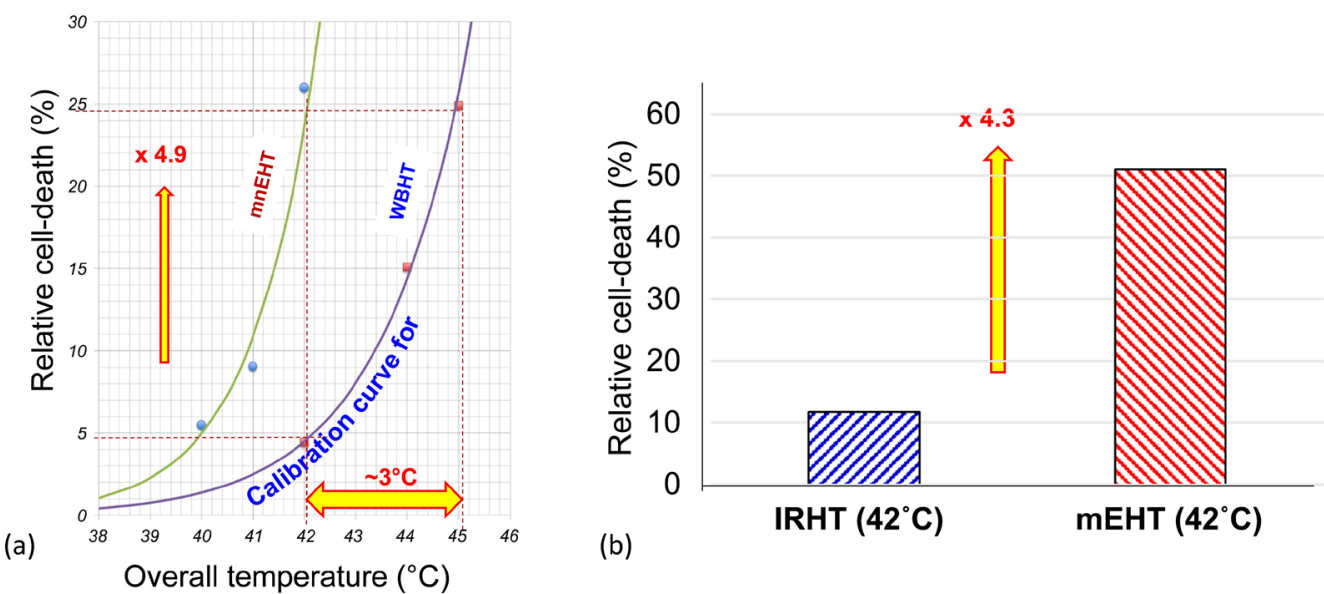

Figure 41. The relative cell-death (\%) (a) in vitro [U937 cell-line] and (b) in vivo [HT-29 cell-line, xenograft]. The mEHT heterogeneous heating is $>4$ times more effective than the homogeneous technique at the $42^{\circ} \mathrm{C}$ reference temperature. (IRHT-infrared, homogeneous heating technics). 
In another experiment, a rough calibration comparison between mEHT and water-bath homogeneous heating shows even higher differences between the nano-scale and macro-average temperature, Figure 42.

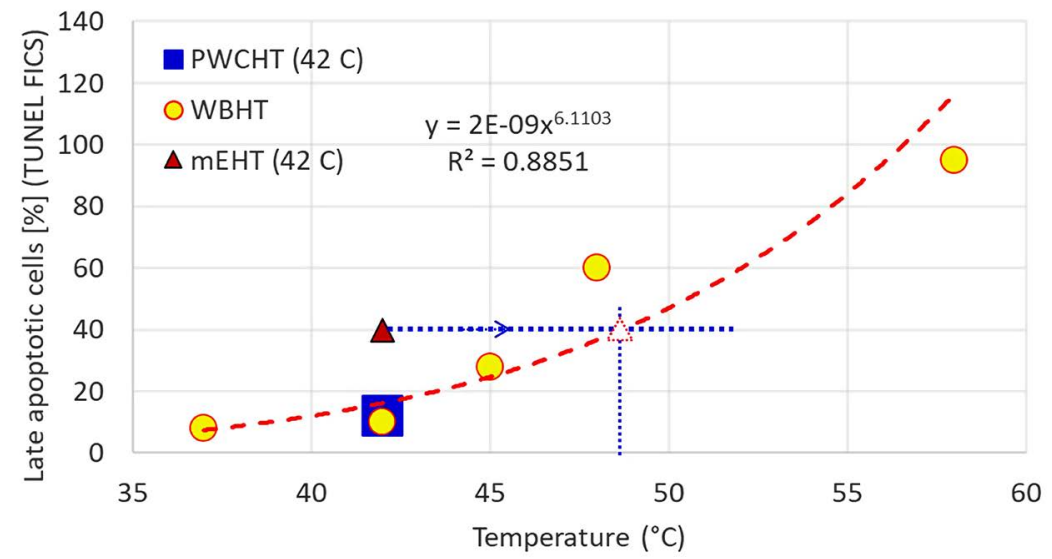

Figure 42. The temperature dependence of the apoptosis. The mEHT at $42^{\circ} \mathrm{C}$ produces such apoptotic level, like homogeneopus heating does at $>45^{\circ} \mathrm{C}$ (WBHT-water bath hyperthermia (homogeneous heating reference); PWCHT-plane-wave capacitive hyperthermia at $42^{\circ} \mathrm{C}, \mathrm{mEHT}$ at $42^{\circ} \mathrm{C}$ ). (Apoptosis final state TUNEL (Annexin V positive cells \%))

A direct temperature measurement of membrane rafts also shows a significant difference in a pilot experiment, Figure 43 [124].
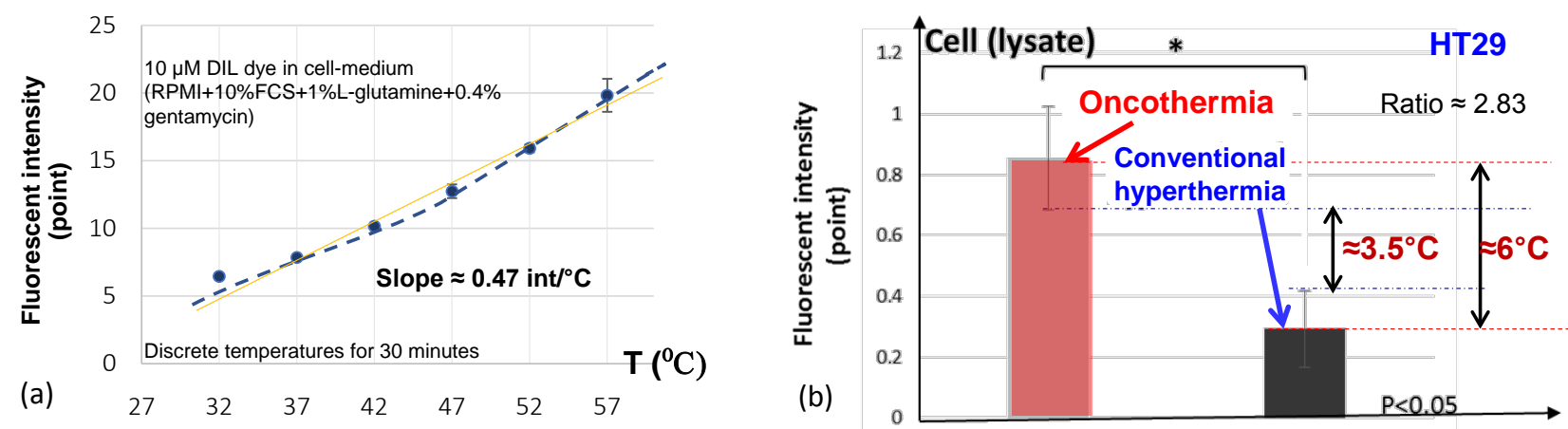

Figure 43. Membrane temperature measurement in vivo (mice, HT29 cells) $42^{\circ} \mathrm{C}, 30 \mathrm{~min}$. (a) DIL (Dilatometry)temperature calibration; (b) Fluorescent measurement, show the much higher temperature on the membrane of mEHT treated sample than on the membrane of the homogeneously (WBHT) heated one.

The heating certainly causes stress, producing chaperone proteins. The most characteristic protein family of chaperons is the heat shock protein 70 (HSP70). This protein has a double edge sword reaction: intracellularly it tries to avoid the cell's apoptosis, extracellularly it acts oppositely: it promotes the cellular apoptosis. Any kind of hyperthermia results in the expression of HSP70, but at different levels. Due to the large electromagnetic load that accompanies the heating processes, mEHT trigger the expression of more HSP70 than homogeneous heating, Figure 44. This difference is most significant 48 hours after treatment. 


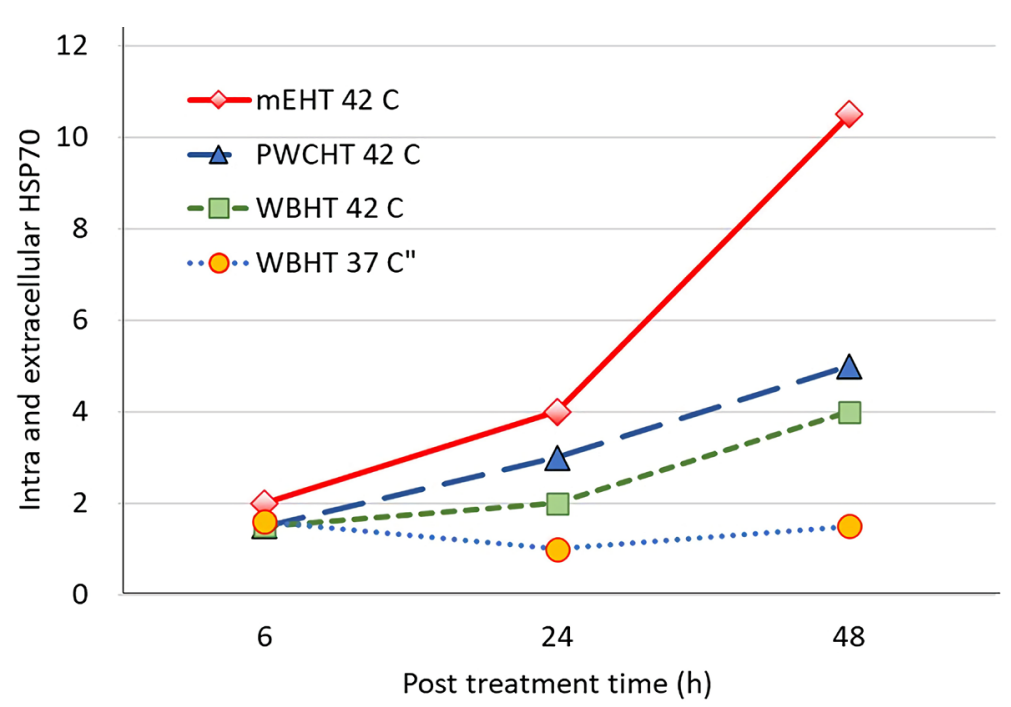

Figure 44. Comparison of the cleaved Caspase CD3+ expression. (WBHT-water bath hyperthermia (homogeneous heating reference); PWCHT-plane-wave capacitive hyperthermia at $42^{\circ} \mathrm{C}$, $\mathrm{mEHT}$ at $42^{\circ} \mathrm{C}$ ).

However, the location of the measured HSP70 is different. After 48 hours the concentration of the intracellular HSP70 returns to the level it was before the heating, but the extracellular levels increase, Figure 45 [125].
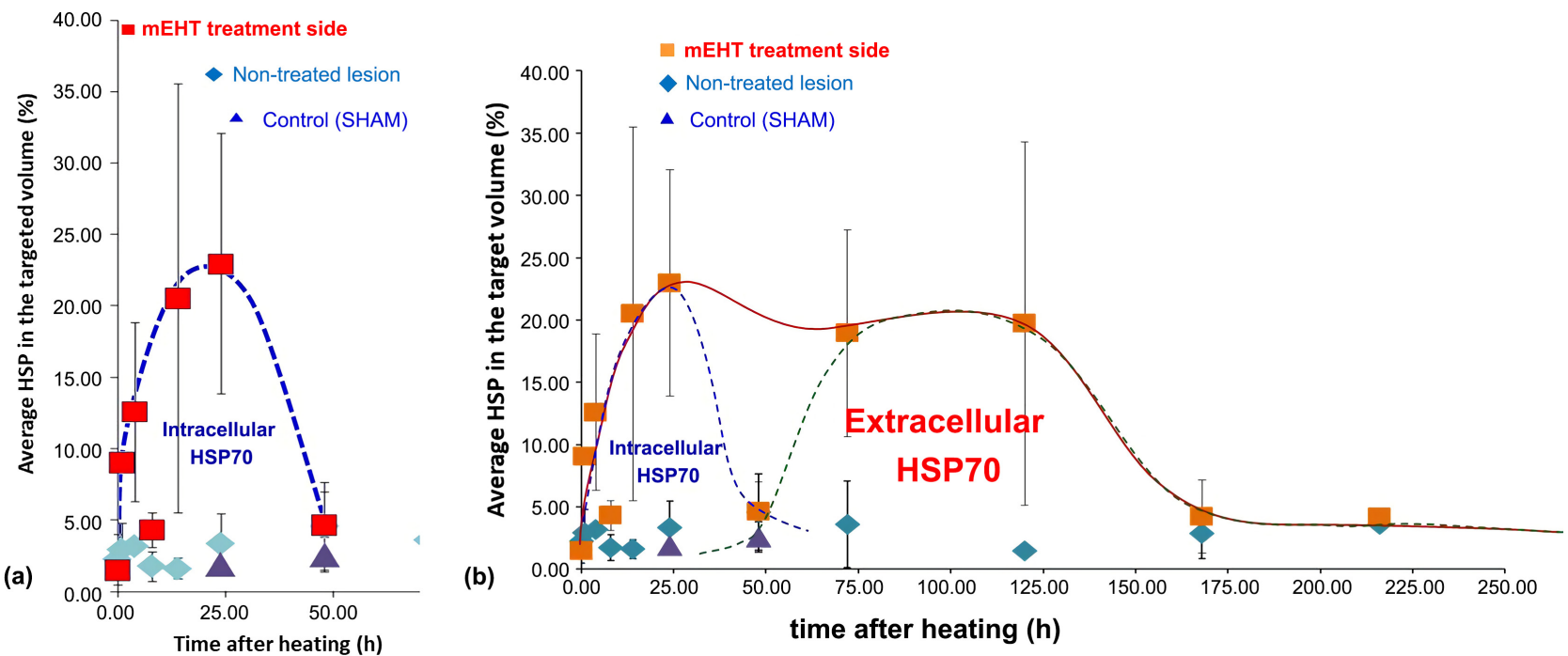

Figure 45. Development of HSP70 after mEHT treatment of in vivo xenograft mouse model (HT29 cell-line, at $42^{\circ} \mathrm{C}$, $30 \mathrm{~min}$ ). (a) The level of HSP70 returned to the baseline level at $48 \mathrm{~h}$ post-treatment; (b) The development of the extracellular HSP70 only returns to the baseline level after a week.

A detailed review of cancer models describes the molecular mechanisms of mEHT [126].

\subsubsection{Immunogenic Cell-Death}

The apoptosic process caused by mEHT causes special immunogenic type of changes, allowing the genetic information to form antigen-presenting cell (APC) 
by the maturation of the dendritic cells (DCs) or the macrophages. The excitation of the actual membrane rafts initiates immunogenic cell death (ICD). This process starts by producing a particular damage-associated molecular pattern (DAMP) (Figure 46) [127].

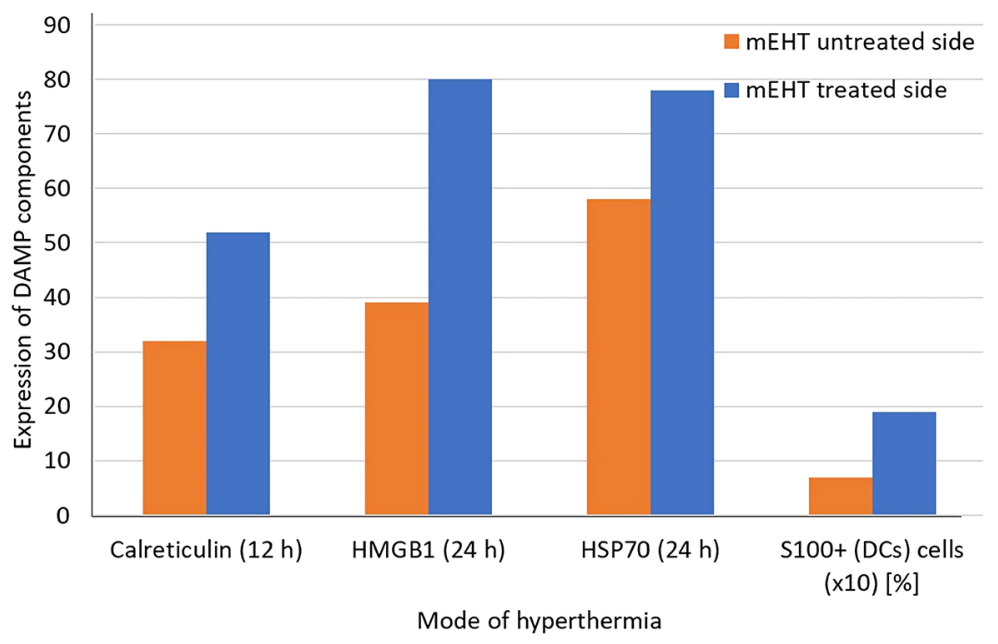

Figure 46. The DAMP development in vivo in an allograft mouse model (CT26 cells).

The proper signal transfer, and DAMP production could be limited or blocked by too much energy absorption on the rafts, which destroys it instead of exciting the transmembrane proteins, and receptors. The high energy-absorption may ignite phase transition mechanisms. For example, the kink in the Arrhenius plot at $\sim 42.5^{\circ} \mathrm{C}$ is probably a lipid-associated phase transition [128] [129] [130], which could lower the activation energy needed to facilitate the desired changes [131]. The change in the kink is expected to be influenced by the blood flow [33]. Among such conditions, the immunogenic cell-death is seldom, and also the APC and the immune actions will not be produced, because the temperature is high, and the membrane phase-transition makes hard producing apoptotic bodies. Well-defined sequences and spatio-temporal actions are necessary for the DAMP, which high energy technologies are not able to do. The possible small amount of proper DAMP production by high energy technologies would be disrupted, resulting in a mixture of effects, as is often observed many hyperthermia studies. This causes inconsistent results as there is no control of the processes in the complex dynamical network seen at a nanoscopic level.

\subsubsection{Tumor-Specific Immune Effect}

The main effect of mEHT is the energy absorption, like in all hyperthermia treatments, but it is further enhanced by the selection mechanisms, which makes it heterogenic, targeting, and energy-focused. The bio-electromagnetic and structural differences of malignancies appear in their spatial and temporal self-organized fractal structure, harnessed by the modulation effect. The DAMP-ICD associated tumor-specific immune effect is active in the entire body and therefore acts as vaccination. The re-challenge of the body with the same 
malignancy therefore be expected to be unsuccessful [121]. It is an excellent advantage that without any invasive sampling and extra laboratory preparation, the immune effect is in situ and real-time.

Studies with DC, Figure 47 [121]; and Marsdenia Tenacissima (MTE), Figure 48 [127] as an immune-support suggest that when the patient's immune system is weak, due to tumor-development and the side effects of the previous treatments, additional immune support could help for complete action.

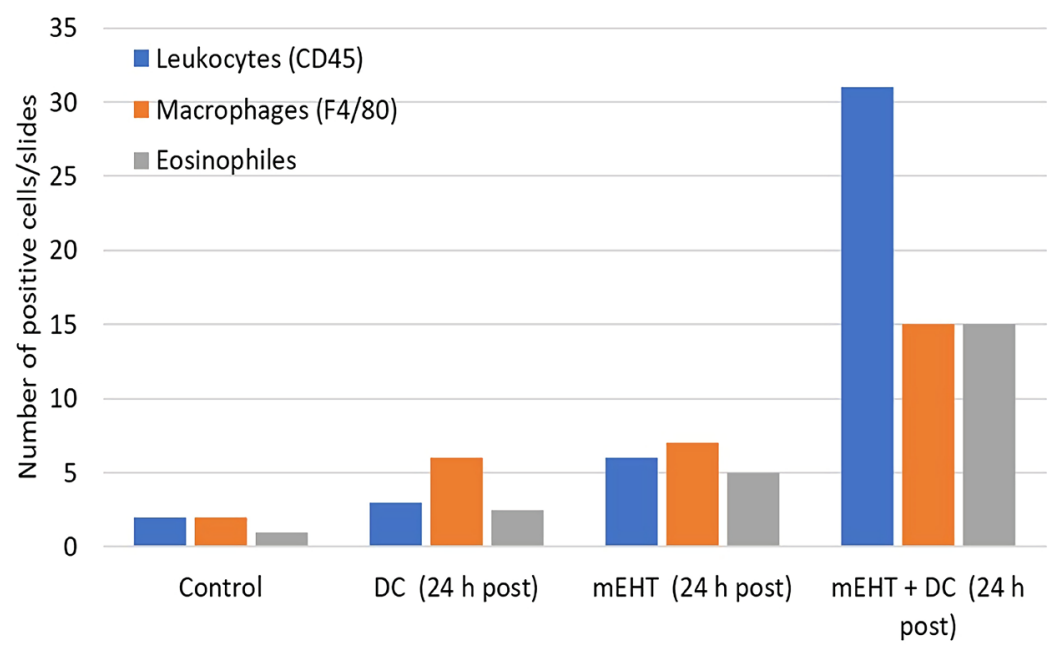

Figure 47. Immune invasion at the tumor $24 \mathrm{~h}$ post-treatment (DC-dendritic cell injection).

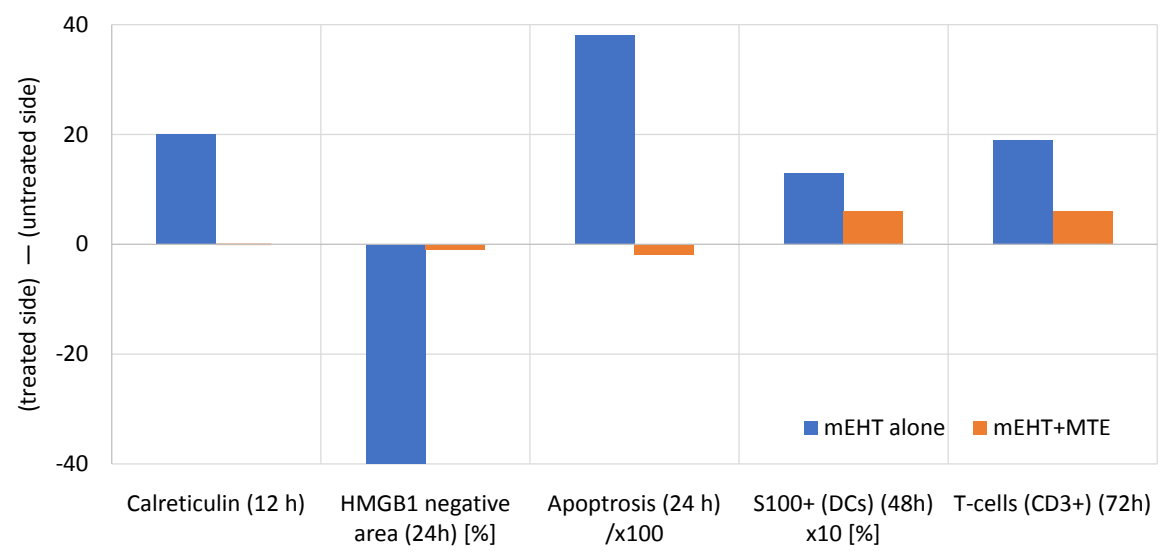

Figure 48. Effect of the immune-support Marsdenia Tenacissima (MTE).

This way, mEHT can create a favorable tumor microenvironment for an immunological chain reaction, improving the success rate of intratumoral dendritic cell immunotherapy [104] [121]. The applied paradigm's strategic point is that our task is to help the body recognize and destroy the malignancy. Targeting a product (such as weak points of tumor growth or simple destruction of the cell by thermal necrosis) could not repair the complex system. The entire process has to be targeted in order to re-establish the healthy state [132]. Developing a tumor-specific immune reaction directly drives the immune system to reparation. 
The mEHT method recognizes the tumor by its biophysical, mainly electric impedance parameters, which at the same time has diagnostic value, Figure 49 [104] [133] [134].

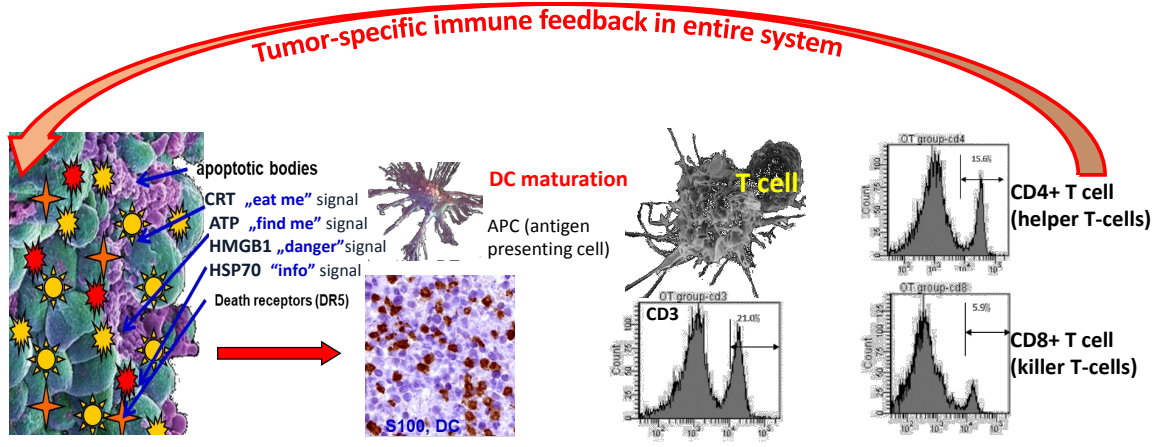

Figure 49. Producing the tumor-specific immune reaction. The gentle apoptosis produces DAMP and ICD presenting genetic information to antigen-presenting cells (APCs) which produces killer T-cells which are active in the entire body. (Works like a tumor-vaccination.)

The mEHT in this combination is a typical theranostic [135] therapy, which could be applied in combination with other standard tumor therapies like chemotherapies [136] [137], radiotherapies [138] [139], or check-point inhibitors [140]. A promising immunological approach is the combination of mEHT with viral therapies [141] [142].

\subsection{Clinical Applications}

A review of the clinical pieces of evidence of mEHT summarized essential clinical evidence [143]. The clinical trials are summarized in Table 1.

Table 1. Clinical trials that used $\mathrm{mEHT}$ in combination with other treatments.

\begin{tabular}{|c|c|c|c|c|c|}
\hline No. & Tumor site & $\begin{array}{l}\text { Number of } \\
\text { patients }\end{array}$ & Treatment used & Results & Reference \\
\hline 1 & $\begin{array}{l}\text { Relapsed high-grade } \\
\text { gliomas }\end{array}$ & 15 & $\begin{array}{l}\text { mEHT + alkylating } \\
\text { chemotherapy }\end{array}$ & $\begin{array}{l}\text { Tolerable and safe for patients with relapses by } \\
\text { high escalation of the dose too. }\end{array}$ & $\begin{array}{c}\text { Wismeth, et al. } 2010 \\
{[144]}\end{array}$ \\
\hline 2 & Advanced gliomas & 12 & $\begin{array}{l}\text { Chemotherapy, radiotherapy }+ \\
\text { mEHT }\end{array}$ & $\begin{array}{l}C R=1, P R=2, R R=25 \% . \text { Median duration of } \\
\text { response }=10 \mathrm{~m} . \text { Median survival }=9 \mathrm{~m}, 25 \% \\
\text { survival rate at } 1 \text { year. }\end{array}$ & $\begin{array}{l}\text { Fiorentini, Giovanis, } \\
\text { et al. } 2006 \text { [145] }\end{array}$ \\
\hline 3 & $\begin{array}{l}\text { Relapsed } \\
\text { malignant gliomas }\end{array}$ & 24 & mEHT & $\begin{array}{l}\text { Median survival }=19.5 \text { months, } 55 \% \text { survival } \\
\text { rate at } 1 \text { year, } 15 \% \text { at } 2 \text { years. }\end{array}$ & $\begin{array}{l}\text { Fiorentini, Sarti, et al. } \\
\quad 2018[146]\end{array}$ \\
\hline 4 & $\begin{array}{l}\text { Advanced } \\
\text { glioblastoma }\end{array}$ & 60 & mEHT + immunotherapy & $\begin{array}{l}\text { No added toxicity by immunotherapy. Median } \\
\text { progression-free survival (PFS) }=13 \mathrm{~m} \text {. Median } \\
\text { follow up } 17 \mathrm{~m} \text {, median OS was not reached. } \\
\text { Estimated OS at } 30 \mathrm{~m} \text { was } 58 \% \text {. }\end{array}$ & $\begin{array}{l}\text { Van Gool, et al. } 2018 \\
{[142]}\end{array}$ \\
\hline 5 & $\begin{array}{l}\text { Various } \\
\text { brain-gliomas }\end{array}$ & 140 & $\begin{array}{l}\text { Chemotherapy + radiotherapy } \\
+ \text { mEHT }\end{array}$ & OS $=20.4 \mathrm{~m} . \mathrm{mEHT}$ was safe and well tolerated. & $\begin{array}{c}\text { Sahinbas, et al. } 2007 \\
{[147]}\end{array}$ \\
\hline 6 & High-grade gliomas & 179 & $\begin{array}{l}\text { mEHT + radiotherapy + } \\
\text { chemotherapy }\end{array}$ & $\begin{array}{l}\text { Longstanding complete and partial remissions } \\
\text { after recurrence in both groups. }\end{array}$ & $\begin{array}{l}\text { Hager, Groenemeyer, } \\
\text { et al. } 2008[148]\end{array}$ \\
\hline
\end{tabular}




\section{Continued}

7 Glioblastoma \& Astrocytoma

8

Advanced hepatocell. carcinoma

Refractory

9 hepatocell. carcinoma

10

Small-cell lung cancer (SCLC)

11

Advanced cervical cancer

Advanced cervical cancer

Advanced cervical cancer

Advanced cervical carcinoma

Advanced

15 cervical carcinoma

Advanced

16 cervical carcinoma

Random. Phase III (chemoradiation alone $(\mathrm{CHR})$ and $\mathrm{mEHT}$ group (mEHT + CHR) [preliminary data]

Advanced cervical carinoma

mEHT + chemoradiotherapy

Ascorbic acid (AA) infusion + mEHT

mEHT + radiotherapy + chemotherapy
$5 \mathrm{y}-\mathrm{OS}=83 \%$ (AST) in mEHT vs. $5 \mathrm{y}-\mathrm{OS}=25 \%$ by BSC. $5 \mathrm{y}-\mathrm{OS}=3.5 \%$ in $\mathrm{mEHT}$ vs. $5 \mathrm{y}-\mathrm{OS}=$ $1.2 \%$ by BSC for GBM. Median OS $=14 \mathrm{~m}$ of $\mathrm{mEHT}$ for $\mathrm{GBM}$ and $\mathrm{OS}=16.5 \mathrm{~m}$ for AST.

$\mathrm{PR}=1, \mathrm{CR}=0, \mathrm{SD}=11$. Combined therapy was effective, and no major complications were observed.

Gadaleta-Caldarola, et al. 2014 [150],

$\mathrm{CR}=1, \mathrm{PR}=0$. Median OS $=20.5$ weeks. $50 \%$ showed evidence of increasing QoL and minimal Ferrari, Ponti et al. toxicity. 2007 [151]

mEHT enhanced destroying the cancer cells. Improved the OS of patients too.

Lee, Haam et al. 2013

Preliminary data for first 100 participants. A positive trend in survival and local disease control by mEHT. No significant differences in acute adverse events or quality of life between

Minnaar, Baeyens et al. 2016 [153] the groups.

The overall response $(\mathrm{CR}+\mathrm{PR}+\mathrm{SD}$ vs. $\mathrm{PD})$ to was significantly greater with $\mathrm{mEHT}$. No complications or extra adverse effect by mEHT.

Lee, Lee et al. 2017

$$
\text { [136] }
$$

$\mathrm{CR}+\mathrm{PR}=73.5 \% ; \mathrm{SD}=14.7 \%$. The addition of mEHT increased the QoL and OS.

Pesti, et al. 2013 [139] mEHT increases the peri-tumour temperature and blood flow in human cervical tumours, promoting the radiotherapy + chemotherapy.

Lee, Kim, et al. 2018 [154]

The metabolicly complete remnission (CMR) of disease outside the radiation field at $6 \mathrm{~m}$ post-treatment shows abscopal effect, significantly associated with the addition of mEHT.

Minnaar, Kotzen, et al. $2020 \mathrm{~b}$ [155]

Compliance to mEHT treatment was high (97\% completed $\geq 8$ treatments) with no significant differences in CRT-related toxicity between treatment groups or between HIV-positive and

Minnaar, Kotzen, et al. 2020a [156] -negative participants.

Six month local disease-free survival (LDFS) $=$ $38.6 \%$ for $\mathrm{mEHT}$ and LDFS $=19.8 \%$ without $\operatorname{mEHT}(p=0.003)$. Local disease control (LDC) $=45.5 \%$ with $\mathrm{mEHT}$ LDC $=24.1 \%$ without

Minnaar, Kotzen, et al. 2019 [157] mEHT; $(p=0.003)$.

AA safely synergies with mEHT and well tolerated, no major adverse effects

Ou, Zhu, et al. 2017 [158],

Median OS $=9.4 \mathrm{~m}$ with $\mathrm{mEHT}$ OS $=5.6 \mathrm{~m}$ without mEHT; $(p<0.0001)$. Median PFS $=3 \mathrm{~m}$ Ou, Zhu, et al. 2020 for $\mathrm{mEHT}$ and PFS $=1.85 \mathrm{~m}$ without $\mathrm{mEHT} ; p$ [159] $<0.0001$.

Two centres PFY $(n=61)$, HTT $(n=197)$ control ( $n=53$ ). $80 \%$ (PFY), $80 \%$ (HTT) had $311(61+$ Radiotherapy + chemotherapy distant metastases, conventional therapies failed. Dani, Varkonyi, et al. $197+53)+$ mEHT
Median OS $=16.4 \mathrm{~m}$

(control); 1st y survival 67.2\% (PFY), 64\%

(HTT), 26.5\% (control). 


\begin{tabular}{|c|c|c|c|c|c|}
\hline 21 & Advanced NSCLC & 44 & $\begin{array}{l}\text { Chemotherapy + ketogenic diet } \\
\text { + hyperbaric oxygen }+ \text { mEHT }\end{array}$ & $\begin{array}{l}\text { Mean OS }=42.9 \mathrm{~m}, \mathrm{PFS}=41 \mathrm{~m} . \text { No problems } \\
\text { were encountered due to fasting, hypoglycemia, } \\
\text { ketogenic diet, mEHT or hyperbaric oxygen } \\
\text { therapy. }\end{array}$ & Iyikesici, 2019 [161], \\
\hline 22 & $\begin{array}{l}\text { Peritoneal } \\
\text { carcinomatosis with } \\
\text { malignant ascites }\end{array}$ & 260 & $\begin{array}{l}\mathrm{mEHT}+\text { traditional Chinese } \\
\text { medicine }(\mathrm{TCM}) \text { compared to } \\
\text { intraperitoneal chemoinfusion } \\
\text { (ICI) }\end{array}$ & $\begin{array}{l}\text { The Objective response rate }(\mathrm{OPR})=77.7 \% \text { in } \\
\text { study group ( } \mathrm{mEHT}+\mathrm{TCM}) \text { vs. OPR }=63.8 \% \\
\text { in the ICI group. The QoL }=49.2 \% \text { vs. } 32.3 \% \text { in } \\
\text { the active and control group. Adverse effect rate } \\
(\mathrm{AER})=2.3 \% \text { vs. } 12.3 \% \text {. }\end{array}$ & $\begin{array}{l}\text { Pang, Zhang, et al. } \\
2017[162]\end{array}$ \\
\hline 23 & $\begin{array}{l}\text { Advanced rectal } \\
\text { cancer }\end{array}$ & 76 & $\begin{array}{l}\text { mEHT + radiotherapy }+ \\
\text { chemotherapy }\end{array}$ & $\begin{array}{l}\text { Downstaging + tumor regression, ypT0, and } \\
\text { ypN0 was better with mEHT than without. No } \\
\text { statistical significance. }\end{array}$ & You et al. 2020 [163] \\
\hline 24 & $\begin{array}{l}\text { Liver metastasis from } \\
\text { colorectal cancer }\end{array}$ & 80 & Chemotherapy + mEHT & $\begin{array}{l}\text { Median OS = } 24.5 \mathrm{~m} \text {, and expected (historical) } \\
\text { OS }=11 \mathrm{~m} .\end{array}$ & $\begin{array}{l}\text { Hager, et al. } 1999 \\
{[164]}\end{array}$ \\
\hline 25 & $\begin{array}{l}\text { Various types } \\
\text { of sarcoma }\end{array}$ & 13 & $\begin{array}{l}\text { Radiotherapy }+ \text { chemotherapy } \\
+\mathrm{mEHT}\end{array}$ & $\begin{array}{l}\text { Primary, recurrent, and metastatic sarcomas } \\
\text { responded to } \mathrm{mEHT} \text {, the masses regressed. }\end{array}$ & $\begin{array}{l}\text { Jeung, et al. } 2015 \\
{[165]}\end{array}$ \\
\hline 26 & Soft-tissue sarcoma & 24 & Chemotherapy + mEHT & $\begin{array}{l}\text { Pathological response rate }(\mathrm{pRR})=42 \% \text { in } \\
\text { neoadjuvant chemo-hyperthermia treatment } \\
\text { median } \mathrm{OS}=31 \mathrm{~m} .\end{array}$ & $\begin{array}{l}\text { Volovat, Volovat et } \\
\text { al. 2014a [166] }\end{array}$ \\
\hline 27 & $\begin{array}{l}\text { Advanced pancreas } \\
\text { carcinoma }\end{array}$ & 25 & $\begin{array}{l}\text { mEHT }+ \text { chemotherapy }+ \\
\text { ketogenic diet }+ \text { oxygen therapy }\end{array}$ & $\begin{array}{l}\text { Mean follow-up }=25.4 \mathrm{~m}, \text { median } \mathrm{OS}=15.8 \mathrm{~m} \text {, } \\
\text { median PFS }=15.8 \mathrm{~m} .\end{array}$ & Iyikesici, 2020a [167] \\
\hline 28 & $\begin{array}{c}\text { Advanced } \\
\text { pancreas carcinoma }\end{array}$ & 26 & Chemotherapy + mEHT & $\mathrm{SD}=9(48 \%), \mathrm{PR}=4(21 \%) \mathrm{PD}=6(31 \%)$ & $\begin{array}{l}\text { Volovat, Volovat et } \\
\text { al. 2014b [168] }\end{array}$ \\
\hline 29 & Advanced pancreas & 106 & $\begin{array}{l}\text { mEHT + radiotherapy }+ \\
\text { chemotherapy }\end{array}$ & $\begin{array}{l}\text { After } 3 \mathrm{~m}, \mathrm{PR}=22(64.7 \%), \mathrm{SD}=10(29.4 \%), \\
\mathrm{PD}=2(8.3 \%) \text { with } \mathrm{mEHT} \text { after } 3 \mathrm{~m} \text { of the } \\
\text { therapy. In group without } \mathrm{mEHT} \text { in the same } \\
\text { time: } \mathrm{PR}=3(8.3 \%), \mathrm{SD}=10(27.8 \%), \mathrm{PD}=23 \\
(34.3 \%) . \text { The median } \mathrm{OS}=18 \mathrm{~m} \text { with } \mathrm{mEHT} \\
\text { and } \mathrm{OS}=10.9 \mathrm{~m} \text { without } \mathrm{mEHT} \text {. }\end{array}$ & $\begin{array}{l}\text { Fiorentini, Sarti, et al. } \\
\qquad 2019^{a}[169],\end{array}$ \\
\hline 30 & $\begin{array}{l}\text { Advanced pancreas } \\
\text { carcinoma }\end{array}$ & 20 & $\begin{array}{l}\text { Enzyme-therapy }+ \\
\text { immunolo-modulation }+ \\
\text { hormone therapy }+ \text { mEHT }\end{array}$ & $\begin{array}{l}\text { Median OS > } 10 \mathrm{~m} \text {. Most patients experienced } \\
\text { partially excellent improvement of QoL. }\end{array}$ & $\begin{array}{l}\text { Hager, Süsse, et al. } \\
1994[170]\end{array}$ \\
\hline 31 & $\begin{array}{l}\text { Advanced pancreas } \\
\text { carcinoma }\end{array}$ & $\begin{array}{l}133(26+ \\
73+34)\end{array}$ & $\begin{array}{l}\text { Radiotherapy + chemotherapy } \\
+ \text { mEHT }\end{array}$ & $\begin{array}{l}\text { Two centres PFY }(n=26) \text {, HTT }(n=73) \text { control } \\
(n=34) .59 \% \text { (PFY), } 88 \% \text { (HTT) had distant } \\
\text { metastases, conventional therapies failed. } \\
\text { Median OS = } 12.0 \mathrm{~m} \text { (PFY), } 12.7 \text { m (HTT), } 6.5 \\
\text { m (control); 1st y survival } 46.2 \% \text { (PFY), } 52.1 \% \\
\text { (HTT), 26.5\% (control) QoL was improved. }\end{array}$ & $\begin{array}{l}\text { Dani, Varkonyi, et al. } \\
2008 \text { [171] }\end{array}$ \\
\hline 32 & Ovarian cancer & 19 & mEHT with dose escalation & $\begin{array}{l}\text { The mEHT treatment was feasible in patients } \\
\text { with recurrent or progressive ovarian cancer } \\
\text { without any complication. }\end{array}$ & Yoo et al. 2019 [163], \\
\hline 33 & $\begin{array}{l}\text { Metastatic cancers } \\
\text { (colorectal, ovarian, } \\
\text { breast) }\end{array}$ & 23 & $\begin{array}{l}\text { mEHT + radio-therapy }+ \\
\text { chemotherapy }\end{array}$ & $\begin{array}{l}\text { OS and time to progression (TTP) were } \\
\text { influenced by the number of chemotherapy } \\
\text { cycles }(p<0.001) \text { and mEHT sessions ( } p< \\
0.001) \text {. Bevacizumab-based chemotherapy with } \\
\text { mEHT has a favorable tumor response, is } \\
\text { feasible and well tolerated for metastatic cancer } \\
\text { patients. }\end{array}$ & $\begin{array}{l}\text { Ranieri, et al. } 2017 \\
{[172]}\end{array}$ \\
\hline
\end{tabular}




\section{Continued}

\begin{tabular}{|c|c|c|c|c|c|}
\hline 34 & $\begin{array}{c}\text { Different types of } \\
\text { metastatic/recurrent } \\
\text { cancers }\end{array}$ & 33 & $\mathrm{mEHT}+$ radiotherapy & $\begin{array}{l}\mathrm{CR}=2(6.1 \%), \text { Very good } \mathrm{PR}=5(15.2 \%), \mathrm{PR}= \\
13(39.4 \%), \mathrm{SD}=9(27.3 \%), \mathrm{PD}=4(12.1 \%) . \\
\text { Three patients }(9.1 \%) \text { developed autoimmune } \\
\text { toxicities. All these three ptients had long-lasting } \\
\text { abscopal responses outside the irradiated area. }\end{array}$ & $\begin{array}{l}\text { Chi, Mehta, et al. } \\
\quad 2020[173]\end{array}$ \\
\hline 35 & $\begin{array}{l}\text { Advanced gastric } \\
\text { cancer }\end{array}$ & 24 & $\begin{array}{l}\text { mEHT }+ \text { chemotherapy }+ \\
\text { ketogenic diet }+ \text { oxygen therapy }\end{array}$ & $\begin{array}{l}\mathrm{CR}=22(88 \%) \text { Mean follow-up }=23.9 \mathrm{~m}, \text { mean } \\
\mathrm{OS}=39.5 \mathrm{~m}, \text { mean PFS }=36.5 \mathrm{~m}\end{array}$ & Iyikesici, 2020b [174], \\
\hline 36 & Various & & mEHT + chemotherapy & $\begin{array}{l}\text { The feasibility and success of oncothermia is } \\
\text { proven. }\end{array}$ & Fiorentini 2020 [175] \\
\hline 37 & GBM & & mEHT + chemotherapy & $\begin{array}{l}\text { The feasibility and success of oncothermia is } \\
\text { proven. }\end{array}$ & Van Gool 2021 [176] \\
\hline 38 & Rectal cancer & 120 & $\begin{array}{l}\text { mEHT + radiotherapy } \\
+ \text { surgery }\end{array}$ & $\begin{array}{l}\text { In mEHT group, } 80.7 \% \text { showed down-staging } \\
\text { compared with } 67.2 \% \text { in non-mEHT group. }\end{array}$ & Kim 2021 [177], \\
\hline 39 & Gliomas & 164 & $\begin{array}{l}\mathrm{mEHT}+\text { chemotherapy } \\
\text { + radiotherapy }\end{array}$ & $\begin{array}{l}\mathrm{CR}+\mathrm{PR} \text { is } 41.4 \% \text { for } \mathrm{mEHT} \text { and } 33.4 \% \text { for } \\
\text { conventional therapies. }\end{array}$ & Fiorentini 2020 [178] \\
\hline 40 & $\begin{array}{l}\text { Gastrointestinal } \\
\text { cancer }\end{array}$ & 34 & mEHT + chemotherapy & $\begin{array}{l}\text { The feasibility and success of oncothermia is } \\
\text { proven. }\end{array}$ & Garay 2020 [179] \\
\hline 41 & $\begin{array}{l}\text { Ovarian, } \\
\text { cervical cancer }\end{array}$ & & $\begin{array}{l}\text { mEHT + chemotherapy } \\
\text { + radiotherapy }\end{array}$ & $\begin{array}{l}\text { The feasibility and success of oncothermia is } \\
\text { proven. }\end{array}$ & $\begin{array}{l}\text { Wookyeom } 2018 \\
{[180]}\end{array}$ \\
\hline 42 & Breast cancer & 13 & $\begin{array}{l}\text { mEHT + chemotherapy } \\
+ \text { surgery }\end{array}$ & $\begin{array}{l}\text { The feasibility and success of oncothermia is } \\
\text { proven. }\end{array}$ & Szasz AM 2020 [181] \\
\hline 43 & Cervical cancer & 38 & mEHT + chemotherapy & $\begin{array}{l}\text { Cox-regression for CTx }+ \text { mEHT study-group, } \\
\text { (Rs-variable time-ratio of start of mEHT } \\
\text { compared to OS (overall survival) Coefficient }= \\
6.1 \text {, CI }(95 \%)=7.96 \text {; StErr }=4.06, p=0.13 \text {, } \\
\text { Hazard }=449 \text {. }\end{array}$ & Lee $2020[81]$ \\
\hline 44 & Various sites & 277 & mEHT + chemotherapy & $\begin{array}{l}52 \% \text { of the entire group was subjected to result } \\
\text { analysis. } 48 \% \text { was not traceable. The result of the } \\
52 \% \text { was } 21.5 \% \text { PR, } 36 \% \text { SD, } 28.9 \% \text { PD, and } \\
12.6 \% \text { exitus. So } 58.5 \% \text { of the patients showed } \\
\text { either stable disease or partial remission. }\end{array}$ & Lee 2013 [182] \\
\hline 45 & Various sites & 784 & $\begin{array}{l}\mathrm{mEHT}+\text { chemotherapy } \\
+ \text { radiotherapy + surgery }\end{array}$ & $\begin{array}{l}\text { Preliminary results show promising survival } \\
\text { trajectories. mEHT is a safe treatment with very } \\
\text { few adverse events or side effects, allowing } \\
\text { patients to maintain a higher quality of life. }\end{array}$ & Parmar 2020 [183] \\
\hline 46 & Various sites & & $\begin{array}{l}\text { mEHT + chemotherapy } \\
\text { + radiotherapy }\end{array}$ & Planned trial & Arrojo 2020 [184] \\
\hline 47 & Various sites & & $\begin{array}{l}\mathrm{mEHT}+\text { chemotherapy } \\
+ \text { radiotherapy }\end{array}$ & $\begin{array}{l}\text { The feasibility and success of oncothermia is } \\
\text { proven. }\end{array}$ & Szasz AM 2019 [143] \\
\hline 48 & Brain tumor & 54 & mEHT + chemotherapy & $\begin{array}{l}\text { mEHT strongly and significantly enhances the } \\
\text { efficacy of the ddTMZ } 21 / 28 \mathrm{~d} \text { regimen ( } p= \\
0.011 \text { ), with a maximum attainable MST of } 10.10 \\
\text { months ( } 95 \% \text { CI } 9.10 \text { to } 11.10) \text {. }\end{array}$ & $\begin{array}{c}\text { Roussakow } 2017 \\
{[185]}\end{array}$ \\
\hline
\end{tabular}

\section{Conclusions}

The two variants of capacitive coupling, the plane-wave, and impedance matching, make different treatment applications in preclinical experiments and human 
medical applications. Technically the difference between these capacitive methods is the design for homogeneous or heterogeneous heating. The homogeneous heating needs to measure the target's temperature, obtaining information about the amount of absorbed energy, while the impedance matching gets direct information about the energy-absorption. This results in a difference in the dosing method because, in the homogeneous approach, the temperature is the mandatory part of the heating dose, while in the heterogeneous case, the absorbed energy characterizes the process. The heterogeneous heating without artificial nanoparticles is realized in the mEHT method. This method has special qualities which improve the conventional hyperthermia results:

1) Excites apoptotic signals by extrinsic pathways.

2) Though the selected membrane rafts, mEHT excites the TRAIL DR5 death-receptor (with FADD and FAS complex), and this extrinsic excitation triggers the ICD.

3) The raft excitation triggers the DAMP and ICD, crucial for the immunogenic (abscopal) effect. This turns the local treatment into a systemic treatment, shown in the elongation of the survival time, without being limited to local control.

4) The immunogenic effect is vital for the cases with far advanced, relapsed, metastatic disease, and not only locally advanced cases.

\section{Acknowledgements}

This work was supported by the Hungarian National Research Development and Innovation Office PIACI KFI grant: 2019-1.1.1-PIACI-KFI-2019-00011.

\section{Conflicts of Interest}

The author declares no conflicts of interest regarding the publication of this paper.

\section{References}

[1] von Bertalanffy, K.L. (1934) Untersuchungen Über die Gesetzlichkeit des Wachstums: I. Teil: Allgemeine Grundlagen der Theorie; Mathematische und physiologische Gesetzlichkeiten des Wachstums bei Wassertieren. Wilhelm Roux' Archiv für Entwicklungsmechanik der Organismen, 131, 613-652. https://doi.org/10.1007/BF00650112

[2] Green, D.M. (1991) Chaos, Fractals and Nonlinear Dynamics in Evolution and Phylogeny. Trends in Ecology \& Evolution, 6, 334-337. https://doi.org/10.1016/0169-5347(91)90042-V

[3] Szentgyorgyi, A. (1978) The Living State and Cancer. Marcel Dekker Inc., New York.

[4] Balmain, A., Gray, J. and Ponder, B. (2014) The Genetics and Genomics of Cancer. Nature Genetics, 33, 238-244. https://doi.org/10.1038/ng1107

[5] Szigeti, G.P., Szasz, O. and Hegyi, G. (2017) Connections between Warburg's and Szentgyorgyi's Approach about the Causes of Cancer. Journal of Neoplasm, 1, 1-13. http://neoplasm.imedpub.com/connections-between-warburgs-and-szentgyorgyis-a 
pproach-about-thecauses-of-cancer.pdf

[6] Hanahan, D. and Weinberg, R.A. (2000) The Hallmarks of Cancer. Cell, 100, 57-70. https://doi.org/10.1016/S0092-8674(00)81683-9

[7] Hanahan, D. and Weinberg, R.A. (2011) Hallmarks of Cancer: The Next Generation. Cell, 144, 646-674. https://doi.org/10.1016/j.cell.2011.02.013

[8] Aktipis, C.A., Bobby, A.M., Jansen, G., et al. (2015) Cancer across the Tree of Life: Cooperation and Cheating in Multicellularity. Philosophical Transactions of the Royal Society B, 370, Article ID: 20140219. https://doi.org/10.1098/rstb.2014.0219

[9] Popkin, G. (2011) Physics Sheds Light on Cancer and Bacteria Evolution. APC News, 20. https://www.aps.org/publications/apsnews/201105/cancerbacteria.cfm .

[10] Trigos, A.S., Pearson, R.B., Paenfuss, A.T., et al. (2018) How the Evolution of Multicellularity Set the Stage for Cancer. British Journal of Cancer, 118, 145-152. https://doi.org/10.1038/bjc.2017.398

[11] Trigos, A.S., Pearson, R.B., Papenfuss, A.T., et al. (2016) Altered Interactions between Unicellular and Multicellular Genes Drive Hallmarks of Transformation in a Diverse Range of Solid Tumors. Proceedings of the National Academy of Sciences of the United States of America, 114, 6406-6411.

https://doi.org/10.1073/pnas.1617743114

[12] Davidson, C.D., Wang, W.Y., Zaimi, I., et al. (2019) Cell Force-Mediated Matrix Reorganization Underlies Multicellular Network Assembly. Scientific Reports, 9, Article No. 12. https://doi.org/10.1038/s41598-018-37044-1

[13] Meng, X., Riordan, N.H. (2006) Cancer Is a Functional Repair Tissue. Medical Hypotheses, 66, 486-490. https://doi.org/10.1016/j.mehy.2005.09.041

[14] Dvorak, H.F. (1986) Tumors: Wounds That Do Not Heal, Similarities between Tumor Stroma Generation and Wound Healing. The New England Journal of Medicine, 315, 1650-1659. https://doi.org/10.1056/NEJM198612253152606

[15] National Cancer Institute. National Cancer Act of 1971. https://www.cancer.gov/about-nci/overview/history/national-cancer-act-1971

[16] Spector, R. (2010) The War on Cancer A Progress Report for Skeptics. Skeptical Inquirer, 34, 25-31.

[17] Brecht, B. (1935) Leben des Galilei. In: Losey, J. (1975), Galileo, Grove Press, New York.

[18] DiTrocchio, F. (1994) Der grosse schwindel: Betrug und falschung in der wissenschaft. Campus Verlag, Frankfurt.

[19] Roussakow, S. (2013) The History of Hyperthermia Rise and Decline. Conference of the International Clinical Hyperthermia Society 2012, 2013, Article ID: 428027. https://doi.org/10.1155/2013/428027

[20] Van der Zee, J. (2005) Radiotherapy and Hyperthermia in Cervical Cancer. ESTRO/TMH Presentation, Mumbai, 2 March 2005. http://www.docstoc.com/docs/73493260/Welcome-to-Tata-Memorial-Centre

[21] ITU Radio Regulations, CHAPTER II-Frequencies, ARTICLE 5 Frequency Allocations, Section IV-Table of Frequency Allocations.

[22] Hajimiri, A. (2010) Generalized Time- and Transfer-Constant Circuit Analysis. IEEE Transactions on Circuits and Systems I: Regular Papers, 57, 1105-1121. https://doi.org/10.1109/TCSI.2009.2030092

[23] Szasz, A. (2014) Oncothermia: Complex Therapy by EM and Fractal Physiology. 2014 XXXIth URSI General Assembly and Scientific Symposium (URSI GASS), Beijing, 16-23 August 2014, 1-4. https://doi.org/10.1109/URSIGASS.2014.6930100 
[24] Rao, N.N. (1994) Elements of Engineering Electromagnetics, Prentice Hall, Englewood Cliffs, NJ.

[25] Szasz, A. (2015) Bioelectromagnetic Paradigm of Cancer Treatment Oncothermia. In: Rosch, P.J., Ed., Bioelectromagnetic and Subtle Energy Medicine, CRC Press, Taylor \& Francis Group, 323-336.

[26] Fiorentini, G. and Szasz, A. (2006) Hyperthermia Today: Electric Energy, a New Opportunity in Cancer Treatment. Journal of Cancer Research and Therapeutics, 2, 41-46. https://doi.org/10.4103/0973-1482.25848

[27] Keisari, Y. (2013) Tumor Ablation, Effects on Systemic and Local Anti-Tumor Immunity and on Other Tumor-Microenvironment Interactions. Springer Science + Business Media, Dordrecht. https://doi.org/10.1007/978-94-007-4694-7

[28] Szasz, O., Szigeti, G.P., Vancsik, T. and Szasz, A. (2018) Hyperthermia Dosing and Depth of Effect. Open Journal of Biophysics, 8, 31-48. https://doi.org/10.4236/ojbiphy.2018.81004

[29] Szasz, A., Szasz, N. and Szasz, O. (2010) Experimental Condition in Vivo. In: Oncothermia: Principles and Practices, Springer Science, Heidelberg, 476-477. https://doi.org/10.1007/978-90-481-9498-8

[30] Moran, C.H., Wainerdi, S.M., Cherukuri, T.K., et al. (2009) Size-Dependent Joule Heating of Gold Nanoparticles Using Capacitively Coupled Radiofrequency Fields. Nano Research, 2, 400-405. https://doi.org/10.1007/s12274-009-9048-1

[31] Raoof, M., Cisneros, B.T., Corr, S.J., et al. (2013) Tumor Selective Hyperthermia Induced by Short-Wave Capacitively-Coupled RF Electric-Fields. PLOS ONE, 8, e68506. https://doi.org/10.1371/journal.pone.0068506

[32] Raoof, M. and Curley, S.A. (2011) Non-Invasive Radiofrequency-Induced Targeted Hyperthermia for the Treatment of Hepatocellular Carcinoma. International Journal of Hepatology, 2011, Article ID: 676957. https://doi.org/10.4061/2011/676957

[33] Erdmann, B., Lang, J. and Seebass, M. (1998) Optimization of Temperature Distributions for Regional Hyperthermia Based on a Nonlinear Heat Transfer Model. Annals of the New York Academy of Sciences, 858, 36-46. https://doi.org/10.1111/j.1749-6632.1998.tb10138.x

[34] Szasz, O., Szigeti, G.P. and Szasz, A. (2016) Connections between the Specific Absorption Rate and the Local Temperature. Open Journal of Biophysics, 6, 53-74. http://file.scirp.org/pdf/OJBIPHY 2016063014260548.pdf https://doi.org/10.4236/ojbiphy.2016.63007

[35] Andocs, G., Renner, H., Balogh, L., Fonyad, L., Jakab, C. and Szasz, A. (2009) Strong Synergy of Heat and Modulated Electro-Magnetic Field in Tumor Cell Killing. Strahlentherapie und Onkologie, 185, 120-126. http://www.ncbi.nlm.nih.gov/pubmed/19240999 https://doi.org/10.1007/s00066-009-1903-1

[36] Warburg, O. (1956) On the Origin of Cancer Cells. Science, 123, 309-314. https://doi.org/10.1126/science.123.3191.309

[37] Semenza, G.L. (2008) Tumor Metabolism: Cancer Cells Give and Take Lactate. The Journal of Clinical Investigation, 118, 3835-3837. https://doi.org/10.1172/JCI37373

[38] Stoy, R.D., Foster, K.R. and Schwan, H.P. (1982) Dielectric Properties of Mammalian Tissues form 0.1 to $100 \mathrm{MHz}$ : A Summary of Recent Data. Physics in Medicine \& Biology, 27, 501-513. https://doi.org/10.1088/0031-9155/27/4/002

[39] Gershing, E. (1999) Monitoring Temperature-Induced Changes in Tissue during Hyperthermia by Impedance Methods. Annals of the New York Academy of Sciences, 
873, 13-20. https://doi.org/10.1111/j.1749-6632.1999.tb09444.x

[40] Oehr, P., Biersack, H.J., Coleman, R.E., Eds. (2004) PET and PET-CT in Oncology. Springer Verlag, Berlin-Heidelberg. https://doi.org/10.1007/978-3-642-18803-9

[41] Larson, S.M. (2004) Positron Emission Tomography-Based Molecular Imaging in Human Cancer: Exploring the Link between Hypoxia and Accelerated Glucose Metabolism. Clinical Cancer Research, 10, 2203-2204. https://doi.org/10.1158/1078-0432.CCR-0002-4

[42] Sha, L., Ward, E.R. and Story, B. (2002) A Review of Dielectric Properties of Normal and Malignant Breast Tissue. Proceedings IEEE SoutheastCon 2002, Columbia, SC, 5-7 April 2002, 457-462.

[43] Blad, B., Wendel, P., Jönsson, M., et al. (1999) An Electrical Impedance Index to Distinguish between Normal and Cancerous Tissues. Journal of Medical Engineering \& Technology, 23, 57-62. https://doi.org/10.1080/030919099294294

[44] Szentgyorgyi, A. (1968) Bioelectronics: A Study on Cellular Regulations, Defense, and Cancer. Academic Press, New York, London.

[45] Foster, K.R. and Schepps, J.L. (1981) Dielectric Properties of Tumor and Normal Tissues at Radio through Microwave Frequencies. Journal of Microwave Power, 16, 107-119. https://doi.org/10.1080/16070658.1981.11689230

[46] Blad, B. and Baldetorp, B. (1996) Impedance Spectra of Tumour Tissue in Comparison with Normal Tissue: A Possible Clinical Application for Electric Impedance Tomography. Physiological Measurement, 17, A105-A115. https://doi.org/10.1088/0967-3334/17/4A/015

[47] Babaeizadeh, S. (2007) 3-D Electrical Impedance Tomography of Piecewise Constant Domains with Known Internal Boundaries. IEEE Transactions on Biomedical Engineering, 54, 2-10. https://doi.org/10.1109/TBME.2006.886839

[48] TransCan TS: Transcan Medical Ltd. Migdal Ha'Emek, Israel, distributed by Siemens AG, Germany, 2000.

[49] Joy, M.L.G. (2004) MR Current Density and Conductivity Imaging: The State of the Art. IEMBS 26th Annual International Conference of the IEEE, 2, 5315-5319.

[50] Suk, H.O. (2003) Conductivity and Current Density Image Reconstruction Using Harmonic $B_{z}$ Algorithm in Magnetic Resonance Electrical Impedance Tomography. Physics in Medicine \& Biology, 48, 3101-3116. https://doi.org/10.1088/0031-9155/48/19/001

[51] Mikac, U., Demsar, F., Beravs, K. and Sersa, I. (2001) Magnetic Resonance Imaging of Alternating Electric Currents. Magnetic Resonance Imaging, 19, 845-856. https://doi.org/10.1016/S0730-725X(01)00393-9

[52] Muftuler, T.L., Hamamura, M.J., Birgul, O. and Nalcioglu, O. (2006) In Vivo MRI Electrical Impedance Tomography (MREIT) of Tumors. Technology in Cancer Research \& Treatment, 5, 381-387.

[53] Papp, E., Vancsik, T., Kiss, E. and Szasz, O. (2017) Energy Absorption by the Membrane Rafts in the Modulated Electro-Hyperthermia (mEHT). Open Journal of Biophysics, 7, 216-229. https://doi.org/10.4236/ojbiphy.2017.74016

[54] Caduff, A., Talary, M.S. and Zakharov, P. (2010) Cutaneous Blood Perfusion as a Perturbing Factor for Noninvasive Glucose Monitoring. Diabetes Technology \& Therapeutics, 12, 1-9. https://doi.org/10.1089/dia.2009.0095

[55] Schwan, H.P. (1982) Nonthermal Cellular Effects of Electromagnetic Fields: AC-Field Induced Ponderomotoric Forces. British Journal of Cancer, 45, 220-224. 
[56] Pething, R. (1979) Dielectric and Electronic Properties of Biological Materials. John Wiley \& Sons, New York.

[57] Szasz, O., Andocs, G., Kondo, T., Rehman, M.U., Papp E, Vancsik T. (2015) Heating of Membrane Raft of Cancer-Cells. Journal of Clinical Oncology, 33, e22176. https://doi.org/10.1200/jco.2015.33.15 suppl.e22176

[58] Astumian, R.D. and Chock, P.B. (1989) Effects of Oscillations and Energy-Driven Fluctuations on the Dynamics of Enzyme Catalysis and Free-Energy Transduction. Physical Review A, 39, 6416-6435. https://doi.org/10.1103/PhysRevA.39.6416

[59] Musha, T. and Sawada, Y. (1994) Physics of the Living State. IOS Press, Amsterdam.

[60] West, B.J. (1990) Fractal Physiology and Chaos in Medicine. World Scientific, Singapore, London.

[61] Lovelady, D.C., Richmond, T.C., Maggi, A.N., Lo, C.M. and Rabson, D.A. (2007) Distinguishing Cancerous from Noncancerous Cells through Analysis of Electrical Noise. Physical Review E, 76, Article ID: 041908. https://doi.org/10.1103/PhysRevE.76.041908

[62] Szasz, O., Andocs, G. and Meggyeshazi, N. (2013) Modulation Effect in Oncothermia. Conference of the International Clinical Hyperthermia Society 2012, 2013, Article ID: 395678. http://www.hindawi.com/archive/2013/398678/ https://doi.org/10.1155/2013/398678

[63] Szentgyorgyi, A. (1998) Electronic Biology and Cancer. Marcel Dekker, New York.

[64] Kirson, E.D., Gurvich, Z., Schneiderman, R., et al. (2004) Disruption of Cancer Cell Replication by Alternating Electric Fields. Cancer Research, 64, 3288-3295. https://doi.org/10.1158/0008-5472.CAN-04-0083

[65] Vincze, G. and Sziget, G.P. (2016) Reorganization of the Cytoskeleton. Journal of Advances in Biology, 9, 1872-1882. https://cirworld.com/index.php/jab/article/view/4059

[66] Springer, M. and Paulsson, J. (2006) Harmonies from Noise. Nature, 439, 27-28. https://doi.org/10.1038/439027a

[67] West, J.B. (2013) Fractal Physiology and Chaos in Medicine. World Scientific, Singapore. https://doi.org/10.1142/8577

[68] Hoop, B. and Peng, C.-K. (2000) Fluctiations and Fractal Noise in Biological Membranes. The Journal of Membrane Biology, 177, 177-185. https://doi.org/10.1007/s002320010001

[69] Szasz, O., Vincze, G., Szigeti, G.P. and Szasz, A. (2017) Intrinsic Noise Monitoring of Complex Systems. Open Journal of Biophysics, 7, 197-215. https://doi.org/10.4236/ojbiphy.2017.74015

[70] Szasz, A., Szasz, N. and Szasz, O. (2010) Oncothermia-Principles and Practices. Springer Science, Heidelberg. (Ch 4.1, pp. 220, Fig. 4.52)

[71] Yang, K.-L., Huang, C.-C., Chi, M.-S., Chiang, H.-C., Wang, Y.-S., Andocs, G., et al. (2016) In Vitro Comparison of Conventional Hyperthermia and Modulated Electro-Hyperthermia. Oncotarget, 7, 84082-84092. https://doi.org/10.18632/oncotarget.11444

[72] Shinitzky, M. (1984) Membrane Fluidity in Malignancy Adversative and Recuperative. Biochimica et Biophysica Acta, 738, 251-261. https://doi.org/10.1016/0304-419X(83)90007-0

[73] Goldman, D.E. (1943) Potential, Impedance, and Rectification in Membranes. Journal of General Physiology, 27, 37-60. https://doi.org/10.1085/igp.27.1.37 
[74] Ramachandran, S., Blick, R.H. and van der Weide, DW. (2010) Radio Frequency Rectification on Membrane Bound Pores. Nanotechnology, 21, Article ID: 075201. https://doi.org/10.1088/0957-4484/21/7/075201

[75] Tanaka, A. and Tokimasa, T. (1999) Theoretical Background for Inward Rectification. The Tokai Journal of Experimental and Clinical Medicine, 24, 147-153.

[76] Astumian, R.D., Weaver, J.C. and Adair, R.K. (1995) Rectification and Signal Averaging of Weak Electric Fields by Biological Cells. Proceedings of the National Academy of Sciences of the United States of America, 92, 3740-3743. https://doi.org/10.1073/pnas.92.9.3740

[77] Szasz, A., Vincze, G., Szasz, O. and Szasz, N. (2003) An Energy Analysis of Extracellular Hyperthermia. Electromagnetic Biology and Medicine, 22, 103-115. https://doi.org/10.1081/JBC-120024620

[78] Vincze, G., Szigeti, G., Andocs, G. and Szasz, A. (2015) Nanoheating without Artificial Nanoparticles. Biology and Medicine, 7, Article Number 1000249.

http://www.omicsonline.com/open-access/nanoheating-without-artificial-nanoparti cles-0974-8369-1000249.php?aid=61783

[79] Andocs, G., Rehman, M.U., Zhao, Q.L., Papp, E., Kondo, T. and Szasz, A. (2015) Nanoheating without Artificial Nanoparticles Part II. Experimental Support of the Nanoheating Concept of the Modulated Electro-Hyperthermia Method, Using U937 Cell Suspension Model. Biology and Medicine, 7, 1-9.

https://www.omicsonline.org/open-access/nanoheating-without-artificial-nanoparti cles-part-ii-experimental-support-of-the-nanoheating-concept-of-the-modulated-el ectrohyperthermiamethod-0974-8369-1000247.php?aid=60362 https://doi.org/10.4172/0974-8369.1000247

[80] Lee, S.-Y, Kim, J.-H, Han, Y.-H., et al. (2018) The Effect of Modulated Electro-Hyperthermia on Temperature and Blood Flow in Human Cervical Carcinoma. International Journal of Hyperthermia, 34, 953-960. https://doi.org/10.1080/02656736.2018.1423709

[81] Lee, S.-Y. (2020) Concurrent Chemo-Hyperthermia for Recurrent Cervical Cancer after Previous CCRT. In: Szasz, A., Ed., Challenges and Solutions of Oncological Hyperthermia, Ch. 9, Cambridge Scholars Publishing, Newcastle upon Tyne, 163-186. https://www.cambridgescholars.com/challenges-and-solutions-of-oncological-hype rthermia

[82] Lee, S.-Y. and Kim, M.-G. (2015) The Effect of Modulated Electro-Hyperthermia on the Pharmacokinetic Properties of Nefopam in Healthy Volunteers: A Randomised, Single-Dose, Crossover Open-Label Study. International Journal of Hyperthermia, 31, 869-874. http://www.ncbi.nlm.nih.gov/pubmed/26507458 https://doi.org/10.3109/02656736.2015.1095358

[83] Lee, S.-Y. and Kim, M.-G. (2016) Effect of Modulated Electrohyperthermia on the Pharmacokinetics of Oral Transmucosal Fentanyl Citrate in Healthy Volunteers. Clinical Therapeutics, 38, 2548-2554.

https://www.ncbi.nlm.nih.gov/pubmed/27866658

https://doi.org/10.1016/j.clinthera.2016.10.012

[84] Lee, S.-Y., Szigeti, G.P. and Szasz, A.M. (2019) Oncological Hyperthermia: The Correct Dosing in Clinical Applications. International Journal of Oncology, 54, 627-643. https://www.spandidos-publications.com/10.3892/ijo.2018.4645\# https://doi.org/10.3892/ijo.2018.4645

[85] Wust, P., Ghadjar, P., Nadobny, J., et al. (2019) Physical Analysis of Temperature-Dependent Effects of Amplitude-Modulated Electromagnetic Hyperthermia. 
International Journal of Hyperthermia, 36, 1246-1254.

https://www.ncbi.nlm.nih.gov/pubmed/31818170

https://doi.org/10.1080/02656736.2019.1692376

[86] Szasz, A. (2019) Thermal and Nonthermal Effects of Radiofrequency on Living State and Applications as an Adjuvant with Radiation Therapy. Journal of Radiation and Cancer Research, 10, 1-17.

http://www.journalrcr.org/article.asp?issn=2588-9273; year $=2019$; volume $=10$;issue $=$ 1 ; spage $=1$; epage $=17$; aulast $=$ Szasz

https://doi.org/10.4103/jrcr.jrcr 2518

[87] Wust, P., Kortum, B., Strauss, U., Nadobny, J., Zschaeck, S., Beck, M., et al. (2020) Non-Thermal Effects of Radiofrequency Electromagnetic Fields. Scientific Reports, 10, Article No. 13488. https://www.nature.com/articles/s41598-020-69561-3 https://doi.org/10.1038/s41598-020-69561-3

[88] Wust, P., Nadobny, J., Zschaeck, S. and Ghadjar, P. (2020) Physics of Hyperthermia-Is Physics Really against Us? In: Szasz, A., Ed., Challenges and Solutions of Oncological Hyperthermia, Ch. 16, Cambridge Scholars Publishing, Newcastle upon Tyne, 346-376.

https://www.cambridgescholars.com/challenges-and-solutions-of-oncological-hype rthermia

[89] Rao, N.N. (2004) Elements of Engineering Electromagnetics. Pearson-Prentice Hall International, Pearson Education Inc., London UK.

[90] Szasz, A., Szasz, O. and Szasz, N. (2006) Physical Background and Technical Realization of Hyperthermia. In: Baronzio, G.F. and Hager, E.D., Eds., Hyperthermia in Cancer Treatment. A Primer, Springer, Boston, MA, 27-59. https://doi.org/10.1007/978-0-387-33441-7 3

[91] http://www.nist.gov/pml/div682/grp02/upload/FT11Bourland.pdf

[92] Fluoroscopy Radiation Safety Training Manual (FDA Involved). https://www.case.edu/ehs/Training/RadSafety/fluoro.htm

[93] Beddar, A.S. and Krishnan, S. (2005) Intraoperative Radiotherapy Using a Mobile Electron LINAC: A Retroperitoneal Sarcoma Case. Journal of Applied Clinical Medical Physics, 6, 95-107.

http://www.jacmp.org/index.php/jacmp/rt/printerFriendly/2109/1220 https://doi.org/10.1120/jacmp.v6i3.2109

[94] Szasz, A. (2006) Physical Background, and Technical Realization of Hyperthermia. In: Baronzio, G.F. and Hager, E.D., Eds., Hyperthermia in Cancer Treatment. $A$ Primer. Springer Science, Berlin.

[95] Gabriel, C. and Gabriel, S. (1996) Compilation of the Dielectric Properties of Body Tissues at RF and Microwave Frequencies.

http://niremf.ifac.cnr.it/docs/DIELECTRIC/Report.html

[96] Findlay, R.P. and Dimbylow, P.J. (2005) Effects of Posture on FDTD Calculations of Specific Absorption Rate in a Voxel Model of the Human Body. Physics in Medicine \& Biology, 50, 3825-3835. https://doi.org/10.1088/0031-9155/50/16/011

[97] Joo, E., Szasz, A. and Szendro, P. (2005) Metal-Framed Spectacles and Implants and Specific Absorption Rate among Adults and Children Using Mobile Phones at 900/1800/2100 MHz. Electromagnetic Biology and Medicine, 25, 103-112. https://doi.org/10.1080/15368370600719042

[98] Jianging, W., Mukaide, N. and Fujiwara, O. (2003) FTDT Calculation of Organ Resonance Characteristics in an Anatomically Based Human Model for Plane-Wave Exposure. Proceedings of the Asia-Pacific Conference on Environmental Electro- 
magnetics, Hangzhou, 4-7 November 2003, 126-129.

[99] Armstron Laboratory, USAF School of Aerospace Medicine, AFSC (1997) Radiofrequency Radiation Dosimetry Handbook. http://niremf.ifac.cnr.it/docs/HANDBOOK/chp1.htm

[100] Slosarek, K., Konopacka, M., Rogoliński, J., Latocha, M. and Sochanik, A. (2005) Effect of Depth on Radiation-Induced Cell Damage in a Water Phantom. Reports of Practical Oncology and Radiotherapy, 10, 37-41. https://doi.org/10.1016/S1507-1367(05)71080-4

[101] Meggyeshazi, N., Andocs, G., Balogh, L., Balla, P., Kiszner, G., Teleki, I., et al. (2014) DNA Fragmentation and Caspase-Independent Programmed Cell Death by Modulated Electrohyperthermia. Strahlentherapie und Onkologie, 190, 815-822. https://doi.org/10.1007/s00066-014-0617-1

[102] Vincze, G., Szasz, O. and Szasz, A. (2015) Generalization of the Thermal Dose of Hyperthermia in Oncology. Open Journal of Biophysics, 5, 97-114. https://doi.org/10.4236/ojbiphy.2015.54009

[103] Andocs, G., Meggyeshazi, N., Balogh, L., et al. (2015) Up-Regulation of Heat Shock Proteins and the Promotion of Damage-Associated Molecular Pattern Signals in a Colorectal Cancer Model by Modulated Electrohyperthermia. Cell Stress and Chaperones, 20, 37-46. https://doi.org/10.1007/s12192-014-0523-6

[104] Qin, W., Akutsu, Y., Andocs, G., Suganami, A., Hu, X., Yusup, G., et al. (2014) Modulated Electro-Hyperthermia Enhances Dendritic Cell Therapy through an Abscopal Effect in Mice. Oncology Reports, 32, 2373-2379. https://doi.org/10.3892/or.2014.3500

[105] Jones, E., Thrall, D., Dewhirst, M.W. and Vujaskovic, Z. (2006) Prospective Thermal Dosimetry: The Key to Hyperthermia's Future. International Journal of Hyperthermia, 22, 247-253. https://doi.org/10.1080/02656730600765072

[106] Dewhirst, M.W., Viglianti, B.L., Lora-Michiels, M., Hanson, M. and Hoopes, P.J. (2003) Basic Principles of Thermal Dosimetry and Thermal Thresholds for Tissue Damage from Hyperthermia. International Journal of Hyperthermia, 19, 267-294. https://doi.org/10.1080/0265673031000119006

[107] Dewey, W.C. (1994) Arrhenius Relationships from the Molecule and Cell to the Clinic. International Journal of Hyperthermia, 10, 457-483. https://doi.org/10.3109/02656739409009351

[108] Perez, C.A. and Sapareto, S.A. (1984) Thermal Dose Expression in Clinical Hyperthermia and Correlation with Tumor Response/Control. Cancer Research, 44, 4818-4825.

[109] Hegyi, G., Vincze, G. and Szasz, A. (2012) On the Dynamic Equilibrium in Homeostasis. Open Journal of Biophysics, 2, 64-71.

http://file.scirp.org/pdf/OJBIPHY20120300001 81525786.pdf https://doi.org/10.4236/ojbiphy.2012.23009

[110] Maguire, P.D., Samulski, T.V., Prosnitz, L.R., Jones, E.L., Rosnre, G.L., Powers, B., Layfield, L.W., Brizel, D.M., Scully, S.P., Herrelson, M., et al. (2001) A Phase II Trial Testing the Thermal Dose Parameter CEM43oCT90 as a Predictor of Response in Soft Tissue Sarcomas Treated with Pre-Operative Thermoradiotherapy. International Journal of Hyperthermia, 17, 283-290. https://doi.org/10.1080/02656730110039449

[111] Dewhirst, M.W., Vujaskovic, Z., Jones, E. and Thrall, D. (2005) Re-Setting the Biologic Rationale for Thermal Therapy. International Journal of Hyperthermia, 21, 779-790. https://doi.org/10.1080/02656730500271668 
[112] de Bruijne, M., van der Holt, B., van Rhoon, G.C. and van der Zee, J. (2010) Evaluation of CEM $43^{\circ} \mathrm{CT} 90$ Thermal Dose in Superficial Hyperthermia: A Retrospective Analysis. Strahlentherapie und Onkologie, 186, 436-443. https://doi.org/10.1007/s00066-010-2146-x

[113] Assi, H. (2009) A New CEM43 Thermal Dose Model Based on Vogel-TammannFulcher Behaviour in Thermal Damage Processes. Ryerson University, Toronto, Ontario.

[114] Thrall, D.E., Prescott, D.M., Samulski, T.V., Rosner, G.L., Denman, D.L., Legorreta, R.L., Dodge, R.K., Page, R.L., Cline, J.M., Lee, J., Case, B.C., Evans, S.M., Oleson, J.R. and Dewhirst, M.W. (1996) Radiation plus Local Hyperthermia versus Radiation plus the Combination of Local and Whole-Body Hyperthermia in Canine Sarcomas. International Journal of Radiation Oncology · Biology · Physics, 34, 1087-1096.

[115] Szasz, O. and Szasz, A. (2016) Heating, Efficacy and Dose of Local Hyperthermia. Open Journal of Biophysics, 6, 10-18. https://doi.org/10.4236/ojbiphy.2016.61002

[116] Szasz, O. (2019) Bioelectromagnetic Paradigm of Cancer Treatment-Modulated Electro-Hyperthermia (mEHT). Open Journal of Biophysics, 9, 98-109. https://doi.org/10.4236/ojbiphy.2019.92008

[117] Szasz, O. and Szasz, A. (2021) Approaching Complexity: Hyperthermia Dose and Its Possible Measurement in Oncology. Open Journal of Biophysics, 11, 68-132. https://doi.org/10.4236/ojbiphy.2021.111002

[118] Kao, P.H.-J., Chen, C.-H., Chang, Y.-W., et al. (2020) Relationship between Energy Dosage and Apoptotic Cell Death by Modulated Electro-Hyperthermia. Scientific Reports, 10, Article No. 8936. https://www.nature.com/articles/s41598-020-65823-2 https://doi.org/10.1038/s41598-020-65823-2

[119] Meggyeshazi, N., Andocs, G. and Krenacs, T. (2013) Programmed Cell Death Induced by Modulated Electro-Hyperthermia. Conference of the International Clinical Hyperthermia Society 2012, 2013, Article ID: 187835, http://www.hindawi.com/archive/2013/187835/

[120] Danics, L., Schvarcz, C.A.., Viana, P., et al. (2020) Exhaustion of Protective Heat Shock Response Induces Significant Tumor Damage by Apoptosis after Modulated Electro-Hyperthermia Treatment of Triple Negative Breast Cancer Isografts in Mice. Cancers, 12, 2581. https://pubmed.ncbi.nlm.nih.gov/32927720/ https://doi.org/10.3390/cancers12092581

[121] Tsang, Y.-W., Huang, C.-C., Yang, K.-L., et al. (2015) Improving Immunological Tumor Microenvironment Using Electro-Hyperthermia Followed by Dendritic Cell Immunotherapy. BMC Cancer, 15, Article No. 708.

http://www.ncbi.nlm.nih.gov/pubmed/26472466 https://doi.org/10.1186/s12885-015-1690-2

[122] Andocs, G., Rehman, M.U., Zhao, Q.-L., Tabuchi, Y., Kanamori, M. and Kondo, T. (2016) Comparison of Biological Effects of Modulated Electro-Hyperthermia and Conventional Heat Treatment in Human Lymphoma U937 Cell. Cell Death Discovery, 2, Article No. 16039. http://www.nature.com/articles/cddiscovery201639 https://doi.org/10.1038/cddiscovery.2016.39

[123] Jeon, T.-W., Yang, H., Lee, C.G., Oh, S.T., et al. (2016) Electro-Hyperthermia Up-Regulates Tumour Suppressor Septin 4 to Induce Apoptotic Cell Death in Hepatocellular Carcinoma. International Journal of Hyperthermia, 32, 648-656. https://doi.org/10.1080/02656736.2016.1186290

[124] Vancsik, T., Andocs, G., Kovago, C., et al. (2015) Electro-Hyperthermia May Target Tumor-Cell Membranes. 33rd Annual Conference of International Clinical Hyper- 
thermia Society (ICHS), Nidda, Germany, 11-13 July 2015.

[125] Meggyeshazi, N. (2015) Studies on Modulated Electrohyperthermia Induced Tumor Cell Death in a Colorectal Carcinoma Model. PhD Thesis, Semmelweis University, Budapest. http://repo.lib.semmelweis.hu/handle/123456789/3956

[126] Krenacs, T., Meggyeshazi, N., Forika, G., Kiss, E., et al. (2020) Modulated Electro-Hyperthermia-Induced Tumor Damage Mechanisms Revealed in Cancer Models. International Journal of Molecular Sciences, 21, 6270.

https://www.mdpi.com/1422-0067/21/17/6270 https://doi.org/10.3390/ijms21176270

[127] Vancsik, T., Kovago, C., Kiss, E., et al. (2018) Modulated Electro-Hyperthermia Induced Loco-Regional and Systemic Tumor Destruction in Colorectal Cancer Allografts. Journal of Cancer, 9, 41-53.

https://www.ncbi.nlm.nih.gov/pmc/articles/PMC5743710/pdf/jcav09p0041.pdf https://doi.org/10.7150/jca.21520

[128] Biosca, J.A., Travers, F. and Barman, T.E. (1983) A Jump in an Arrhenius Plot Can Be the Consequence of a Phase Transition. The Binding of ATP to Myosin Subfragment 1. FEBS Letters, 153, 217-220. https://doi.org/10.1016/0014-5793(83)80151-3

[129] Hasegawa, T., Gu, Y.H., Takahashi, T., Hasegawa, T. and Yamamoto, I. (2001) Enhancement of Hyperthermic Effects Using Rapid Heating. In: Kosaka, M., Sugahara, T., Schmidt, K.L., et al., Eds., Thermotherapy for Neoplasia, Inflammation, and Pain, Springer Verlag, Tokyo, 439-444. https://doi.org/10.1007/978-4-431-67035-3 49

[130] Watson, K., Bertoli, E. and Griffiths, D.E. (1975) Phase Transitions in Yeast Mitochondrial Membranes. The Effect of Temperature on the Energies of Activation of the Respiratory Enzymes of Saccharomyces cerevisiae. Biochemical Journal, 146, 401-407. https://doi.org/10.1042/bj1460401

[131] Szigeti, G.P., Szasz, O. and Hegyi, G. (2016) Personalised Dosing of Hyperthermia. Journal of Cancer Diagnosis, 1, 107. https://doi.org/10.4172/2476-2253.1000107

[132] Rosenberg, S.M. and Queitsch, C. (2014) Combacting Evolution to Fight Disease. Science, 343, 1088-1089. https://doi.org/10.1126/science.1247472

[133] Szasz, A. (2020) Towards the Immunogenic Hyperthermic Action: Modulated Electro-Hyperthermia. Clinical Oncology and Research, 3, 1-6.

https://www.sciencerepository.org/towards-the-immunogenic-hyperthermic-action -modulated-electro-hyperthermia COR-2020-9-107 https://doi.org/10.31487/j.COR.2020.09.07

[134] Szasz, O. (2020) Local Treatment with Systemic Effect: Abscopal Outcome. In: Szasz, A., Ed., Challenges and Solutions of Oncological Hyperthermia, Ch. 11, Cambridge Scholars Publishing, Newcastle upon Tyne, 192-205.

https://www.cambridgescholars.com/challenges-and-solutions-of-oncological-hype rthermia

[135] Palekar-Shanbhag, P., Jog, S.V., Chogale, M.M. and Gaikwad, S.S. (2013) Theranostics for Cancer Therapy. Current Drug Delivery, 10, 357-362.

https://doi.org/10.2174/1567201811310030013

[136] Lee, S.-Y., Lee, N.-R., Cho, D.-H., et al. (2017) Treatment Outcome Analysis of Chemotherapy Combined with Modulated Electro-Hyperthermia Compared with Chemotherapy Alone for Recurrent Cervical Cancer, Following Irradiation. Oncology Letters, 14, 73-78. https://doi.org/10.3892/ol.2017.6117

[137] Iyikesici, M.S., Slocum, A.K., Slocum, A., et al. (2017) Efficacy of Metabolically 
Supported Chemotherapy Combined with Ketogenic Diet, Hyperthermia, and Hyperbaric Oxygen Therapy for Stage IV Triple-Negative Breast Cancer. Cureus, 9, e1445. https://doi.org/10.7759/cureus.1445

[138] Yeo, S.-G. (2015) Definitive Radiotherapy with Concurrent Oncothermia for Stage IIIB Non-Small-Cell Lung Cancer: A Case Report. Experimental and Therapeutic Medicine, 10, 769-772. https://doi.org/10.3892/etm.2015.2567

[139] Pesti, L., Dankovics, Z., Lorencz, P., et al. (2013) Treatment of Advanced Cervical Cancer with Complex Chemoradio-Hyperthermia. Conference of the International Clinical Hyperthermia Society 2012, 2013, Article ID: 192435. https://doi.org/10.1155/2013/192435

[140] Kleef, R., Kekic, S. and Ludwig, N. (2012) Successful Treatment of Advanced Ovarian Cancer with Thermochemotherapy and Adjuvant Immune Therapy. Case Reports in Oncology, 5, 212-215. https://doi.org/10.1159/000338617

[141] Schirrmacher, V., Bihari, A.-S., Stücker, W., et al. (2014) Long-Term Remission of Prostate Cancer with Extensive Bone Metastases upon Immuno- and Virotherapy: A Case Report. Oncology Letters, 8, 2403-2406. https://doi.org/10.3892/ol.2014.2588

[142] Van Gool, S.W., Makalowski, J., Feyen, O., Prix, L., Schirrmacher, V. and Stuecker, W. (2018) The Induction of Immunogenic Cell Death (ICD) during Maintenance Chemotherapy and Subsequent Multimodal Immunotherapy for Glioblastoma (GBM). Austin Oncology Case Reports, 3, 1010.

[143] Szasz, A.M., Minnaar, C.A., Szentmartoni, G., et al. (2019) Review of the Clinical Evidences of Modulated Electro-Hyperthermia (mEHT) Method: An Update for the Practicing Oncologist. Frontiers in Oncology, 9, Article 1012.

https://www.frontiersin.org/articles/10.3389/fonc.2019.01012/full https://doi.org/10.3389/fonc.2019.01012

[144] Wismeth, C., Dudel, C., Pascher, C., et al. (2010) Transcranial Electro-Hyperthermia Combined with Alkylating Chemotherapy in Patients with Relapsed High-Grade Gliomas-Phase I Clinical Results. Journal of Neuro-Oncology, 98, 395-405.

http://www.ncbi.nlm.nih.gov/pubmed/?term=Transcranial+electro-hyperthermia+co mbined+with+alkylating+chemotherapy+in+patients+with+relapsed+high-grade+gli omas+\%E2\% $80 \% 93+$ Phase $+\mathrm{I}+$ clinical+results https://doi.org/10.1007/s11060-009-0093-0

[145] Fiorentini, G., Giovanis, P., Rossi, S., et al. (2006) A Phase II Clinical Study on Relapsed Malignant Gliomas Treated with Electro-Hyperthermia. In Vivo, 20, 721-724. https://www.ncbi.nlm.nih.gov/pubmed/17203754

[146] Fiorentini, G. and Casadei, V. (2018) Modulated Electro-Hyperthermia (mEHT) in Integrative Cancer Treatment for Relapased Malignant Gliobastroma and Astrocytoma: A Retrospective Multicenter Controlled Study. Oncothermia Journal, 24, 464-481.

https://oncotherm.com/sites/oncotherm/files/2018-10/Modulated electro hyperthe rmia \%28mEHT\%29 in integrative cancer treatment.pdf

[147] Sahinbas, H., Groenemeyer, D.H.W., Boecher, E. and Szasz, A. (2007) Retrospective Clinical Study of Adjuvant Electro-Hyperthermia Treatment for Advanced Brain-Gliomas. Deutsche Zeitschrift für Onkologie, 39, 154-160. https://www.thieme-connect.com/products/ejournals/abstract/10.1055/s-2007-9860 $\underline{20}$ https://doi.org/10.1055/s-2007-986020

[148] Hager, E.D., Sahinbas, H., Groenemeyer, D.H., et al. (2008) Prospective Phase II 
Trial for Recurrent High-Grade Malignant Gliomas with Capacitive Coupled Low Radiofrequency (LRF) Deep Hyperthermia. Journal of Clinical Oncology, 26, 2047. https://ascopubs.org/doi/abs/10.1200/jco.2008.26.15 suppl.2047 https://doi.org/10.1200/jco.2008.26.15 suppl.2047

[149] Fiorentini, G., Sarti, D., Milandri, C., et al. (2018) Modulated Electrohyperthermia in Integrative Cancer Treatment for Relapsed Malignant Glioblastoma and Astrocytoma: Retrospective Multicenter Controlled Study. Integrative Cancer Therapies, 18. https://www.ncbi.nlm.nih.gov/pubmed/30580645 https://doi.org/10.1177/1534735418812691

[150] Gadaleta-Caldarola, G., Infusino, S., Galise, I., et al. (2014) Sorafenib and Locoregional Deep Electro-Hyperthermia in Advanced Hepatocellular Carcinoma. A Phase II Study. Oncology Letters, 8, 1783-1787.

http://www.ncbi.nlm.nih.gov/pmc/articles/PMC4156230/ https://doi.org/10.3892/ol.2014.2376

[151] Ferrari, V.D., De Ponti, S., Valcamonico, F., et al. (2007) Deep Electro-Hyperthermia (EHY) with or without Thermo-Active Agents in Patients with Advanced Hepatic Cell Carcinoma: Phase II Study. Journal of Clinical Oncology, 25, Article ID: 15168. http://ascopubs.org/doi/abs/10.1200/jco.2007.25.18 suppl.15168 https://doi.org/10.1200/jco.2007.25.18 suppl.15168

[152] Lee, D.-J., Haam, S.-J., Kim, T.-H., et al. (2013) Oncothermia with Chemotherapy in the Patients with Small-Cell Lung Cancer. Conference of the International Clinical Hyperthermia Society 2012, 2013, Article ID: 910363.

http://www.hindawi.com/archive/2013/910363/

https://doi.org/10.1155/2013/910363

[153] Minnaar, C., Baeyens, A. and Kotzen, J. (2016) Update on Phase III Randomized Clinical Trial Investigating the Effects of the Addition of Electro-Hyperthermia to Chemoradiotherapy for Cervical Cancer Patients in South Africa. Physica Medica, 32, 151-152.

http://www.physicamedica.com/article/S1120-1797(16)30175-2/abstract https://doi.org/10.1016/j.ejmp.2016.07.042

[154] Lee, S.-Y., Kim, J.-H., Han, Y.-H., et al. (2018) The Effect of Modulated Electro-Hyperthermia on Temperature and Blood Flow in Human Cervical Carcinoma. International Journal of Hyperthermia, 34, 953-960. https://doi.org/10.1080/02656736.2018.1423709

[155] Minnaar, C.A., Kotzen, J.A., Ayeni, O.A., et al. (2020) Potentiation of the Abscopal Effect by Modulated Electro-Hyperthermia in Locally Advanced Cervical Cancer Patients. Frontiers in Oncology, 10, 376.

https://www.ncbi.nlm.nih.gov/pmc/articles/PMC7105641/ https://doi.org/10.3389/fonc.2020.00376

[156] Minnaar, C.A., Kotzen, J.A., Naidoo, T., et al. (2020) Analysis of the Effects of mEHT on the Treatment-Related Toxicity and Quality of Life of HIV-Positive Cervical Cancer Patients. International Journal of Hyperthermia 37, 263-227. https://www.ncbi.nlm.nih.gov/pubmed/32180481 https://doi.org/10.1080/02656736.2020.1737253

[157] Minnaar, C.A., Kotzen, J.A., Ayeni, O.A., et al. (2019) The Effect of Modulated Electro-Hyperthermia on Local Disease Control in HIV-Positive and -Negative Cervical Cancer Women in South Africa: Early Results from a Phase III Randomized Controlled Trial. PLoS ONE, 14, e0217894.

https://www.ncbi.nlm.nih.gov/pmc/articles/PMC6584021/

https://doi.org/10.1371/journal.pone.0217894 
[158] Ou, J., Zhu, X., Lu, Y., et al. (2017) The Safety and Pharmacokinetics of High Dose Intravenous Ascorbic Acid Synergy with Modulated Electrohyperthermia in Chinese Patients with Stage III-IV Non-Small Cell Lung Cancer. European Journal of Pharmaceutical Sciences, 109, 412-418.

http://www.sciencedirect.com/science/article/pii/S0928098717304554?via\%3Dihub https://doi.org/10.1016/j.ejps.2017.08.011

[159] Ou, J., Zhu, X., Chen, P., et al. (2020) A Randomized Phase II Trial of Best Supportive Care with or without Hyperthermia and Vitamin C for Heavily Pretreated, Advanced, Refractory Non-Small-Cell Lung Cancer. Journal of Advanced Research, 24, 175-182. https://www.ncbi.nlm.nih.gov/pubmed/32368355 https://doi.org/10.1016/j.jare.2020.03.004

[160] Szasz, A. (2014) Current Status of Oncothermia Therapy for Lung Cancer. Korean Journal of Thoracic and Cardiovascular Surgery, 47, 77-93.

http://www.ncbi.nlm.nih.gov/pmc/articles/PMC4000888 https://doi.org/10.5090/kjtcs.2014.47.2.77

[161] Iyikesici, M.S. (2019) Feasibility Study of Metabolically Supported Chemotherapy with Weekly Carboplatin/Paclitaxel Combined with Ketogenic Diet, Hyperthermia and Hyperbaric Oxygen Therapy in Metastatic Non-Small Cell Lung Cancer. International Journal of Hyperthermia, 36, 445-454.

https://www.ncbi.nlm.nih.gov/pubmed/30931666 https://doi.org/10.1080/02656736.2019.1589584

[162] Pang, C.L.K., Zhang, X., Wang, Z., Ou, J.W., et al. (2017) Local Modulated Electro-Hyperthermia in Combination with Traditional Chinese Medicine vs. Intraperitoneal Chemoinfusion for the Treatment of Peritoneal Carcinomatosis with $\mathrm{Ma}$ lignant Ascites: A Phase II Randomized Trial. Molecular and Clinical Oncology, 6, 723-732. https://pubmed.ncbi.nlm.nih.gov/28529748/

https://doi.org/10.3892/mco.2017.1221

[163] You, S.H. and Kim, S. (2019) Feasibility of Modulated Electro-Hyperthermia in Preoperative Treatment for Locally-Advanced Rectal Cancer: Early Phase 2 Clinical Results. Neoplasma, 67, 677-683. https://www.ncbi.nlm.nih.gov/pubmed/32039629 https://doi.org/10.4149/neo_2020_190623N538

[164] Hager, E.D., Dziambor, H., Höhmann, D., et al. (1999) Deep Hyperthermia with Radiofrequencies in Patients with Liver Metastases from Colorectal Cancer. Anticancer Research, 19, 3403-3408. http://www.ncbi.nlm.nih.gov/pubmed/10629627

[165] Jeung, T.-S., Ma, S.-Y., Choi, J., et al. (2015) Results of Oncothermia Combined with Operation, Chemotherapy and Radiation Therapy for Primary, Recurrent and Metastatic Sarcoma. Case Reports in Clinical Medicine, 4, 157-168. http://www.scirp.org/journal/PaperInformation.aspx?PaperID $=56280$ https://doi.org/10.4236/crcm.2015.45033

[166] Volovat, C., Volovat, S.R., Scripcaru, V., et al. (2014) The Results of Combination of Ifosfamid and Locoregional Hyperthermia (EHY 2000) in Patients with Advanced Abdominal Soft-Tissue Sarcoma after Relapse of First Line Chemotherapy. Romanian Reports in Physics, 66, 175-181. http://www.rrp.infim.ro/2014 66 1/A19.pdf

[167] Iyikesici, M.S. (2020) Long-Term Survival Outcomes of Metabolically Supported Chemotherapy with Gemcitabine-Based or FOLFIRINOX Regimen Combined with Ketogenic Diet, Hyperthermia, and Hyperbaric Oxygen Therapy in Metastatic Pancreatic Cancer. Complementary Medicine Research, 27, 31-39.

https://www.ncbi.nlm.nih.gov/pubmed/31527373

https://doi.org/10.1159/000502135

[168] Volovat, C., Volovat, S.R., Scripcaru, V., et al. (2014) Second-Line Chemotherapy 
with Gemcitabine and Oxaliplatin in Combination with Loco-Regional Hyperthermia (EHY-2000) in Patients with Refractory Metastatic Pancreatic Cancer-Preliminary Results of a Prospective Trial. Romanian Reports in Physics, 66, 166-174. http://www.rrp.infim.ro/2014 66 1/A18.pdf

[169] Fiorentini, G., Sarti, D., Casadei, V., et al. (2019) Modulated Electro-Hyperthermia as Palliative Treatment for Pancreas Cancer: A Retrospective Observational Study on 106 Patients. Integrative Cancer Therapies, 18, 1-8.

https://journals.sagepub.com/doi/pdf/10.1177/1534735419878505

https://doi.org/10.1177/1534735419878505

[170] Hager, E.D., Süsse, B., Popa, C., et al. (1994) Complex Therapy of the Not in Sano Resectable Carcinoma of the Pancreas-A Pilot Study. Journal of Cancer Research and Clinical Oncology, 120, R47.

[171] Dani, A., Varkonyi, A., Magyar, T. and Szasz, A. (2008) Clinical Study for Advanced Pancreas Cancer Treated by Oncothermia. Forum Hyperthermie, 1, 13-20.

http://www.pyatthealth.com/wp-content/uploads/2015/03/Hyperthermia-Pancreati c-Cancer.pdf

[172] Ranieri, G., Ferrari, C., Di Palo, A., et al. (2017) Bevacizumab-Based Chemotherapy Combined with, Regional Deep Capacitive Hyperthermia in Metastatic Cancer Patients: A Pilot Study. International Journal of Molecular Sciences, 18, 1458.

https://www.ncbi.nlm.nih.gov/pubmed/28684680

https://doi.org/10.3390/ijms18071458

[173] Chi, M.-S., Mehta, M.P., Yang, K.-L., et al. (2020) Putative Abscopal Effect in Three Patients Treated by Combined Radiotherapy and Modulated Electrohyperthermia. Frontiers in Oncology, 10, 254.

https://www.frontiersin.org/articles/10.3389/fonc.2020.00254/full https://doi.org/10.3389/fonc.2020.00254

[174] Iyikesici, M.S. (2020) Survival Outcomes of Metabolically Supported Chemotherapy Combined with Ketogenic Diet, Hyperthermia, and Hyperbaric Oxygen Therapy in Advanced Gastric Cancer. Nigerian Journal of Clinical Practice, 23, 734-740.

https://www.ncbi.nlm.nih.gov/pubmed/32367884

https://doi.org/10.25000/acem.650341

[175] Fiorentini, G., Sarti, D., Gadaleta, C.D., et al. (2020) A Narrative Review of Regional Hyperthermia: Updates from 2010-2019. Integrative Cancer Therapies, 19, 1-13. https://pubmed.ncbi.nlm.nih.gov/33054425/ https://doi.org/10.1177/1534735420932648

[176] Van Gool, S.W., Makalowski, J., Fiore, S., et al. (2021) Randomized Controlled Immunotherapy Clinical Trials for GBM Challenged. Cancers, 13, 32.

https://pubmed.ncbi.nlm.nih.gov/33374196/ https://doi.org/10.3390/cancers13010032

[177] Kim, S., Lee, J.H., Cha, J. and You, S.H. (2021) Beneficial Effects of Modulated Electro-Hyperthermia during Neoadjuvant Treatment for Locally Advanced Rectal Cancer. International Journal of Hyperthermia, 38, 144-151.

https://pubmed.ncbi.nlm.nih.gov/33557636/ https://doi.org/10.1080/02656736.2021.1877837

[178] Fiorentini, G., Sarti, D., Casadei, V., et al. (2020) Modulated Electro-Hyperthermia for the Treatment of Relapsed Brain Gliomas. In: Szasz, A., Ed., Challenges and Solutions of Oncological Hyperthermia, Ch. 6, Cambridge Scholars Publishing, Newcastle upon Tyne, 110-125.

https://www.cambridgescholars.com/challenges-and-solutions-of-oncological-hype rthermia 
[179] Garay, T., Kiss, E., Szentmartoni, G., et al. (2020) Gastrointestinal Cancer Series Treated with Modulated Electro-Hyperthermia (mEHT) -A Single Centre Experience In: Szasz, A., Ed., Challenges and Solutions of Oncological Hyperthermia, Ch. 8, Cambridge Scholars Publishing, Newcastle upon Tyne, 159-162.

https://www.cambridgescholars.com/challenges-and-solutions-of-oncological-hype rthermia

[180] Wookyeom, Y., Han, G.H., Shin, H.-Y., et al. (2018) Combined Treatment with Modulated Electro-Hyperthermia and an Autophagy Inhibitor Effectively Inhibit Ovarian and Cervical Cancer Growth. International Journal of Hyperthermia, 36, 9-20. https://doi.org/10.1080/02656736.2018.1528390

[181] Szasz, A.M., Szentmartoni, G., Garay, T., et al. (2020) Breast Cancer Series Treated with Modulated Electro-Hyperthermia (mEHT) - A Single Centre Experience. In: Szasz, A., Ed., Challenges and Solutions of Oncological Hyperthermia, Ch. 5, Cambridge Scholars Publishing, Newcastle upon Tyne, 105-109,

https://www.cambridgescholars.com/challenges-and-solutions-of-oncological-hype rthermia

[182] Lee, Y. (2013) Oncothermia Application for Various Malignant Diseases. Conference of the International Clinical Hyperthermia Society 2012, 2013, Article ID: 245156.

http://www.hindawi.com/archive/2013/245156/ https://doi.org/10.1155/2013/245156

[183] Parmar, G., Rurak, E., Elderfield, M., et al. (2020) 8-Year Observational Study on Naturopathic Treatment with Modulated Electro-Hyperthermia (mEHT): A Single-Centre Experience. In: Szasz, A., Ed., Challenges and Solutions of Oncological Hyperthermia, Ch. 13, Cambridge Scholars Publishing, Newcastle upon Tyne, 227-266. https://www.cambridgescholars.com/challenges-and-solutions-of-oncological-hype rthermia

[184] Arrojo, E.E. (2020) The Position of Modulated Electro-Hyperthermia (Oncothermia) in Combination with Standard Chemo- and Radiotherapy in Clinical Practice-Highlights of Upcoming Phase III Clinical Studies in Hospital Universitario Marqués de Valdecilla (HUMV). In: Szasz, A., Ed., Challenges and Solutions of Oncological Hyperthermia, Ch. 4, Cambridge Scholars Publishing, Newcastle upon Tyne, 91-104.

https://www.cambridgescholars.com/challenges-and-solutions-of-oncological-hype rthermia

[185] Roussakow, S. (2017) Clinical and Economic Evaluation of Modulated Electrohyperthermia Concurrent to Dose-Dense Temozolomide 21/28 Days Regimen in the Treatment of Recurrent Glioblastoma: A Retrospective Analysis of a Two-Centre German Cohort Trial with Systematic Comparison and Effect-to-Treatment Analysis. BMJ Open, 7, e017387.

http://bmjopen.bmj.com/content/bmjopen/7/11/e017387.full.pdf https://doi.org/10.1136/bmjopen-2017-017387 